\title{
TESTES DE HIPÓTESES EM MODELOS LINEARES \\ COM DADOS DESBALANCEADOS E CASELAS VAZIAS
}

\section{JOMAR ANTONIO CAMARINHA FILHO}

Engenheiro Agrônomo

Orientador: Prof. Dr. Antonio Francisco Iemma

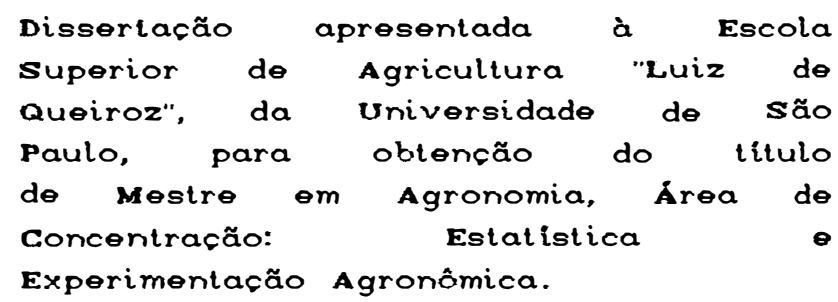

P I R A C I C A B A

Estado de São Paulo - Brasil

Janeiro - 1995 
Ficha catalografica preparada pela Seço de Livrcs da Divisáo de Bitulioteca e Docunertaça - FCLOUSF

\footnotetext{
Camarinhe Filto, Jomar Antonio

C172t Testes de hipoteses en modelas lineares com dadas desbalanceados e caselas varias. Firacicaba, 1995. $142 \mathrm{p}$. i.145.

Dis5-(Mestre) - ESALQ

Eibliografia.
}

1. Analise de variancia 2. Hipotese estatistica 3. Modelo linear I. Escola Superior de Agricultura Luia de Gueiroz, Firacicaba 


\section{TESTES DE HIPÓTESES EM MODELOS LINEARES \\ COM DADOS DESBALANCEADOS E CASELAS VAZIAS}

JOMAR ANTONIO CAMARINHA FILHO

Aprovado em: 02. 03. 95

Comissão Julgadora:

Prof. Dr. Antonio Francisco Iemma

Prof. Dr. Décio Barbin

Prof ${ }^{a}$. Dr ${ }^{a}$. Marinéia de Lara Haddad

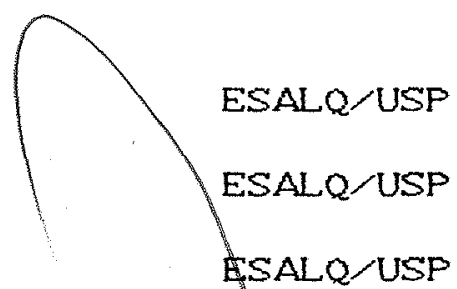

Frof. Dr.

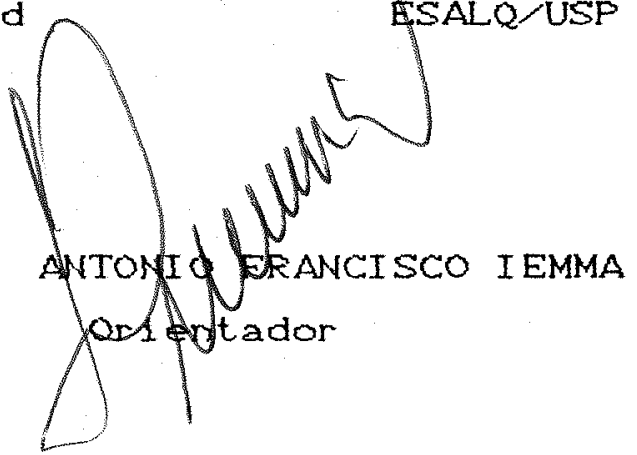


$1 v$.

À Adríana

e aos meus pais 


\section{AGRADECI MENTO}

Ao Prof. Dr. Antonio Francisco Iemma, pela orientacão no decorrer deste trabalho e, principalmente, pela confiança.

A CAPES, pela bolsa de estudos concedida.

Aos amigos do Departamento de Estatística da Uni versidade Federal do Paraná.

Aos professores e funcionários do Departamento de Matemática e Estatistica da ESALQ. Especialmente, aos professores doutores: Clarice Garcia Borges Demétrio, Décio Barbin e Roberto Simionato Moraes. 
RESUMO

SUMMARY

1. INTRODUCূÃO

2. REVISÃo DE LITERATURA • • • • • • • • • 3

3. MATERIAL E MÉTODOS • • • • • • • • • • 32

3.1. Material • . . • . . . . . . . . 32

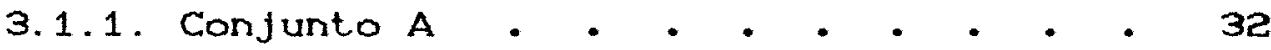

3.1.2. Conjunto B • . . . . . • . . 34

3.1.3. Pacotes Estatisticos • . • • • . 37

3. 2. Métodos • • • • • • • • • • • • 38

3.2.1. Modelo Linear . . . . . . . . 38

3.2.1.1. Modelo com Interacão • • . 38

3.2.1.2. Modelo sem Interaç̃o • . . 40

3. 2. 2. Sol ução de MInimos Quadrados . . . 40

3.2.2.1. Modelo com Interacão . . . 40

3.2.2.2. Modelo sem Interacão • • . 41

3.2.3. Somas de Quadrados . . . . . 41

3.2.4. Hipóteses Estatisticas . . . . . 42

3.2. 4.1. Modelo com Interacão . . . 43

3.2. 4.2. Modelo sem Interacão . . . 44

3.2.5. Construcão das Matrizes . . . . . 45

3.2.5.1. Modelo com Interacão . . . 46

3.2.5.2. Modelo sem Interacăo . . . 49 
vil.

3.2.6. Quadro da Análise de Variância . . . 51

3.2.7. Projetores ortogonais . . . . . . 52

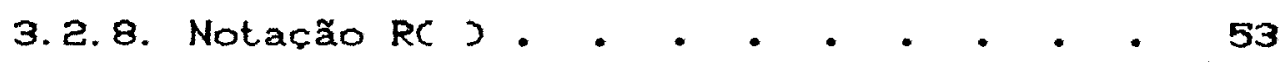

3.2.9. Pacotes Estatisticos . . . . . . 55

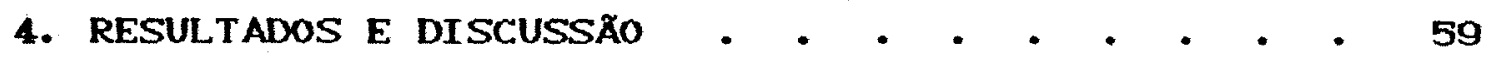

4.1 Exemplo 1 - . . . . . . . . . . . 59

4.1.1. Caso A1 . . . . . . . . . . 60

4.1.2. Caso AZ . . . . . . . . . . . 71

4.1.3. Caso $A 3$. . . . . . . . . . 79

4.1.4. Caso $A 4$. . . . . . . . . . 87

4.1.5. Caso As . . . . . . . . . . . . 91

4. 2. Exemplo 2 • • . • . • . • . . . . 95

4.2.1. Caso B1 . . . . . . . . . . 95

4.2.2. Caso Be . . . . . . . . . . 102

4.2.3 Caso B3 . . . . . . . . . . . 108

4.2.4. Caso B4 . . . . . . . . . . . 113

4.2.5. Caso B5 . . . . . . . . . . . 120

4.2.6. Caso BO . . . . . . . . . . 125

4.2.7. Caso B7 . . . . . . . . . . . 129

5. CONCLUSốES $•$ •

6. REFERENCI AS BIBLIOGRAFICAS - • • • • • • • 136 
TESTES DE HIPÓTESES EM MODELOS LINEARES

COM DADOS DESBALANCEADOS E CASELAS VAZIAS

\author{
Autor: IOMAR ANTONIO CAMARINHA FILHO \\ Orientador: PROF. DR. ANTONIO FRANCISCO IEMMA
}

\title{
RESUMO
}

Os usuários de sistemas computacionas para estatistica (pacotes estatisticos), especialmente os pesquisadores de ciências aplicadas, são, em geral, vulneráveis no tocante à interpretacão das hipóteses testadas através das somas de quadrados por eles fornecidas. Queremos crer que isso ocorra devido à facilidade de acesso e manuseio, muitas vezes inadequado, desses programas. De fato, o acesso imediato aos pacotes estatisticos e a escassez de profissionais da estatistica, têm motivado os pesquisadores das áreas aplicadas a planejar e analisar suas próprias pesquisas. Naturalmente, nesses casos, o processo é agilizado e os resultados são obtidos rapidamente. No entanto, a documentacão insuficiente, inerente a alguns pacotes, e a ausência do profissional especializado em análise de dados, pode levar, 
em geral, a erros de interpretacão, que podem comprometer os resultados obtidos a altos custos e após vários anos de experimentação.

Com o objetivo de amenizar essa deficiência e visando iniciar o pesquisador nas idéias sobre interpretacão das hipóteses testadas, no presente trabalho foram utilizados dois pacotes estatisticos, o SAS CStatistical Analyses System e o STATGRAPHICS (Statistical Graphics System. Essa escolha se deveu ao fato de que o primeiro apresenta quatro tipos de somas de quadrados e, portanto, quatro tipos de hipóteses; o segundo, duas delas. Naturalmente, ambos são uni versalmente adotados.

Foram tomados dois exemplos práticos, a fim de auxiliar na escolha das hipóteses mais adequadas para as diversas caracterizaçóes impostas ao modelo linear proposto, ou seja, experimentos balanceados e desbal anceados, com e sem caselas vazias.

Nesse contexto, foi possivel mostrar que as hipóteses para dados balanceados não apresentaram diferencas, isto é, as quatro hipóteses do SAS e as duas do STATGRAPHICS foram idênticas. Já para dados desbal anceados, as diferencas entre as hipóteses tornaram-se evidentes. Para o caso de caselas vazias, o problema agravou-se severamente, a construcão das hipóteses tornou-se difícil e sua interpretacão extremamente complexa. 


\section{TESTS OF HYPOTHESIS IN LINEAR MODELS \\ WITH UNBALANCED DATA AND MISSING CELLS}

Author: Jomar Antonio Camarinha Filho Adviser: PROF. DR. ANTONIO FRANCISCO IEMMA

SUMMARY

The users of statistical packages, specially the searchers of pratical sciences are generally vulnerable relating to the interpretation of the tested hypothesis through the sum of squares provided by them. We want to believe that this occur due to the facility of access and handling, inadequated many times, of these programs. In fact, the immediate access to the statistical packages and the lack of statistical profissionals have motivated the searchers of the practical areas to plan and analyze their own searchs. Naturally, in these cases, the procedure is rapid and the results are achieved rapidly. But the insufficient documentation inherent to some packages and the lack of the specialized profissional in data analysis, may lead, generrally, to interpretation mistakes wich can promise the results achieved at a high effort and after 
$x i$.

many years of experimentation.

On the purpose of easing this lack and seeking to initiate the searcher in these ideas about interpretation of the tested hypothesis, the present production made use of two statistical packages, the SAS CStatistical Analyses System) and the STATGRAPHICS CStatistical Graphics System. This choice occured by the fact of the first one presents four kinds of sum of squares and therefore, four kinds of hypothesis and the second one, two of them. Naturally, both are adapted universally.

Two practical examples were taken, so that they help in the suitable choices of hypotesis to the several characterizations imposed to the innear model proposed, that is, balanced and unbalanced experiments, with or without missing cells.

In this respect, it was possible to show that the hypothesis for balanced data didn't present differences, that is, the four hypothesis of the SAS and the both of STATGRAPHICS were exactly the same. But for unbalanced data the differences among the hipothesis became evident. To the case of missing cells, the problem grew very worse and the construction of the hypothesis became hard and its interpretation extremely complex. 


\section{INTRODUČ̃O}

Testes de hipóteses têm sido amplamente utilizados, como alternativa para se concluir a respeito da influencia das fontes de variacão em modelos lineares. Para tanto, é comum a utilizacão de pacotes estatísticos que fornecem análises de variância, baseadas em testes $F$ de Snedecor, para a tomada de decisốes.

Como é bem sabido, na análise de variância obtém-se uma soma de quadrados para cada efelto do modelo linear que, por sua vez, está intimamente ligada à hípótese a ser testada sobre o referido efelto. Em contrapartida, os quadros convencionais apresentados por muitos pacotes estatisticos estão, na verdade, sendo utilizados para o teste de funcões lineares paramétricas, muitas vezes, de pouco interesse do pesquisador. Na verdade, não haveria problema algum se ele soubesse disso.

De fato, esta situacão pode ocorrer com uma frequência considerável.

Grande parte deste problema poderia ser resolvida se os pacotes existentes mostrassem, de maneira explictta, que hipóteses estão sendo testadas. Dessa forma, os pesquisadores, principalmente os que não conhecem profundamente a estatistica, teriam condicões de avaliar o grau de adequacão ou não, aos objetivos de sua pesquisa, da hipótese que está sendo testada. Infelizmente, isso, em 
geral, não ocorre.

Devido à factilidade de manuseto dos diversos pacotes estatísticos, um considerável número de usuários costuma cometer erros de interpretacão de hipóteses. Nesse contexto, um dos objetivos deste trabalho está na necessidade de se criar, com base em situacões práticas, subsidios para alertar a esses pesquisadores.

Foram criados, portanto, dois exemplos com várias situacões procurando evidenciar, exatamente, o que se testa e como cada um deles obtém a estatística F. o modelo usado para o exemplo é o de classificacão dupla cruzada, com e sem interacão, tanto para dados bal anceados quanto para dados desbalanceados. Ademals, acrescentou-se o caso onde ocorrem perdas totals de observacões, ocasionando um problema ainda maior: o de caselas vazias.

Para auxiliar nessas interpretacões, utilizaram-se dois pacotes estatísticos de ampla aplicacão, - SAS (Statistical Analyses System) e o STATGRAPHICS CStatistical Graphics System, tendo como enfoque principal as somas de quadrados fornecidas pelo Procedimento GLM (General Linear Models Procedure) do SAS, que são as somas de quadrados dos tipos I, II. III e IV. 


\section{REVISÃO DE LITERATURA}

YATES (1934) comentou que o método estatístico apropriado para o caso de dados balanceados é simples e muito desenvol vido em associacão com experimentos de campo na agricultura. O método é um caso específico do método conhecido como análise de variância, que foi Introduzido por R. A. Fisher. Alertou, no entanto, que na presenca de dados desbalanceados, a análise necessita de consideráveis modificacões. Nesse trabalho, o autor relatou a análise de ensaios fatoriais com dados desbalanceados e apresentou quatro métodos para solucionar o problema. Tais métodos, segundo HERR (1986), estão relacionados com os principais métodos utilizados nos dias de hoje. Os métodos são:

a) Quadrado de médias ponderadas de Yates que, incorporado pelo SAS, fornece as Somas de Quadrados do tipo III e testa hipóteses sobre médias não ponderadas de inhas (IEMMA, 1991, médias não ponderadas). Todos podendo ser descritos pela notação RC $)$ de Searle (ver SEARLE, 1971 ou IEMMA, 1991$\rangle$ pela forma: $\operatorname{RC} \alpha \mid \mu, \beta, \gamma)$;

b) Tamanhos proporcionais de caselas de Yates que, incorporado pelo SAS, fornece as Somas de Quadrados do tipo I e testa hipóteses sobre médias ponderadas de Iinhas CIEMMA, 1991 , médias ponderadass, ou $R(\alpha / \mu)$ de Searle;

c) Ajustamento de constantes de Yates que, incorporado pelo SAS, fornece as Somas de Quadrados do tipo 
II e testa hipóteses sobre médias ponderadas de linhas ajustadas para colunas (IEMMA, 1991, médias ponderadas), ou

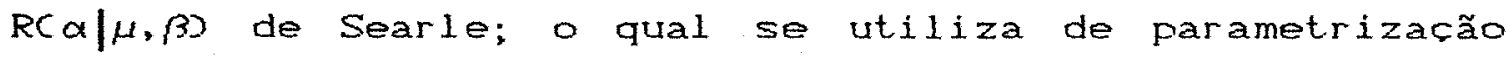
sucessiva;

d) o quarto método não é de interesse ao trabalho, pois não está incorporado ao PROC GLM.

YATES (1934) alertou que os métodos diferem de acordo com a suposicão de existência de interacão. Disse ainda que, se suposicốes são feitas, o método de ajuste de constantes fornece estimativas e testes de hipóteses eficientes. Caso contrário, as médias das caselas fornecem estimativas eficientes, e o método dos quadrados de médias ponderadas, eficientes testes de significancia. No caso do fatorial $2^{k}$ a análise pode ser feita de forma simples, com ou sem interacão. O autor considerou que, no resultado da análise com um fator, a soma de quadrados total ajustada pode ser decomposta em soma de quadrados do resíduo e soma de quadrados do modelo. Notou, ainda, que a soma de quadrados do modelo dividida pelos graus de liberdade Cg.1.J forneceu uma estimativa eficiente da variância das observaçóes individuais, quando a hipótese de não diferenca entre os efeitos principais foi verdadeira. Deixou claro que, usando-se "boas" estimativas ter-se-iam "bons" testes. Uma visão extremamente lúcida do artigo, principalmente para a época em que fol escrito, foi a preocupacão em descrever "como" os cálculos deveriam ser realizados e, 
também, "o que" se estava calculando.

YATES (1933) desenvolveu explicitamente o que ol preteridia para o efelto de médias de caselas. Ele distinguiu, claramente, o modelo aditivo csem interacãole - modelo superparametrizado. Declarou ser o método tipo II - preferido se o modelo é aditivo, caso contrário, tipo III. Porém, para se provar essa afirmacão de Yates, esperou-se mais 40 anos, comentam BURDICK \& HERR $(1980)$

Segundo HERR (1986), no mesmo vol ume da JASA CJournal of the American Statistical Association). Snedecor (1934) sugeriu outro modo para se contornar o problema, através de um teste de $x^{2}$. Mais tarde. Snedecor \& Cox (1935) resumiram os métodos, apresentados até aquele momento, para dados desbal anceados.

KRAMER (1955) ponderou que a principal dificuldade resultava em se determinar a correta soma de quadrado para os efeitos do modelo. Ele preferiu identificar "o que" estava sendo calculado, ou testado, e não "como" calcular. Ressaltou que a soma de quadrados do tipo II é ótima se a suposicão de não interação for feita, caso contrário, deu preferência a do tipo III, concordando

\footnotetext{
SNEDECOR, O. W. "The Method of Expected Number for Tables of Multiple classification. With Disproportionate subclasses Numbers". Journal of The Americam statistical Association. $20,380-03.1534$.

SNEDECOR, a.W. \& COX, a., "Disproportionate subclass Numbers in rables of Multiple classification". rowa state Agricul ture Experiment station Research Bulletin 190. 1995.
} 
com YATES (1934). Sua visão fol que a soma de quadrados do tipo III era mals fácil de se calcular, mas não era tão boa se o modelo fosse aditivo. Trabalhando com um exemplo com dois fatores, relembrou o método de quadrados de médias ponderadas de YATES (1934) e notou que o número desigual de elementos em cada subclasse $1 \mathrm{mplica}$ em falta de ortogonalidade entre os efeltos principais e as interacóes.

DI TCHBURNE (1955), trabalhando com um experimento com dois fatores, afirmou que, quando cada fator é testado em todos os niveis do outro fator, e o número de observaçóes nas caselas é igual ou proporcional, verifica-se que as estimativas dos efeitos de cada fator são facilmente obtidas, a análise de variância dos dados é simples e a interpretação dos resultados é livre de dificuldades, pols os dados são ortogonais. Porém, se há desbalanceamento, ou se todos os nivels de um fator não são testados para todos nivels do outro cde maneira que al gumas caselas são vaziasł, os dados podem ser não-ortogonais, e um método de análise deve ser encontrado para satisfazer o delineamento do experimento particular. Porém, seu trabalho tratou de uma forma muito especifica o problema de casela vazia, através de tabelas triangulares.

SCHEFFÉ (1959) propos que se fizesse a análise, desconsiderando que as caselas são vazias, ou que os efeitos principals não são estimáveis.

ELSTON \& BUSH (1964) lembraram que, quando se 
testam hipóteses sobre parâmetros de um modelo, certas somas de quadrados são calculadas e servem de base para a análise de variância. Disseram ainda que, se interacõos são assumidas no modelo, as somas de quadrados apropriadas para testar os efeitos principals dependem de como esses efeitos são definidos. Procuraram dei xar claro a respeito do que as hipóteses sobre efeitos principais podiam testar, e ilustraram um método conveniente para se obter as somas de quadrados correspondentes, especialmente para casos onde ocorriam caselas vazias. Enfatizaram que, em experimentacão biológlca, isto era frequente. Além disso, comentaram que o caso de caselas vazias não tem stdo adequadamente discutido na 11 teratura e forneceram estimulos para que programadores de pacotes construam métodos corretos para análise de dados. O método se resume em: o modelo básico em notacáo matricial dado por $E(Y)=A F$, onde $y$ é um vetor coluna de observaçóes. A é uma matriz delineamento e $\zeta$ é um vetor coluna de parâmetros da forma, para o exemplo.

$$
\zeta^{\prime}=\left(\mu \alpha_{1} \alpha_{2} \beta_{1} \beta_{2} \beta_{3} \gamma_{11} \gamma_{12} \gamma_{13} \gamma_{21} \gamma_{22} \gamma_{23}\right)
$$

sendo que A é uma matriz quadrada de ordem doze cujos elementos são "uns" e "zeros". Rearanjando os vetores colunas de $A$ como $E(Y)=A Y=\left[A_{1} A_{2}\right]\left[\begin{array}{l}\zeta \\ \zeta\end{array}\right]=A_{1} \zeta_{1}+A_{2} \zeta_{2}$. onde os vetores colunas em $A_{1}$ são escolhidos para serem qualquer conjunto de vetores independentes ocorrendo em A formando uma base para todos os vetores colunas de A. Assim, pode-se escolher $A_{1}$ e $A_{2}$ de maneira que: 
$\zeta_{1}^{\prime}=C \mu \quad \alpha_{1} \beta_{1} \beta_{2} \gamma_{11} \gamma_{12}{ }^{3}=\zeta_{2}^{\prime}=C_{2} \beta_{3} \gamma_{19} \gamma_{21} \gamma_{22} \gamma_{29}{ }^{2} e$

a hipótese testada pode ser escrita por:

Ho: $\mathrm{Cr}=\varnothing$, isto é, $\left[\mathrm{C}_{1}: \mathrm{C}_{2}\right]\left[\begin{array}{l}\zeta \\ \zeta\end{array}\right]=\varnothing$, onde a particão de $C$ corresponde àquela de $\zeta$, e onde os vetores linhas de $C$ são mutuamente independentes. Então a condicão necessária e suficiente para a testabilidade é $C_{2}=C_{1}\left(A_{1}^{*} A_{1}\right)^{-1} A_{1}^{\prime} A_{2}$, e contando que a hipótese é testável a soma de quadrados aproprtada é $\hat{\zeta}, C_{1}^{\prime}\left[C_{1}\left(A_{1}^{\prime} A_{1}\right)^{-1} C_{1}^{\prime}\right]^{-1} C_{1} \hat{\zeta}_{1}$, onde $\zeta_{1}=\left(A_{1}^{\prime} A_{1}\right) A_{1}^{\prime} y$.

ELSTON \& BUSH (1964) utilizaram o modelo em que todos os efeitos, exceto o erro, são assumidos fixos. Em detalhe, foram considerados apenas dois fatores, $A$ e $B$, com a e b níveis, respectivamente, mas o princípio para uma classificacão maior é exatamente o mesmo. Comentaram que nesse modelo. sempre é possivel desenvolver um teste para cada fator, com $(a-1)$ e $(b-1)$ g.1.. contanto que o delineamento seja conexo CIEMMA, 1991, p. Se). Porém, o teste pode não ser de interesse prático. O teste para interacão sem casela vazia pode ser feito sem dificuldades com $(a-1)(b-1)$ g.l.. Porém, se há $t$ caselas vazias, a Interacão deve ser testada com $(a-1)(b-1)-t$ g.1. e, obviamente, não testa todas as interacões, mas somente aquelas que envol vam médias estimáveis. Utilizaram, também, - conceito de funcões estimávels, relacionando-o com as hipóteses testáveis, ou seja, uma hipótese só é testável se sua funcão linear paramétrica correspondente for estimável 
(ver IEMMA, 1987 e 1991). Apresentaram uma forma geral para as hipóteses testáveis, sobre cada um dos efeitos do quadro da análise de variâncla. Nesse artigo, os autores trabalharam com um "novo" modelo para o tratamento dos dados: o modelo de médias de caselas. Todas as hipóteses testadas foram descritas por esse modelo.

Muitos pesquisadores, depois do trabalho de ELSTON \& BUSH (1964), comecaram a utilizar o modelo de médi as de caselas. Dentre eles, URQUHART, WEEKS \& HENDERSON (1973), KUTNER (1974), SPEED \& HOCKING (1976), SPEED, HOCKING \& HACKNEY (1978), FRANE (1980), SEARLE, SPEED \& HENDERSON (1981), JENNINGS \& WARD (1982) E IEMMA (1991), entre outros.

É comum notar que muitos artigos citam HOCKING \& SPEED (1975) para a escolha do modelo de médias de caselas, embora o trabalho de ELSTON \& BUSH (1964), além de proporcionar uma forte contribuicão para a solucão do problema, é um dos ploneiros na utilizacão desse modelo.

Na literatura existem algumas justificativas para a escolha do modelo de médias de caselas. Dentre essas, destacam-se:

". . modelo permite minimizar muitas das origens da confusão, principalmente, a construcão e o entendimento das hipóteses em funcão dos parâmetros do model o." (SPEED, HOCKING \& HACKNEY, 1978 ).

$$
\text { ". o modelo de médias de caselas é o mais }
$$


adequado para essa situação, pois dá ao pesquisador a flexibilidade de especificar, precisamente, as funcões paramétricas relevantes, em termos das médias de caselas. Os parâmetros do modelo de médias têm clara relacão no contexto experimental, e as médias amostrais correspondentes fornecem boas estimativas. Assim, qualquer funcão linear das médias pode ser estimada." CURQUHART \& WEEKS, 1978 .

". os modelos de médias apresentam, ainda, a vantagem de descrever hipóteses com grande simplicidade, em relacão aos model os superparametrizados." (IEMMA, 1991 ).

SPEED, HOCKING \& HACKNEY (1978) definem o modelo de médias ou modelo-M, como o modelo linear

$$
y=w_{\mu}+e
$$

onde

$n_{k}$ é uma matriz conhecida, ${ }_{k} \mu_{1}$ é um vetor de médias das populacões das quais são retiradas as amostras aleatórias que compóem as caselas, $n_{1}$ é um vetor de observaçóes e $e_{1}$ é um vetor de variáveis aleatórias não observáveis com estrutura de Gauss-Markov.

- conceito de Mínimos Quadrados emergiu por volta de 1800, na tentativa de se obter melhores estimativas para os parâmetros. Comecou através de Gauss, ao redor de 1795, e o interesse continua até o presente, passando por Fisher, que introduziu esse conceito à análise de variância, nome proposto também por ele. 
Segundo OVERALL \& SPIEGEL (1969), o método de mínimos quadrados, quando aplicado a dados bal anceados em delineamentos experimentais, uma análise de variância produz resultados identicos, quando comparado ao método da análise de regressão. Porém, se aplicado em problemas mais complexos, como o desbalanceamento, os resultados são totalmente diferentes do esperado. Dentro desse contexto, os autores fazem a seguinte citacão: "O problema é real e sério, pois programas de computador, para a análise de variância de mínimos quadrados, estão facilmente disponiveis e realizam diferentes tipos de análises, sendo que o método usado, geralmente, não é compreendido pelo usuário".

Na conclusão do artigo de OVERALL \& SPIEGEL (1969) é enfatizada a grande contribuicão que o avanco da informática pode proporcionar, facilitando na escolha do método mals adequado e, consequentemente, na interpretacão dos resultados.

Nesse contexto, os autores apresentaram três métodos de mínimos quadrados para a análise de dados experimentais:

- o método de mínimos quadrados completos ou método do modelo linear geral CGRABILL, 1961; SHEFFÉ, 1959); que corresponde ao método (a) de YATES (1934).

- método do delineamento experimental (SNEDECOR \& COCHRAN, 1967); que corresponde ao método (C) 
de YATES (1934).

- e método da ordenacão "a priori" CCohen, 1968); que correponde ao método (b) de YATES (1934).

Segundo IEMMA (1991), o PROC GLM incorporou em 1976 esses três métodos, e estão consagrados na 1iteratura como sendo propostos por OVERALL \& SPIEGEL (1969). Embora YATES (1934) e Henderson (1953) tivessem proposto anteriormente. Uma boa comparação entre os métodos pode ser vista, também, em IEMMA (1991).

Durante a década de 70 , publicaram-se vários trabalhos sobre ensaios fatoriais com dados desbalanceados, devido à considerável confusão na análise de tais experimentos. Depols da entrada dos computadores, houve uma redescoberta dos artigos de YATES (1933-34), o que não ocorreu sem polêmica (HERR, 1986). Dentre eles podem ser vistos:

URQUHART, WEEKS \& HENDERSON (1973) fizeram um relato histórico a respeito da utilizacão de modelos IIneares, com a análise de conjuntos complexos de dados. o motivo principal para realização do trabalho velo com a dificuldade em se analisar e interpretar confuntos de dados desbal anceados com grande número de caselas vazias.

De acordo com URQUHART, WEEKS \& HENDERSON (1973), modelos ilneares têm sido usados para descrever as COHEN,J. Multiplo Regregión as a oeneral dala - analytic
system. Pgychological Bulletin, $70,420-43,1968$.

HENDERSON, C.R. "Estimation of variance and Covariance Components. Biometrics, o: 220-52, 1059. 
caracteristicas de interesse do experimento, exercendo, assim, efeito substancial na própria análise. Alguns modelos têm sido superparametrizados, no sentido que contêm mals parâmetros que necessitam para descrever o contexto experimental. Assim, o experimento não suportará essas estimacóes. A idéla de estimabilidade de Rao (1945) fol introduzida para evitar esse problema, conjuntamente com o modelo de posto completo. Relataram, atnda, o porquê de se utilizar o método de mínimos quadrados para se obter uma solucão para o vetor de parâmetros, tanto para o modelo restrito, quanto para o irrestrito. Dois exemplos, um fatorial $2 \times 3$ e um $3 \times 3$, ilustram os conceitos descritos. Comentaram ainda que com um modelo já escolhido para o delineamento experimental, "a selecão de um conjunto experimental interessante, descrito por funcões lineares, baseadas em um vetor de médias, conduz a um grande problema para o estatístico e para o pesquisador."

FRANCIS (1973) teceu uma consideracão sobre alguns programas que fornecem o quadro da análise de variancia, entre eles, o SAS. Essa comparacão é feita através de um exemplo de um ensaio fatorial com dois fatores, na presenca de desbalanceamento. Nesse exemplo. foi encontrada uma soma de quadrados negativa para a interacão, o que fez aumentar a discussão e certas 
Indagações, como: "Quantas análises são realizadas e publicadas, usando cálculos computacionals totalmente falsos?", ou: "Nenhuma documentação para a análise de variancia, nem mesmo mensagens escritas, sugerem a causa do problema?". O pesquisador ressalta que um programa sem uma documentacão adequada pode ser perigoso, além do que, o usuário pode se enganar.

Na tentativa de esclarecer o problema. FRANCIS (1973) utilizou três programas. Porém, apenas o BMDX64 esclareceu, através de seu manual, como os cálculos para as somas de quadrados são obtidas, possibilitando que um estatístico ou até mesmo qualquer usuário, decifre os resultados e, consequentemente, faca um melhor uso do programa. Considerou que o erro do SAS é devido à não-ortogonalidade entre os efeitos. Assim, a soma de quadrados da interacão não pode ser obtida por subtracão.

De acordo com KUTNER ( 1974$)$, os resultados de uma análise de dados balanceados são, frequentemente. resumidos por um quadro de análise de variancia. Cada soma de quadrados da análise de variancia está associada a uma hipótese particular do modelo linear. Essas hipóteses são bem conhecldas e não causam confusão a respeito do que se está testando. Porém, as hipóteses para a análise de variância com dados desbalanceados não são tão simples e, portanto, estatisticos se confundem sobre o que se está testando. Inclusive, o teste pode não ser de seu interesse. 
Algo muito semelhante foi dito por DITCHBURNE (1955), ELSTON \& BUSH (1964) E IEMMA (1991).

Um ensaio fatorial com dois fatores CDroga $x$ Doencal foi desenvolvido para ilustrar as idéias de KUTNER (1974). Utilizou o modelo de médias de posto completo. Apresentou as hipóteses adequadas a cada caso, e forneceu, em duas tabelas, as somas de quadrados correspondentes. Mas não esclareceu, explicitamente, como construir matricialmente as hipóteses que estão sendo testadas. Apenas forneceu a fórmula para o cáculo das somas de quadrados de maneira matricial. o teste de hipóteses assumindo o model $0^{-M}=$ a soma de quadrados para testar

$$
\text { Ho: } H^{\prime} \mu=h
$$

onde $H^{\prime}$ é uma matriz $\operatorname{cs} x$ abs de constantes conhecidas de posto Iinha completo, $s(s(a b), e h$ é um vetor $(s \times 1)$ de constantes conhecidas, é da dada pela expressão

$$
\mathrm{SOH} O=\left(H^{\prime} \hat{\mu}-h\right)^{\prime}\left[H ^ { \prime } \left(w^{\prime} w^{-1} H^{-1}\left(H^{\prime} \hat{\mu}-h\right)\right.\right.
$$

e $\hat{\mu}=\left(W^{\prime} W^{-1} W^{\prime} y\right.$. Em relacão à hipótese testada, Ho, a relacão SoHo/ $\alpha^{2}$ tem distribuicão de $\chi^{2}$ central com $s$ graus de liberdade. o quadrado médio do residuo (OMres) é uma estimativa não-viesada de $\alpha^{2}$ e a estatística

$$
\text { (SQHo's)/QMres tem distribuição FCs, } \left.\sum \sum\left(n_{i j}-1\right)\right)
$$

Ver SEARLE (1971, p. 112$)$ para matores detalhes.

SPEED \& HOCKING (1976) mencionaram que as somas de quadrados dadas pelas tabelas de análise de variâncla podem ser escritas de forma mais simples, através da notacão RC 3 , visto que essa notacão pode ser aplicada 
em dois modelos in neares distintos, um de posto incompleto CSEARLE, 1971), outro de posto completo CCARLSON \& TIMM, 1974). Mostraram também onde as duas notacốes são equivalentes. Infelizmente, a notacão não indica a hipótese testada no quadro da análise de variância. Então, é provável a ocorrência de erros nas interpretacões das hipóteses. Quando se utiliza a notação $R C$ J em modelos de posto completo reparametrizado, observa-se que as somas de quadrados obtidas pela imposicão de condicões não estimávels, do tipo $\alpha .=\beta .=\gamma_{i}=\gamma_{. j}=0$, no modelo superparametrizado, são 1dênticas àquelas sugeridas por YATES (1934). Searle (1972) já advertia que essas hipóteses não são de forma simples, quando se trabalha com dados desbalanceados, e a notacão $R C J$ é de pequeno auxílio na identificacão das diferentes hipóteses.

\section{Nesse contexto, SPEED \& HOCKING (1976),} comentaram que a notaçáo RC J é limitada para gerar somas de quadrados na análise de dados, ou seja, nem todos os contrastes de interesse são possiveis de serem descritos por essa notacão. Portanto, a notacão $R C$ I não deve sér usada para descrever quais as hipóteses testadas. Mas, uma vez decidida a hipótese, essa notaço é um algoritmo eficiente para se determinar as somas de quadrados.

\footnotetext{
SEARLE, S.R. "USing the Rt, Notation for Reduction insums of squares when Fiting Linear Models. Presented at the spring Regional Meetings of ENAR. Ames, Iowa. 1972.
} 
URQUHART \& WEEKS (1978) denotaram por dados "messy" aqueles com classificacão cruzada e desigual número de repeticóes, contendo, talvez, caselas vazias. SPEED, HOCKING \& HACKNEY (1978), em sua pesquisa, afirmaram: ". as hipóteses de interesse não são tão fáceis de se construir e, nem tampouco, de se interpretar...". Segundo os autores, quando se optou em fazer a análise para dados "messy", baseada em conhecimentos já sólidos da análise de dados balanceados, muitos pesquisadores criaram métodos diferentes, proporcionando resultados distintos e, assim, muita confusão. Nesse contexto, HERR (1986) comentou que o primeiro pesquisador a se deparar com problema de dados "messy" foi Fisher, em 1925, propondo uma solucão sem malores detalhes. Já em 1931, descreveu a aplicacão do método de mínimos quadrados para o problema da análise com dados desbal anceados e com dois fatores.

SPEED, HOCKING \& HACKNEY (1978) examinaram vários métodos propostos na literatura e fizeram uma assoclacão desses métodos com os pacotes estatísticos da época. Concluiram, portanto, que o critério natural de selecão de qual método utilizar é a hipótese a ser testada. Para descrever e comparar os métodos, empregaram o modelo de médias de caselas. o trabalho também discute, brevemente, sobre o problema de caselas vazias. Propuseram nove hipóteses para a comparacão entre os métodos. Nessa 
apresentacão, comentaram que através de alguns deles pode-se realizar análises com caselas vazias, impondo-se alguma restricão ou observando-se a posicão da casela vazia.

A tabela contendo as nove hipóteses foi descrita da seguinte forma:

Tabela 1 - Hipóteses no modelo linear com dois fatores

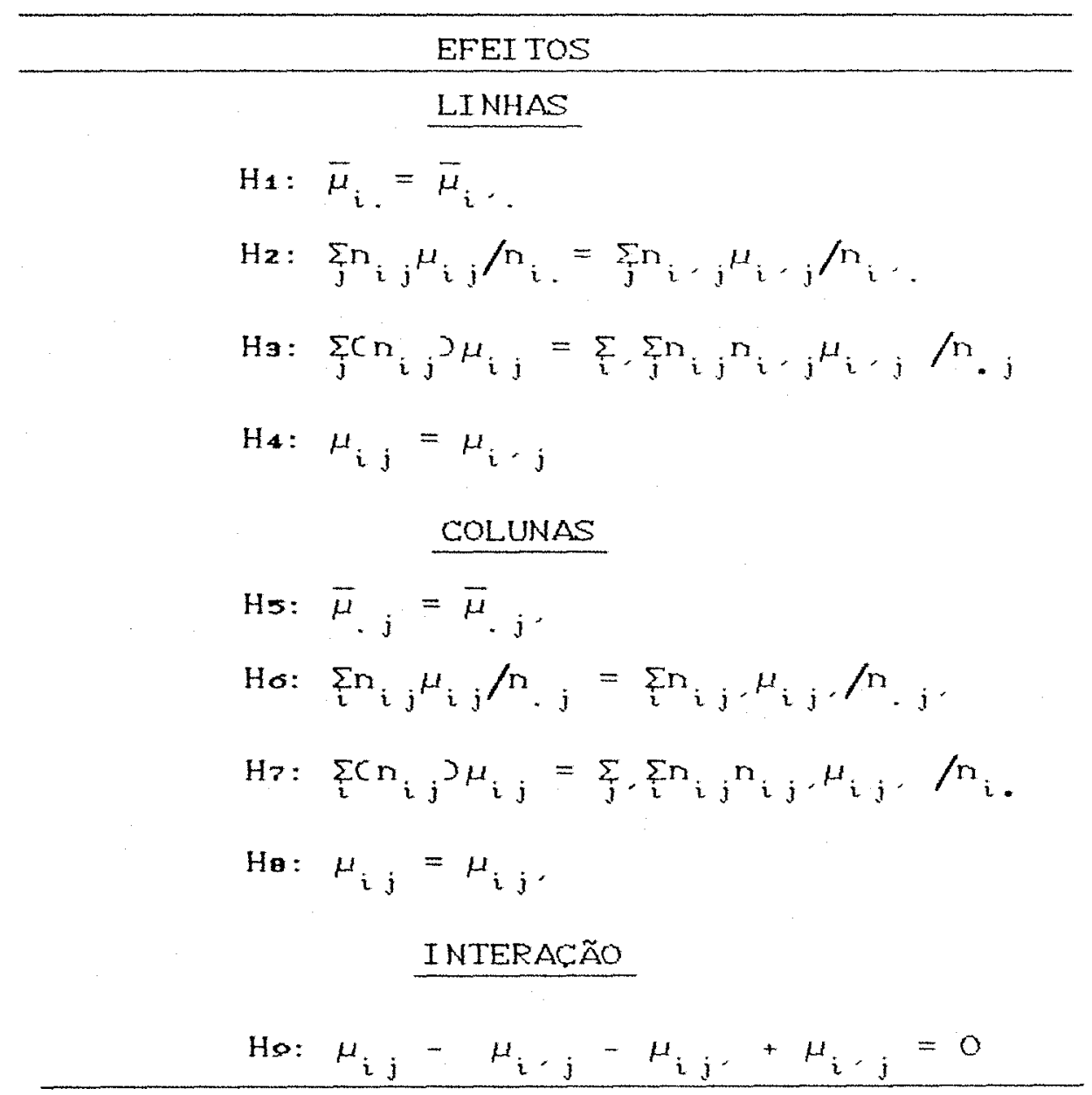

BURDICK (1979) analisou três hipóteses dadas em um modelo com dois fatores de efeitos fixos, e descreveu as situacões onde tais hipóteses são equivalentes. Essas hipóteses são as mesmas fornecidas pelo PROC GLM. Provou, 
através de exposicão geométrica, que a hipótese do tipo I e a hipótese do tipo III do PROC GLM, para linhas, são ditas equivalentes, se a média harmónica para cada coluna for a mesma, no caso de apenas duas Iinhas e, também, quando o tamanho das caselas é Independente das colunas, no caso de mais de duas 11 nhas.

SPEED \& MONLEZUN (1979) propuseram que a análise de um ensaio fatorial do tipo $2^{k}$, com dados desbalanceados, seja feita pelo método de médias não ponderadas. Isto porque não necessita inversão de matriz e pode ser realizado usando pacotes feitos para análise de dados balanceados. Além disso, proporciona testes exatos, no sentido de que todos os quadrados médios do numerador têm ditribuicão de Qui-Quadrado com 1 grau de 1 iberdade, tanto para os efeitos principais quanto para o efeito da interacão. YATES (1934) já havia feito referências a esse fato. Através de um exemplo, comparou o método de médias não ponderadas com o método de mínimos quadrados, mostrando que a escolha de qual se utilizar está nas hipóteses de interesse.

Um dos primeiros artigos encontrados na Iteratura, que trata especificamente do problema de casela vazia, é visto em FREUND (1980). Nesse artigo o autor reconheceu que o problema tem sido relatado durante muitos anos, mas pouco se tem feito para solucioná-10. Comentou, ainda, que os pacotes disponíveis para dados desbal anceados 
fornecem respostas satisfatórias para o caso de caselas vazias. Porém, quando as médias dessas caselas são não-estimáveis (SEARLE, 1971), as estimativas específicas obtidas por tais programas resultam da imposicão de restricões ou suposicões. Além disso, os pacotes não Informam quais são essas suposicões, embora possam fornecer mensagens de que os resultados não são, necessariamente, corretos ou úntcos.

Segundo FREUND (1980), O. PROC GLM usa a metodologia das funcôes estimáveis, para verificar as bases para as estimativas obtidas. 0 método das funcões estimáveis é mais dificil de se utilizar. Por outro lado, além de fornecer uma estimativa particular de uma funcão especifica em relacão a outros parâmetros, possibilita a construcão de testes de hipóteses baseados nos contrastes paramétricos e ainda afirmou: " Não há pretensão de que o PROC GLM tenha a solucão "correta" para tais situacões. entretanto, fornece informacões sobre a natureza das possiveis estimativas e, portanto, permite aos pesquisadores decidirem se os resultados têm algum sentido prático."

o objetivo de FREUND (1980) foi mostrar. através de um exemplo, os tipos de resultados que o PROC GLM oferece, e compará-los com um programa que usa reparametrizacão. Para tanto, dois métodos para obtencão de solução dos parâmetros foram descritos: a reparametrizacão 
e o uso de funções estimáveis.

Nesse contexto, considerou-se que a análise com dados desbalanceados é mais complicada, pelo fato de que as estimativas e os testes sobre alguns parâmetros podem conter contribuicóes de outros, como pode ser visto em SPEED, HOCKING \& HACKNEY (1978).

FREUND (1980) trabalhou apenas com duas das quadro funções estimáveis do GLM Ctipo III e IV) e comentou sobre as diferencas existentes entre as duas, quando há caselas vazias.

HOCKING, SPEED \& COLEMAN (1980) mostraram duas formas de se tratar o problema de casela vazia. A mais conveniente é aquela que constrói as hipóteses, baseando-se nas funçóes estimáveis do GLM. O estímulo para escreverem o artigo, provavelmente, veio da preocupacão mostrada na Introducão do mesmo. Comentam que o usuário do melhor pacote estatístico pode gerar muitos quadros de análise de variância, o que, por sua vez, tem deixado a maioria dos usuários confusos, na escolha das somas de quadrados apropriadas para se proceder ao teste paramétrico desejado. Para tentar dar uma contribuicão ao problema, são feitos três exemplos. Discute-se quais são as hipóteses "eficazes" quando ocorrem caselas vazias, fazendo-se algumas recomendacões: a) no caso de experimento sem caselas vazias, dá-se preferência às mesmas hipóteses que são testadas, se todas as caselas têm a mesma frequência; b) se 
há casela vazia, escolhem-se as hipóteses através das funcões paramétrlcas de interesse do pesquisador; um algoritmo é providenciado para encontrar tais funçôes.

BRYCE (1980), assim como IEMMA (1991), citou - trabalho de SPEED, HOCKING \& HACKNEY (1978) para a escolha do modelo de médias, deixando de lado o modelo superparametrizado. Comentou, também, que o estatistico deve mostrar ao pesquisador como testar hipóteses. Mas a responsabilidade da escolha de quais as hipóteses a serem testadas, deve ser do pesquisador. Forneceu uma boa discussão sobre contrastes "constraints" CSEARLE, 1971 , p. 2093 .

FRANE (1980) discutiu casos particulares onde - pacote estatístico BMDP fornece análises coerentes em relacão a dados "messy". Um exemplo fol criado para a 11 ustracão. Comentou-se, ainda, que o BMD1 ov foi o primeiro programa a tratar a análise com dados desbalanceados, de uma forma conveniente, por volta de 1960 . O exemplo foi um fatorial $2 \times 3$ (modelo com efeitos fixos). As hipóteses usuais (para dados balanceados) para cada efeito do modelo foram descritas pelo modelo de médias de caselas. No caso de casela vazia, essas hipóteses, denotadas por subhipóteses, ficam restritas a algumas caselas cparecidas com a hilpótese do tipo III e a hipótese do tipo IV, do PROC GLM.

GOODNIGHT (1978) usou o conceito de 
estimabilidade para construir testes de hipóteses em modelos lineares nos ensalos fatoriais com efeitos fixos, sem recorrer às suposicões usuais. Três tipos de funcões estimáveis são definidas cequivalentes aquelas do SAS, tipos I, II e IIIJ e comenta-se que existem várias, dentre elas, uma quarta para o caso de caselas vazias (tipo IV.

SEARLE (1980) enfatizou que muitos pesquisadores trabal ham com os pacotes estatísticos de modo a. primeiramente, obter a estatística $F$ da análise de variancia, sem antes formular as hipóteses testadas. Portanto, colocam-se na posicão de primeiro calcular F e. então, tentar entender o que se está testando. Mostrou ainda como as funcões estimáveis, dadas pelo PROC GLM, derivam das hipóteses testadas pelo modo tradicional. Em sua explanacão, descreveu o estimador não viesado de $\alpha^{2}$ e, também, as formas das hipóteses testáveis e das somas de quadrados correspondentes. Uma relacão entre essas descricões fornece a estatística $F$, que tem distribuicão de Snedecor: Através dessa estatística é possível concluir a respeito da hipótese testada. Nesse contexto, de acordo com SEARLE (1980), o procedimento correto para se efetuar um teste de hipótese está, inicialmente, na formulacão da hipótese. Só então, deve-se testá-1a pelo uso da estatistica F.

HEMMERLE (1980) considera situacóes, onde dados desbalanceados podem ser tratados pela substitulcão 
de dados balanceados, para resolucão de problemas em modelos 1 ineares. Uma simples reestruturação de frequîncias nas caselas é aplicada.

BURDICK \& HERR (1980) apresentaram as hipóteses mais comuns sobre Iinhas e colunas através de notação geométrica, baseando-se no modelo de médilas de caselas. Porém, com certo cuidado, nota-se que as hipóteses apresentadas são idênticas àquelas fornecidas pelo PROC GLM do sas (tipos I. II e III). Dois métodos para a análise são providenciados: o método paramétrico, que se concentra nas interpretações paramétricas das hipóteses principais, e o método do modelo de comparacão, que é visto como uma comparacão entre o modelo de posto completo e o reduzido quando este não é completo. o problema do método paramétrico com dados desbalanceados é a não-ortogonalidade. Como consequência, a soma de quadrado da hipótese não "completa" a soma de quadrado total, e há a possibilidade de que efeitos sejam significativos, quando não o são. Já a maior desvantagem do método de comparacão, está no fato de que as interpretacóes paramétricas dependem do tamanho das caselas, quando se testam as hipóteses dos tipos $I$ e II. Mesmo assim, raramente se recomenda a hipótese do tipo III para o teste de dados desbalanceados.

o artigo de SEARLE, SPEED \& HENDERSON (1981) tem como objetivo relacionar métodos para calcular as somas de quadrados para dados desbal anceados. Três métodos são 
avaliados. Um impõe restricões no modelo superparametrizado, tornando-o de posto completo. Outro envolve a inversa de parte da inversa da matriz X'X CTipo III do SASs. o último é o método dos quadrados de médias ponderadas. Para se utilizar desses métodos, é necessário se basear em funçôes estimáveis. Diferenças entre os níveis de um fator, por exemplo, não são estimáveis em modelos com interacão e caselas vazias. Portanto, a hipótese correspondente não será testável Cver IEMMA, $1991, p .14$ e 54). Utilizaram-se o modelo de médias de caselas para se contornar a situacão, pols apresenta menos problemas com estimabilidade. Assim, com as técnicas de modelos lineares, é possivel testar algumas hipóteses de interesse do pesquisador. Analisaram-se quatro pacotes estatísticos, especialmente, para o caso da análise com dados desbalanceados. Dentre os quatro, o SAS. Comenta-se o uso de restricốes do tipo $\Sigma$ (IEMMA, 1991 ) para o cálculo das somas de quadrados do tipo III. Somas de quadrados do tipo I e II são representadas pela notacão $R C$, , e a soma de quadrados do tipo IV são geradas como numeradores de estatisticas F, para testar hipóteses específicas.

$$
\text { o artigo de JENNINGS \& WARD (1982) é o outro }
$$
trabalho pioneiro para o caso de caselas vazlas, encontrado na literatura. Trata-se da identificacão de hipóteses no caso de caselas vazias. Com base no trabalho de FREUND (19803, eles provaram que muitas das dificuldades em se 
entender os problemas quando se trabalha com caselas vazias, estão no uso do modelo superparametrizado. Neste contexto, SMITH \& MURRAY (1983) citam Graybill (1976), ao afirmar que, geralmente, quando se faz a estimacão de mínimos quadrados com um modelo de posto incompleto para dados desbalanceados, há confusão.

JENNING \& WARD (1982), a partir do exemplo de FREUND (1980), buscaram identificar as hipóteses testadas pelo PROC GLM do SAS. Porém, não esclareceram como tais hipóteses são construídas, nem como são calculadas as somas de quadrados correspondentes. CAMARINHA FILHO \& IEMMA (1991) esclarecem esse ponto.

HERR (1986) reconheceu que, para o caso de tamanho de caselas proporcionais, as análises com tipo I e II são iguais, se a interacão está presente. Não há, portanto, diferença entre as hipóteses testadas nesses dois casos. Ainda HERR (1986) comentou que Snedecor \& Cox (1935) providenclaram sugestóes para a utilizacão de cinco métodos de análises, dentre eles, três foram incorporados pelo SAS:

- Somas de Quadrados do Tipo I:

a) em aproximações grosseiras, onde somente informacões sobre efeitos principais são desejadas;

GRAYBILL, F., "Theory and Application of the Linear Model. North scituate, Mass: Duxbury Press. 1976. 
b) para exame dos efeitos principals, onde o número de classes desproporclonais é representativo de uma populacão em que exista interacão.

- Somas de quadrados do Tipo II:

a) para os casos nos quais assume-se que a interacão não existe e um resultado mais confiável é desejado;

b) em casos onde alguns dados são perdidos dentro das caselas.

- Somas de quadrados do Tipo III:

a) em tabelas 2xs, em que interacôes são assumidas;

b) em outras tabelas de classificacão dupla, em que não se desejam informacốes sobre a interacão.

HERR (1986) ainda propõe que, se o artigo de Snedecor \& Cox (1935) fosse mais esclarecedor, proporclonaria uma maior curiosidade sobre o assunto, o que levaria a mais artigos tentando uma solucão para o problema.

o uso do modelo de médias de caselas modificado (MURRAY, 1986), embora seja um modelo interessante, não é tão apropriado quanto o modelo de médias de caselas convencional. Esse parece ser de maior entendimento, tanto para a estimacão de parâmetros, quanto para a obtencão das somas de quadrados, associadas às hipóteses de interesse. Sobretudo, em relacão a pesquisadores de ciências aplicadas.

o modelo proposto por MURRAY (1986), trabalha 
com particões de matrizes, de forma que se obtém a solucão de mínimos quadrados e testes de hipóteses de interesse, em relacão aos parâmetros do vetor de médias de caselas. Seja o modelo difinido como:

$y=w \mu+e$ sujeito a $G \mu=\varnothing$,

onde $G$ é uma matriz de constantes conhecidas de posto $s$, tipicamente especificando contrastes de não-interacão. Se não há casela vazia, Wé de posto completo, caso contrário, W tem uma coluna de "zeros" para cada casela vazia, e $\mu$ flca da mesma forma como se todas as caselas fossem ocupadas. O modelo modificado é mals útil que CIJ se há caselas vazias e é obtido por subtracão do contraste diretamente do modelo, por meio disso se reduz a dimensão do modelo. Isso é feito reordenando as colunas de $G$, assim, $G \mu=\varnothing$ implica em $\mu_{2}=-G_{2}^{-1} G_{1} \mu_{1}$. Agora reordenando as colunas de $W$ similarmente a $G$ e substituindo-se em ' ${ }^{\text {. }}$ tem-se o modelo modificado

$y=V \mu_{1}+e$, onde $\hat{\mu}=\left(V^{\prime} v^{-1} V^{\prime} y\right.$ e se $V$ tem posto coluna completo, então os estimadores de mínimos quadrados para $\mu_{1}$ $\mu_{2}$, existem.

MURRAY (1986) forneceu meios para se estimar caselas vazias. Criou dois exemplos, um para blocos casualizados, outro para quadrado latino e observou o caso dos modelos conexo e desconexo. Se o modelo é conexo, a correta hipótese pode ser obtida sem estimar as caselas vazias. Caso contrário, HOCHING, SPEED \& COLEMAN (1980) sugerem as hipóteses "eficazes". 
IEMMA (1991) discute o problema em se fazer uma análise na presença de desbalanceamento e, também, fornece algumas idéias sobre caselas vazias.

Dentre as indagacóes de IEMMA (1991), podem ser citadas: "Como esperar que um pesquisador faça uma boa interpretação da hipótese que está sendo testada por uma das quatro somas de quadrados fornecidas pelo SAS?" ; "Como esperar que ele possa fazer uma comparacão sensata de seus resultados com os resultados de outros pesquisadores que utilizaram outros pacotes estatísticos, para a análise de seus dados?"

IEMMA (1991) analisou, criteriosamente, todas as somas de quadrados obtidas pelas tabelas de análise de variância, através de diversos métodos de análise de dados encontrados na literatura, desde YATES (1934), até os quatro tipos de somas de quadrados fornecidas pelo PROC GLM do SAS. Posteriormente, apresentou as relacóes entre os métodos de YATES (1934), de OVERALL \& SPIEGEL (1969), de Henderson (1953) e do PROC GLM do SAS. Sem dúvida, esse é o trabalho que mais esclarece o problema. Pois, além de se obter as somas de quadrados para cada fonte de variacão, é mostrado "como" cada uma das hipóteses associadas a essas somas de quadrados, é construída. 0 autor, assim, possibilita que o pesquisador escolha a hipótese correta, de acordo com seu interesse, dentre as quatro fornecidas pelo PROC GLM.

IEMMA (1993), relacionou alguns problemas 
ocasionados pela presenca de caselas vazias, são eles:

a) Podem ocorrer desconexões;

b) O teste da interacão, em geral, testa que somente al gumas interaç̃es são nulas;

c) As hipóteses sobre médias não ponderadas de Iinhas e colunas, em geral, têm uma interpretacão bastante diferente daquel as sem caselas vazias;

d) Os graus de liberdade da interacão devem ser escolhidos com cautela.

IEMMA, PALM \& CLAUSTRIAUX (1993) através de maneira simples mostram como obter o projetor ortogonal associado a hipótese Ho para qualquer nivel de desbal anceamento. Fundamentam-se na definicão de funcões estimáveis e obtêm a soma de quadrados da hipótese por SQHo $=y^{\prime} a\left(a^{\prime} a\right)^{-1} a^{\prime} y=y^{\prime}$ PHoy, onde $y$ é o vetor de observacốes; a é o vetor de coeficientes da combinacão linear dos componentes do vetor $y$; $e$ a $\left(a^{\prime} a\right)^{-1} a^{\prime}=$ PHo é o projetor ortogonal associado a $\mathrm{Ho}$.

SANTOS (1994) comparou vários pacotes estatisticos em relacão as hipóteses fornecidas por estes.

$$
\text { SEARLE (1994) analisou o artigo de Dallal }
$$

(1992), onde este apresentou, através de um exemplo, a dificuldade de entendimento das hipóteses fornecidas por dois pacotes estatisticos: o SAS, usando o PROC GLM Cmais especificamente a hipótese do tipo III e o SPSS MANOVA,

DALLAL, G.E." "The Computer Analysis of Factorial Experiments with Nestod Factors". The Americanstatistician, 40, $24 \mathrm{C}$. 1002 . 
que fornece a hipótese convencional, observou que as somas de quadrados deram resultados distintos.

SEARLE (1994) discutiu vários aspectos da disparidade, quando se usa o PROC GLM para o exemplo Dallal (1992). Ou seja, um delineamento com dados desbalanceados de efeltos fixos e fatores "nested". São apresentadas as hipóteses I igadas as somas de quadrados do tipo III, tanto para o modelo superparametrizado com restricões $\Sigma$, quanto para o modelo de médias de caselas. Um modelo denominado Modelo $C$ fol providenciado para tratar o efeito "nested". Vê-se que as hipóteses diferem para os dois modelos, o de médias de caselas e o modelo $\mathbb{C}$. Conclut-se que a diferenca se deve à presenca de desbalanceamento dentro de um dos fatores. No modelo $\mathbb{C}$, as observacóes dentro de cada casela $A * B$ é rotulado, assim, tem-se três níveis em cada casela de A1 sels nívels em cada casela de $A 2$ e todo nível de C dentro de $A * B$ terá uma observacão a menos. Portanto. o modelo $\mathbb{C}$ tem a forma $y_{i j k}=\mu+\alpha_{i}+\beta_{j}+C a \beta_{i j}+\gamma_{i j: k}$. Note que o termo erro não está presente, pols em cada nível de C. que é "nested" de ntro de $A * B$, há apenas uma observacão.

Finalizando, o autor declarou, veementemente, que "softwares" caseiros precisam fornecer, claramente, mais detalhes e, especialmente, mais descricóes do que se está calculando. E acrescenta: "...qualquer coisa que se fizer para evitar certos usos ridiculos de pacotes estatísticos, valerá a pena." 


\section{MATERIAL E MÉtodOS}

\subsection{MATERI AL}

Visando ilustrar as idéias centrais postas neste estudo foram utilizados dois conjuntos de dados para auxiliar nas discussões dos problemas.

\subsubsection{CONJUNTO A}

o primeiro conjunto foi obtido de um experimento fatorial $2 \times 3$ delineado inteiramente ao acaso, para testar os efeitos de 3 recipientes (COLUNAS) para producão de mudas, e 2 espécies (LINHAS) de eucaliptos, quanto ao desenvolvimento das mudas CBANZATTO \& KRONKA, 1989 , p.132).

$$
\text { Os recipientes e as espécies testadas for am: }
$$

L1 : Eucalyptus citriodora C1: saco plástico pequeno Le: Eucalyptus grandis Ce : saco plástico grande $C 3$ : laminado

Os dados das alturas médias das mudas, em $\mathrm{cm}$, aos 80 dias de idade, constam do Quadro A1.

Quadro Al - Alturas médias das mudas, em cm, aos $80 \mathrm{dias}$. RECIPIENTE

\begin{tabular}{llllll} 
& \multicolumn{2}{c}{1} & \multicolumn{2}{c}{3} \\
\hline \multirow{3}{*}{ ESPECIE } & 1 & 26,$2 ; 26,0$ & 25,$7 ; 26,3$ & 22,$8 ; 19,4$ \\
& 25,$0 ; 25,4$ & 25,$1 ; 26,4$ & 18,$8 ; 19,2$ \\
\cline { 2 - 5 } & 2 & 24,$8 ; 24,6$ & 19,$6 ; 21,1$ & 19,$8 ; 21,4$ \\
& 26,$7 ; 25,2$ & 19,$0 ; 18,6$ & 22,$8 ; 21,3$ \\
\hline
\end{tabular}

Fonte: BANZATTO \& KRONKA (1989) 
De maneira geral, pode-se escrever como no

Quadro A.

Quadro A - Dados genéricos

\section{RECIPIENTE}

\begin{tabular}{cccccc} 
& \multicolumn{1}{c}{1} & 2 & 3 \\
\hline \multirow{2}{*}{ ESPÉCIE } & $y_{111} ; y_{112}$ & $y_{121} ; y_{122}$ & $y_{131} ; y_{132}$ \\
& $y_{113} ; y_{114}$ & $y_{123} ; y_{124}$ & $y_{133} ; y_{134}$ \\
\cline { 2 - 5 } & $y_{211} ; y_{212}$ & $y_{221} ; y_{222}$ & $y_{291} ; y_{232}$ \\
& 2 & $y_{213} ; y_{214}$ & $y_{223} ; y_{224}$ & $y_{293} ; y_{234}$ \\
\hline
\end{tabular}

Note que cada casela contém 4 observaç̃es, ou seja, $n_{i j}=4$ para quaisquer valores de $i$ e $j$.

Com base nesse exemplo, criaram-se, aleatoriamente, cinco situacóes, desde o caso original com dados bal anceados, até o caso onde ocorre desbal anceamento, na presenca de caselas vazias. As situacões são as seguintes (todos os modelos criados contêm interacão):

1 ) dados balanceados sem casela vazia, como no Quadro A1;

2) dados desbal anceados sem casela vazia;

as posicões das observacões perdidas são: $131,132,211$, 213, 214, 222, 231, 234; ou seja: $\mathrm{n}_{11}=\mathrm{n}_{12}=4 ; \mathrm{n}_{13}=\mathrm{n}_{23}=2$; $n_{21}=1$ e $n_{22}=3$, como no Quadro $A Z$;

3) uma casela vazia $\mathrm{Cn}_{11}=0$; e demais dados balanceados $\left(n_{i j}=4\right)$; como no Quadro A3;

$4)$ dados desbalanceados com uma casela vazia $\left.C_{11}=0\right)$, como no Quadro A4;

5) dados desbalanceados com duas caselas vazias $\mathrm{C}_{11}=\mathrm{n}_{23}=0$, como no Quadro A5; 
Os quadros refentes ao conjunto A são vistos

a seguir.

Quadro AZ - Alturas médias das mudas, em $\mathrm{cm}$, aos 80 dias. RECIPIENTE

\begin{tabular}{|c|c|c|c|c|c|}
\hline & & 1 & 2 & 3 & 3 \\
\hline \multirow{2}{*}{ ESPÉCIE } & 1 & $\begin{array}{l}26,2 ; 26,0 \\
25,0 ; 25,4\end{array}$ & $\begin{array}{l}25.7 ; 26,3 \\
25,1 ; 26,4\end{array}$ & 18,$8 ;$ & 19,2 \\
\hline & 2 & $; 24,6$ & $\begin{array}{l}19,6 ; \\
19,0 ; 18,6\end{array}$ & 22,8 & 21,4 \\
\hline
\end{tabular}

Quadro $A 3$ - Alturas médias das mudas, em $\mathrm{cm}$, aos 80 dias. RECI PIENTE

\begin{tabular}{lllll} 
& \multicolumn{1}{c}{1} & \multicolumn{2}{c}{3} \\
\hline \multirow{3}{*}{ ESPÉCIE } & & & 25,$7 ; 26,3$ & 22,$8 ; 19,4$ \\
& & 25,$1 ; 26,4$ & 18,$8 ; 19,2$ \\
\cline { 2 - 5 } & 2 & 24,$8 ; 24,6$ & 19,$6 ; 21,1$ & 19,$8 ; 21,4$ \\
& 26,$7 ; 25,2$ & 19,$0 ; 18,6$ & 22,$8 ; 21,3$ \\
\hline
\end{tabular}

Quadro A4 - Alturas médias das mudas, em $\mathrm{cm}$, aos 80 dias. RECIPIENTE

\begin{tabular}{|c|c|c|c|c|c|}
\hline & & 1 & $\begin{array}{c}\text { RECIPIENTE } \\
2 \\
\end{array}$ & & 3 \\
\hline \multirow{2}{*}{ ESPÉCIE } & 1 & & $\begin{array}{l}25,7 ; 26,3 \\
25,1 ; 26,4\end{array}$ & 18,8 & 19,2 \\
\hline & 2 & $; 24,6$ & $\begin{array}{l}19,6 ; \\
19,0 ; 18,6\end{array}$ & 22,8 & 21,4 \\
\hline
\end{tabular}

Quadro A5 - Alturas médias das mudas, em $\mathrm{cm}$, aos 80 dias. RECIPIENTE

\begin{tabular}{|c|c|c|c|c|}
\hline & & 1 & $\begin{array}{c}2 \\
\end{array}$ & 3 \\
\hline \multirow{2}{*}{ ESPÉCIE } & 1 & & $\begin{array}{l}25,7 ; 26,3 \\
25,1 ; 26,4\end{array}$ & 18,$8 ; 19,2$ \\
\hline & 2 & ; 24,6 & $\begin{array}{l}19,6 ; \\
19,0 ; 18,6\end{array}$ & \\
\hline
\end{tabular}




\subsubsection{CONJUNTO B}

o segundo conjunto é fictício. Trata-se de um ensaio fatorial $4 \times 3$. O primeiro fator (solo) e o segundo (varledade de cana-de-acúcar) têm a seguinte descricão para seus nívets:

Vartedades CV:

Solos (S):

$V_{1}:$ SP71-1143

S1: LVA, fase argilosa

$V_{2}:$ SP71-799

S2: Latossolo Roxo

V9: $R B 79-454$

Sa: LVA, fase arenosa

S4: Podzólico

Os dados constam do Quadro B1.

Quadro B1 - Produtividade média, em t/ha, de três variedades de cana-de-acúcar em quatro solos.

VARIEDADES

\begin{tabular}{|c|c|c|c|c|}
\hline & & & & \\
\hline & & 1 & 2 & 3 \\
\hline$S$ & 1 & $\begin{array}{ll}70 ; & 71 \\
73 ; & 78\end{array}$ & $\begin{array}{l}67 ; 66 \\
65\end{array}$ & $102 ; 110$ \\
\hline $\begin{array}{l}0 \\
L\end{array}$ & 2 & $\begin{array}{l}76 ; 74 \\
78\end{array}$ & 69 & $106 ; 116$ \\
\hline $\begin{array}{l}0 \\
5\end{array}$ & 3 & $66 ; 64$ & 62 & $\begin{array}{l}94 ; 101 \\
102\end{array}$ \\
\hline & 4 & $\begin{array}{l}65 ; 64 \\
63\end{array}$ & $\begin{array}{l}58 ; 52 \\
61\end{array}$ & $91 ; 97$ \\
\hline
\end{tabular}

Fonte: Dados ficticios

Algumas situações também foram criadas. São

elas:

1) com interação, sem casela vazia; como no Quadro B1;

2) sem interacão, sem casela vazia; como no Quadro B1; 
3) com interacão, com uma casela vazia $C_{12}=0$; como no Quadro Be;

4) Sem interacão, com uma casela vazia $\mathrm{Cn}_{12}=0$; como no Quadro Be;

$5)$ com interação, com duas caselas vazias $\mathrm{Cn}_{\mathbf{1 2}}=\mathrm{n}_{\mathbf{3 3}}=0$; como no Quadro B3;

6) Sem interação, com duas casel as vazias $\mathrm{Cn}_{\mathbf{1 2}}=\mathrm{r}_{33}=0$; como no Quadro B3;

7) sem interação, com três caselas vazias $c_{n_{12}}=n_{39}=n_{14}=0$; como no Quadro B4.

Os quadros para conjunto $B$ são dados a seguir.

Quadro Be - Produtividade média, em t/ha, de três vartedades de cana-de-acúcar em quatro solos.

VARI EDADES

\begin{tabular}{|c|c|c|c|c|}
\hline & & 1 & 2 & 3 \\
\hline \multirow{4}{*}{$\begin{array}{l}S \\
0 \\
L \\
0 \\
S\end{array}$} & 1 & $\begin{array}{l}70 ; 71 \\
73 ; 78 \\
\end{array}$ & & $102 ; 110$ \\
\hline & 2 & $\begin{array}{ll}76 ; & 74 \\
78 & \\
\end{array}$ & 69 & $106 ; 116$ \\
\hline & 3 & $66 ; 64$ & 62 & $\begin{array}{l}94 ; 101 \\
102\end{array}$ \\
\hline & 4 & $\begin{array}{l}65 ; 64 \\
63\end{array}$ & $\begin{array}{l}58 ; 52 \\
61\end{array}$ & $91 ; 97$ \\
\hline
\end{tabular}


Quadro B3 - Produtividade média, em t/ha, de três variedades de cana-de-acúcar em quatro solos.

\section{VARIEDADES}

\begin{tabular}{|c|c|c|c|c|}
\hline & & 1 & 2 & 3 \\
\hline \multirow{4}{*}{$\begin{array}{l}S \\
0 \\
L \\
O \\
S\end{array}$} & 1 & $\begin{array}{l}70 ; 71 \\
73 ; 78 \\
\end{array}$ & & $102 ; 110$ \\
\hline & 2 & $\begin{array}{l}76 ; 74 \\
78\end{array}$ & 69 & $106 ; 116$ \\
\hline & 3 & $66 ; 64$ & 62 & \\
\hline & 4 & $\begin{array}{l}65 ; 64 \\
63\end{array}$ & $\begin{array}{l}58 ; 52 \\
61\end{array}$ & $91 ; 97$ \\
\hline
\end{tabular}

Quadro B4 - Produtividade média, em t/ha, de três vartedades de cana-de-acúcar em quatro solos.

\begin{tabular}{|c|c|c|c|c|}
\hline & & \multicolumn{3}{|c|}{ VARI EDADES } \\
\hline & & 1 & $\mathrm{e}$ & 3 \\
\hline \multirow{4}{*}{$\begin{array}{l}S \\
0 \\
L \\
0 \\
S\end{array}$} & 1 & $\begin{array}{ll}70 ; & 71 \\
73 ; & 78 \\
\end{array}$ & & $102 ; 110$ \\
\hline & 2 & $\begin{array}{l}76 ; 74 \\
78 \\
\end{array}$ & 69 & $106 ; 116$ \\
\hline & 3 & $66 ; 64$ & 62 & \\
\hline & 4 & & $\begin{array}{l}58 ; 52 \\
61\end{array}$ & $91 ; 97$ \\
\hline
\end{tabular}

\subsubsection{PACOTES ESTATISTICOS}

Dois pacotes estatisticos fornecem os resultados para os dados apresentados. São eles:

- SAS CStatistical Analyses System)

- STATGRAPHICS (Statistical Graphics System) 


\subsection{MÉTODOS}

\subsubsection{MODELO LINEAR}

o modelo Iinear de efeitos fixos, com ou sem interacão, dependendo do exemplo, é escolhido para a análise dos dados. A caracterizacão do modelo é feita através das médias populacionais das subclasses, denotado por Modelo - M CIEMMA, 1991 ) ou Modelo de Médias de Caselas.

\subsubsection{MODELO COM INTERACÃO}

Considere o modelo linear com dols fatores CA - B) e interacão. As observacões $y_{i j k}$ são independentes e normalmente distribuídas, com médias populacionals $\mu_{i j} e$ vartáncla comum $d^{2}$.

$$
\begin{gathered}
\text { Sua caracterização pode ser dada por: } \\
y_{i j k}=\mu_{i j}+e_{i j k} \\
i=1,2, \ldots, a ; j=1,2, \ldots, b ; k=1,2, \ldots, n_{i j}
\end{gathered}
$$

onde $a$ e b são os números de niveis dos fatores $A$ e $B$, respectivamente, e $n_{i j}$ o número de observacões na subclasse ou casela $(i, j)$, com $E\left[Y_{i j k}\right]=\mu_{i j} e V\left[Y_{i j k}\right]=\underset{a b}{\alpha^{2}}$ Além disso, o número total de observacóes é $\underline{n}$, isto é, $\sum_{i} \sum_{j} n_{i j}=n$.

O modelo linear caracterizado dessa forma é denotado Modelo de Médi as de Caselas.

Pode-se escrever (1) na forma matricial, como:

$$
y=W \mu+e
$$

onde $y$ é um vetor $(n \times 1)$ de observacões, W é uma matriz $\mathrm{Cn}$ x ab) de "uns" e "zeros", $\mu$ é um vetor de parâmetros das 
médias populacionais, e é um vetor $\mathrm{e} n \times 1)$ de variáveis aleatórias não observáveis tais que $e \sim N\left(\varnothing ; I \alpha^{2}\right.$. Mais detal hes podem ser encontrados em ELSTON \& BUSH (1964) e IEMMA (1991).

Alguns autores, por exemplo, GRAYBILL (1961), SNEDECOR \& COCHRAN (1967) \& SEARLE (1971), preferem trabalhar com o modelo Superparametrizado ou modelo - $S$

$$
y_{i j k}=\mu+\alpha_{i}+\beta_{j}+\gamma_{i j}+e_{i j k}
$$

ou matricialmente

$$
y=x \theta+e
$$

para descrever as observacões. Entretanto, como os dois modelos são estatisticamente equi valentes (ver SPEED (1969) ou URQUHART, WEEKS \& HENDERSON (1973)), dá-se preferência ao modelo de médias de caselas neste trabalho. Porém, é bom lembrar que o PROC GLM trabal ha com o modelo superparametrizado, tanto na apresentação de suas funcões estimávels quanto para as estimativas de cada um dos parâmetros do modelo linear.

$$
\begin{aligned}
& \text { Nesse contexto, } \\
& \qquad \mu_{i j}=\mu+\alpha_{i}+\beta_{j}+\gamma_{i j}
\end{aligned}
$$

onde: $\mu$ é uma constante inerente a todas as observacões Cusualmente igual a média geral, deste que se imponham restriçóes paramétricas convenientes’, ver IEMMA (1987, pg. 182$)$

$a_{i}$ é o efelto do fator $A$;

$\beta_{j} \in$ o efelto do fator $B$;

$\gamma_{i j}$ é efelto da interacão entre o 1 -ésimo nível do fator $A$ e o j-ésimo nível do fator $B$. 


\subsubsection{MODELO SEM INTERAÇÃO}

o caso em questão necessita de uma nova caracterizacão para o modelo de médias, pois a interacão não está presente. Assim, o novo modelo pode ser descrito por :

$$
y_{i j}=\mu+\alpha_{i}+\beta_{j}+e_{i j}
$$

$\operatorname{com} \mu+\alpha_{i}=\mu_{i} \cdot$ Entzo.

$$
y_{i j}=\mu_{i}+\beta_{j}+e_{i j}
$$

E conforme (2) matricialmente por:

$$
y=w \mu+e
$$

A comparacão entre os dois modelos, modelo-s e modelo-M, no momento da construcão e interpretação das hipóteses é fundamental para uma boa compreensão do leitor. visto que o modelo-M facilita na construcão das hipóteses, mas o modelo - $S$ deixa claro quais os os efeitos do modelo Iinear envolvidos na referida hipótese, facilitando sua interpretacão.

\subsubsection{SOLUC̆̃̃O DE MÍNIMOS QUADRADOS}

\subsubsection{MODELO COM INTERAÇ̃O}

Usa-se nesse trabalho o modelo de médias de caselas pelos motivos já mencionados no capitulo anterior, além de proporcionar solucão únicado vetor de médias, $\mu$, pois, a matriz w tem posto coluna completo (ab). Assim, a 
matriz quadrada $W^{\prime} W_{\text {de }}$ ordem ab, tem posto completo e tem inversa clássica.

Assim, a solucão de mínimos quadrados coincide com o estimador de mínimos quadrados para $\mu$ é dada por

$$
\hat{\mu}=\left(w^{\prime} w\right)^{-1} w^{\prime} y
$$

que também é o B.L.U.E CBest Linear Unbiased EstimatorJ de $\mu$. Pode ser mostrado que o BLUE de $\mu_{i j}$ é a média amostral da casela $(i, j): \hat{\mu}_{i j}=\bar{y}_{i}$.

\section{2. 2. 2. MODELO SEM INTERAC̆ ĨO}

As solucốes de mínimos quadrados para $\mu$ são dadas por

$$
\hat{\mu}=C w^{\prime} w^{a} w^{\prime} y
$$

onde $\left(W^{\prime} W^{\prime}\right.$ é qualquer inversa generalizada de $W^{\prime} w^{\prime}$ Note que a matriz W'W é singular, ou seja, não tem posto coluna completo como no modelo com interacão visto neste trabalho. O posto de W'W será $a+b-1$.

A obtencão de $\left(W^{\prime} W^{-1}\right.$ e $\left(W^{\prime} W^{a}\right.$, nesse modelo, E trivial e portanto, não será disticutida com detalhes nesse trabalho. Maiores detalhes podem ser encontrados em SEARLE (1982) E IEMMA (1990).

\subsubsection{SOMAS DE QUADRADOS}

Sabe-se que as somas de quadrados fornecidas nos quadros de análise de variância estão estreitamente 
relacionadas com as hipóteses testadas para cada efeito do model o considerado.

Assim, a soma de quadrado para um teste de

Ho: $B^{\prime} \mu=h$ versus $H_{1}: B^{\prime} \mu \neq h$

onde $B^{\prime}$ é uma matriz $\left.C_{r} \times a b\right)$ de constantes conhecidas de posto linha completo $r$, é dada por

$$
\left.S Q H_{0}=\widehat{\left(B^{\prime} \mu\right.}-h\right)^{\prime}\left[B^{\prime}\left(W^{\prime} W^{-1} B\right]^{-1}\left(\widehat{B^{\prime} \mu}-h\right)\right. \text {. }
$$

Como na análise de variância, geralmente, $h=0$, a soHo fica:

$$
S Q H_{0}=\widehat{\left(B^{\prime} \mu\right.} \cdot\left[B^{\prime}(W, W)^{-1} B\right]^{-1} \widehat{\left(B^{\prime} \mu\right)}
$$

$$
\text { A relacão } 50 H_{\circ} / \alpha^{2} \text { tem distribuicão de }
$$

Qui-Quadrado central com $\underline{r}$ graus de liberdade, onde o quadrado médio do resíduo (QMres) é um estimador não viciado de $\alpha^{2}$ e a estatistica

$$
(S Q H o / r) / Q M r e s \sim F\left(r, \sum \Sigma\left(n_{i j}-1\right)\right)
$$

pode ser utilizada para proceder ao teste da hipótese Ho

Mais detalhes encontram-se em SEARLE C1971, P.112) E IEMMA (1987, P. $97 ; 1991$, p.18).

\section{2. 4. HIPótESES ESTATISTICAS}

Visando-se a discussão de certos aspectos do PROC GLM, estudam-se neste trabalho quatro hipóteses para cada um dos efeitos principais, A (LINHAS) e B CCOLUNAS), chamadas de hipóteses mais comuns sobre linhas e colunas 
(IEMMA, 1991, p. 34$)$ e uma hipótese sobre a interação (AB). Essas hipóteses são parte integrante do PROC GLM e são denotadas por hipóteses tipo I, II, III e IV, além da hipótese sobre a interacão. Já o STATGRAPHICS fornece, em sua versão mais recente, 7.0 , as do tipo I e II e sobre a interacão.

A seguir, são apresentadas as hipóteses mais comuns sobre linhas e sobre a interação. As hipóteses sobre colunas são análogas às hipóteses sobre linhas, portanto, serão vistas conjuntamente com os exemplos. Posteriormente, são vistas as hipćteses mais comuns no modelo Iinear sem interação.

\subsection{1. MODELO COM INTERAC̆̃̃O}

(A) Hipóteses sobre as médias ponderadas de Iinhas, ou Hipóteses do Tipo I

$$
H_{0}^{(1)}: \frac{\sum_{j} n_{1 j} \mu_{1 j}}{n_{1}}=\frac{\sum_{j} n_{2 j} \mu_{2 j}}{n_{2}}=\ldots=\frac{\sum_{j} n_{a j} \mu_{a j}}{n_{a}}
$$

onde $n_{i .}=\sum_{j}^{b} n_{i j}$

(B) Hipóteses sobre as médias ponderadas de Iinhas ajustadas para colunas, ou Hipóteses do Tipo II

$$
H_{0}^{(2)}: \sum_{j}^{b} n_{i j} \mu_{i j}=\sum_{i}, \sum_{j} \frac{n_{i j} n_{i}-j \mu_{i}, j}{n \cdot j}(i \neq i>)
$$


(C) Hipóteses sobre as médias não ponderadas de linhas, ou Hipóteses do Tipo II I

onde $\bar{\mu}_{i .}=\sum_{j}^{b} \mu_{i j} / b$

$$
\mathrm{Ho}^{(3)}: \bar{\mu}_{1}=\bar{\mu}_{2 .}=\ldots=\bar{\mu}_{\mathrm{a}} .
$$

(D) Tłpo IV (são hipóteses mais especificas, ligadas à casela vaziaj.

$\mathrm{Na}$ verdade, essa hipótese é equivalente à hipótese do tipo III. Caso se dê alguma diferenca, esta estará ligada à ocorrência de casela vazia. Assim, a forma desta hipótese poderá ser vista atráves do caso $A 3$, do item 4.1 , dentre outros.

(E) Hipótese sobre a interaço

$H^{(5)}: \mu_{i j}+\mu_{i^{\prime} j^{\prime}}-\mu_{i^{\prime} j}-\mu_{i j^{\prime}}=0, \forall C_{1} \neq i \cdot e j \neq j \cdot 3$

\subsection{2. MODELO SEM INTERAC ÃO}

(A) Hipóteses sobre as médias ponderadas de linhas, ou Hipóteses do Tipo I

$H_{0}^{(1)}: \mu_{i}+\sum \frac{n_{i j} \beta_{j}}{n_{i}}=\mu_{i,}+\sum \frac{n_{i} j_{j} \beta_{j}}{n_{i} \cdot}$, assim,

(B) Hipóteses sobre as médias ponderadas de linhas ajustadas para col unas, ou Hipóteses do Tipo II

$H_{0}^{(2)}: \mu_{i}+\Sigma \frac{n_{i j} \beta_{j}}{n_{i}}=\Sigma \frac{n_{i j} \bar{C}_{j}}{n_{i}}$.

onde $\bar{C}_{j}$ é a média ponder ada da coluna $j$.

(C) Hipóteses sobre as médias não ponderadas de I1 nhas, ou Hipóteses do Tipo III

$H_{0}^{(3)}: \mu_{i}+\sum \frac{n_{i j} \beta_{j}}{n_{i}}=\Sigma \frac{n_{i j} C_{j}}{n_{i}}$, 
onde $C_{j}$ é a média aritmética simples dentro da casela $j$.

Porém, convém destacar que, no modelo sem interação, as hipóteses do tipo II e III, serão sempre equivalentes e como em (D):

(D) Hipóteses do tipo IV

Ho: $\mu_{i}=\mu_{i},(i \neq i$ ') pelo modelo-M e

Ho: $a_{i}=a_{i},(i \neq 1$ ') pelo modelo-s

(E) Hipótese sobre a interacão

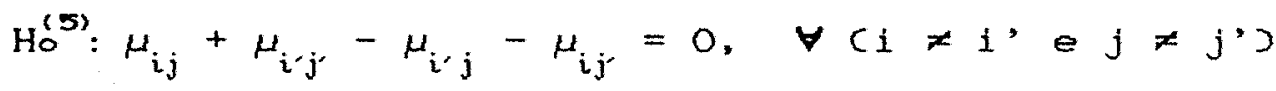

\subsubsection{CONSTRUÇ̃̃O DAS MATRIZES}

Seja um exemplo genérico com dois fatores resumi do no Quadro 1.

Quadro 1 - Esquema geral de um Fatorial a $\times$ b.

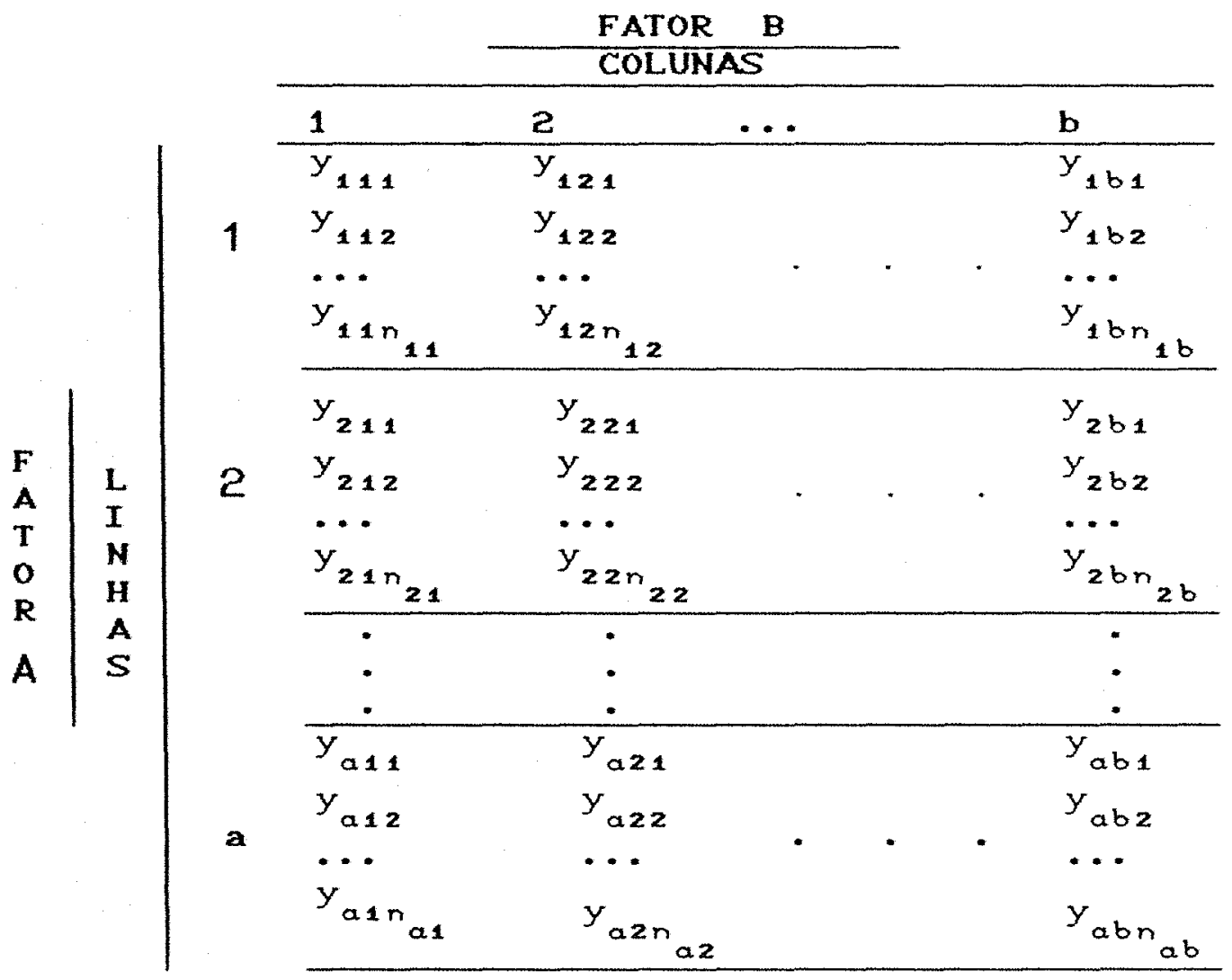




\subsubsection{MODELO COM INTERAC ÃO}

Um quadro similar pode ser construído através das médilas de caselas. Então:

Quadro 2 - Esquema geral de um fatorial a $x$ b, em relacão ao modelo de médias de caselas com interacão.

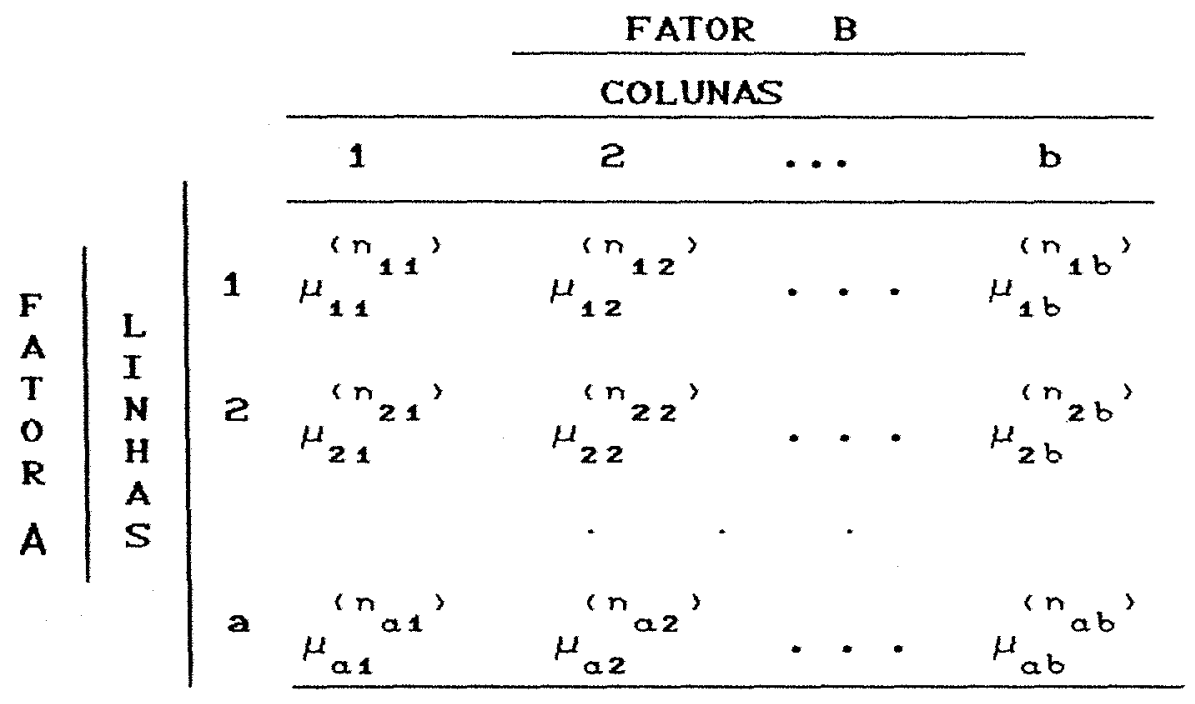

Em funcão do modelo de médias de caselas, $y=W \mu+e$, as matrizes, W, $W^{\prime} W,(W, w)^{-1}, e, y, \mu$ e $B^{\prime}$, ficam da forma:

$$
y_{1}^{y}=\left[\begin{array}{c}
y_{111} \\
y_{112} \\
\ldots \\
y_{11} n_{11} \\
y_{121} \\
y_{122} \\
y_{12 n} \\
\vdots \\
y_{a b n}
\end{array}\right] ; n_{a b} e_{1}=\left[\begin{array}{c}
e_{111} \\
e_{112} \\
e_{11 n_{11}} \\
e_{121} \\
e_{122} \\
e_{12 n} \\
\vdots \\
e_{a b n}
\end{array}\right] ; a_{a b} \mu_{12}=\left[\begin{array}{c}
\mu_{11} \\
\mu_{12} \\
\ldots \\
\mu_{1 b} \\
\mu_{21} \\
\mu_{22} \\
\vdots \\
\mu_{a b}
\end{array}\right]
$$




$$
\mathrm{n}_{\mathrm{ab}}=\left[\begin{array}{ccccc}
J_{1} & & & & \\
& J_{2} & & 0 & \\
& & J_{3} & & \\
& & & \ddots & \\
& 0 & & & J_{a b}
\end{array}\right]
$$

onde $J_{q}$ é um vetor $\left.C_{n_{i j}} \times 1\right)$ de "uns" e uma matriz de "zeros".

Desta forma, $W^{\prime} W e\left(W^{\prime} W^{-1}\right.$ são fácels de serem obtidas.

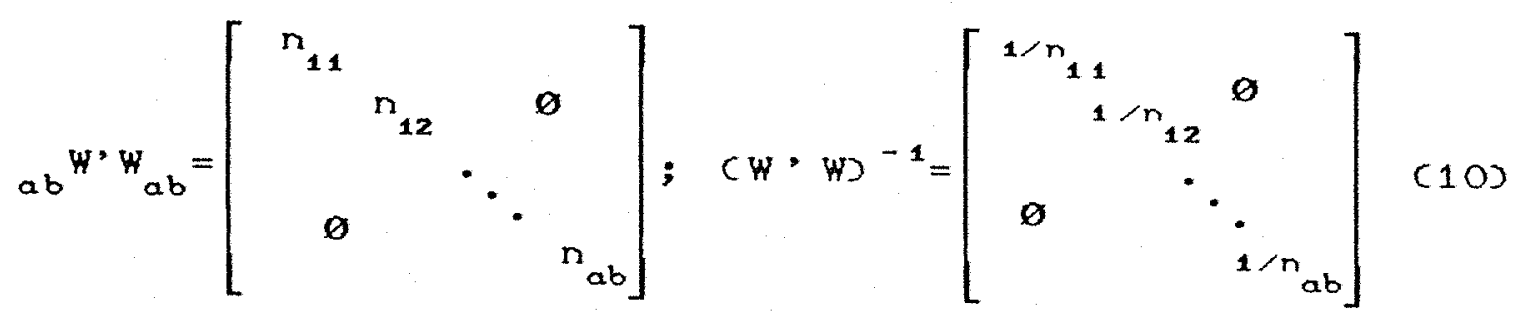

Assim, a solucão de mínimos quadrados para o vetor de parâmetros, $\mu$, fica:

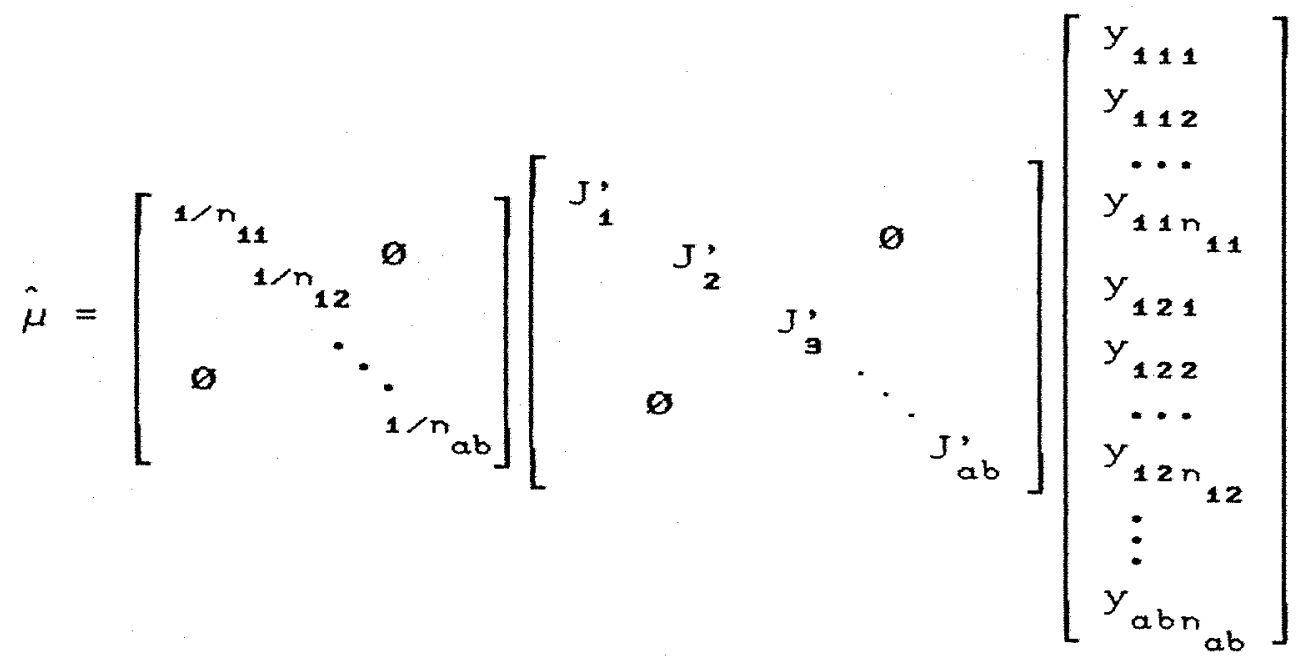


portanto, $\hat{\mu}$, como dito no item 3.2.2.1., fica:

$$
\hat{\mu}=\left[\begin{array}{cc}
y_{11} . & / n_{11} \\
y_{12} . & / n_{12} \\
\vdots & \\
y_{a b} & / n_{a b}
\end{array}\right]=\left[\begin{array}{c}
\bar{y}_{11 .} \\
\bar{y}_{12 .} \\
\vdots \\
\bar{y}_{a b .}
\end{array}\right]
$$

A matriz B', será denotada nesse trabalho por "Matriz Hipótese", que dependerá da hipótese testada, por exemplo:

a) Tipo I:

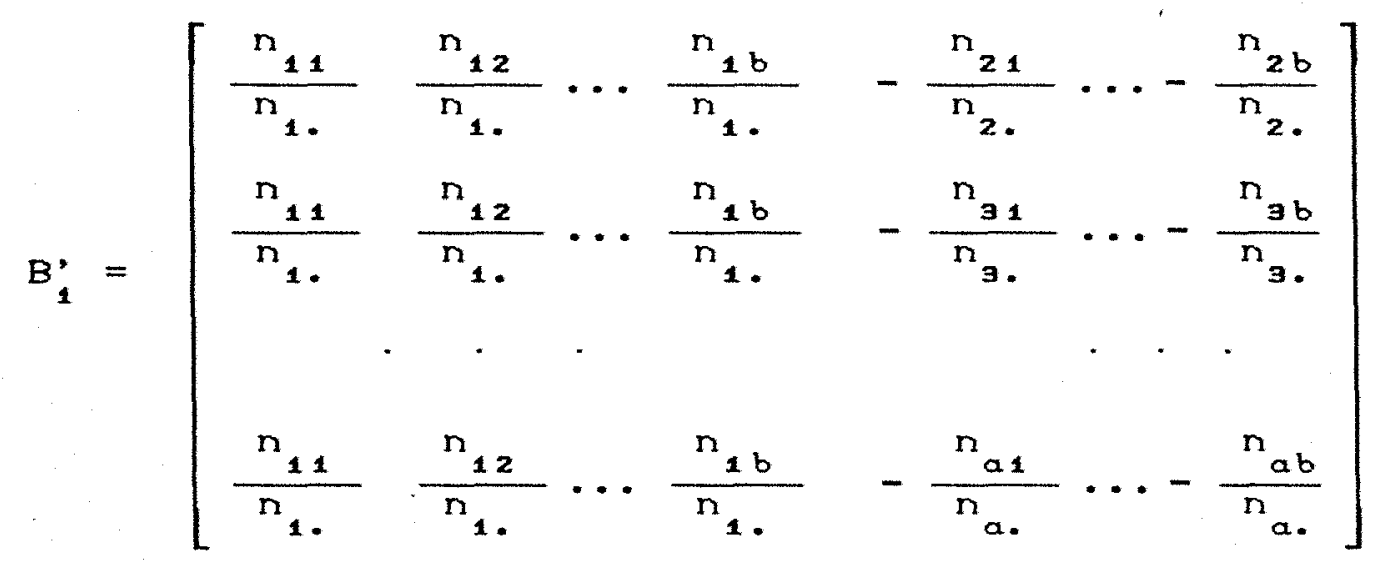

b) Tipo II

$$
B_{2}^{\prime}=
$$

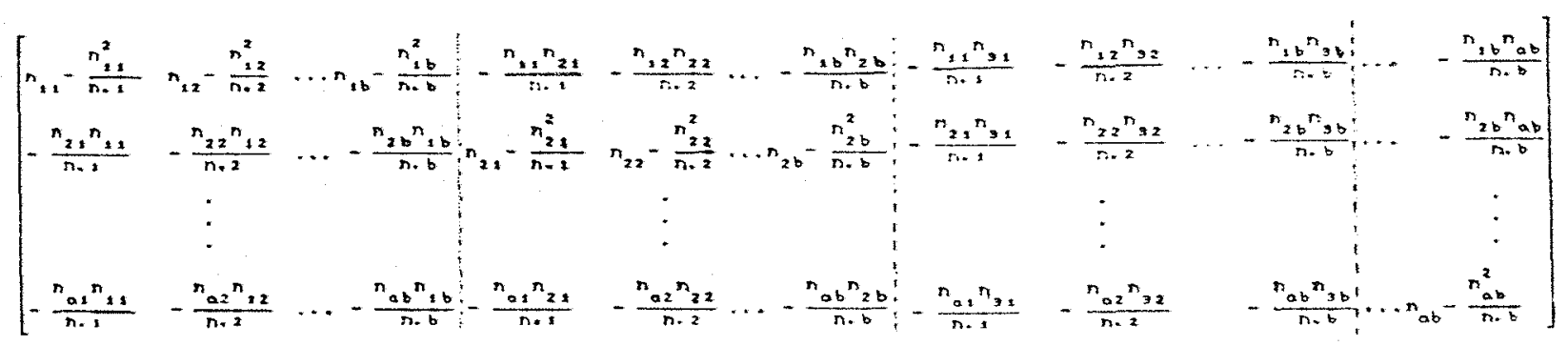




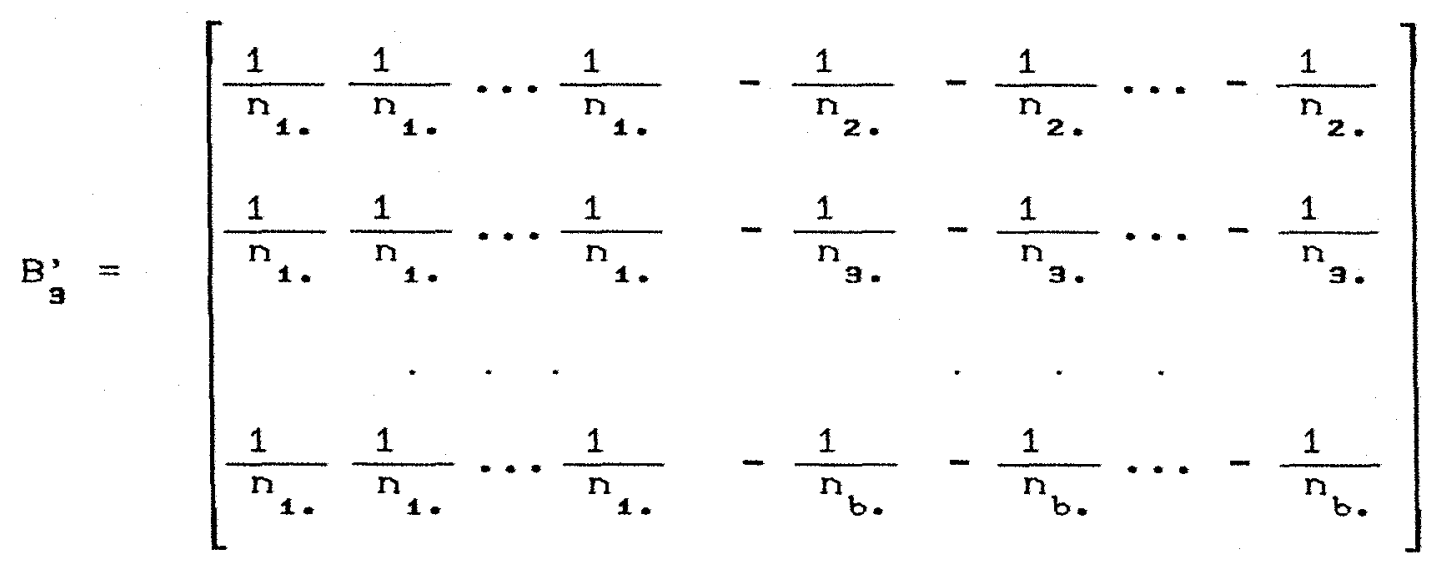

d) Tipo IV

Por se tratar de um caso particular. $B_{4}^{\prime}$ será vista conjuntamente com os exemplos.

e) Interação

A forma de $B_{5}^{\prime}$ para a interação também será vista através dos exemplos.

É bom salientar que todas as matrizes apresentadas não resolvem o problema de casela vazia. o caso de caselas vazia terá um tratamento especial com o auxilio dos exemplos. Embora, seja suficiente eliminar dentro de cada matriz a linha ou coluna referente à casela vazia.

3.2.5.2. MODELO SEM INTERACÃO

o esquema para o modelo de médias é visto no Quadro 3. 
Quadro 3 - Esquema geral de um fatorial axb, em relacão ao modelo de médias de caselas sem interacão.

\section{COLUNAS}

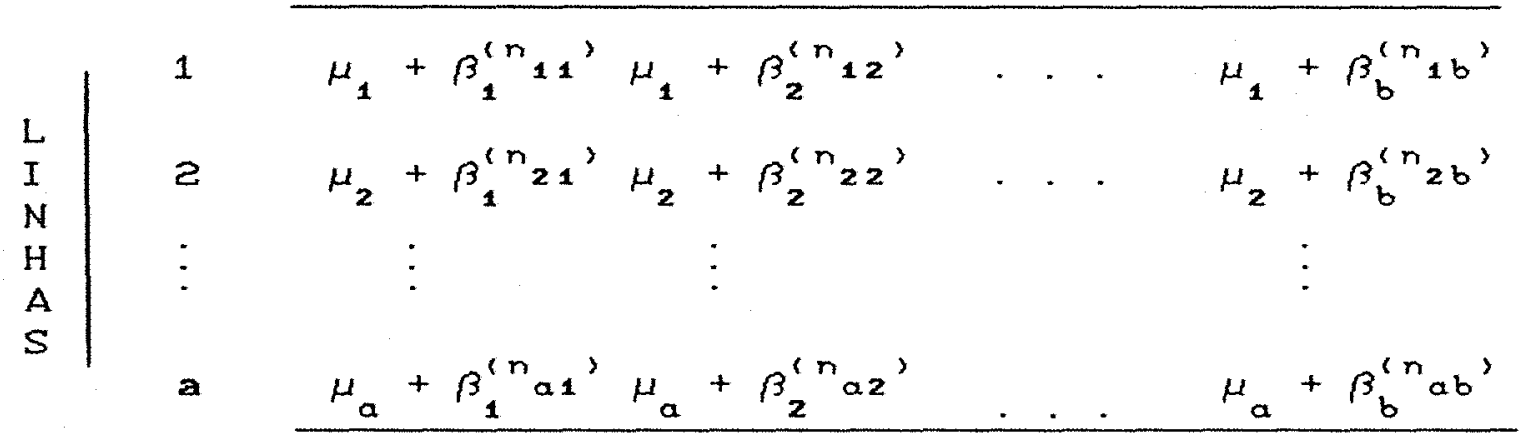

A matriz $w$, de or dem $(n \times a+b)$ e vetor $\mu$ de ordem $(a+b \quad 1)$, são da forma:

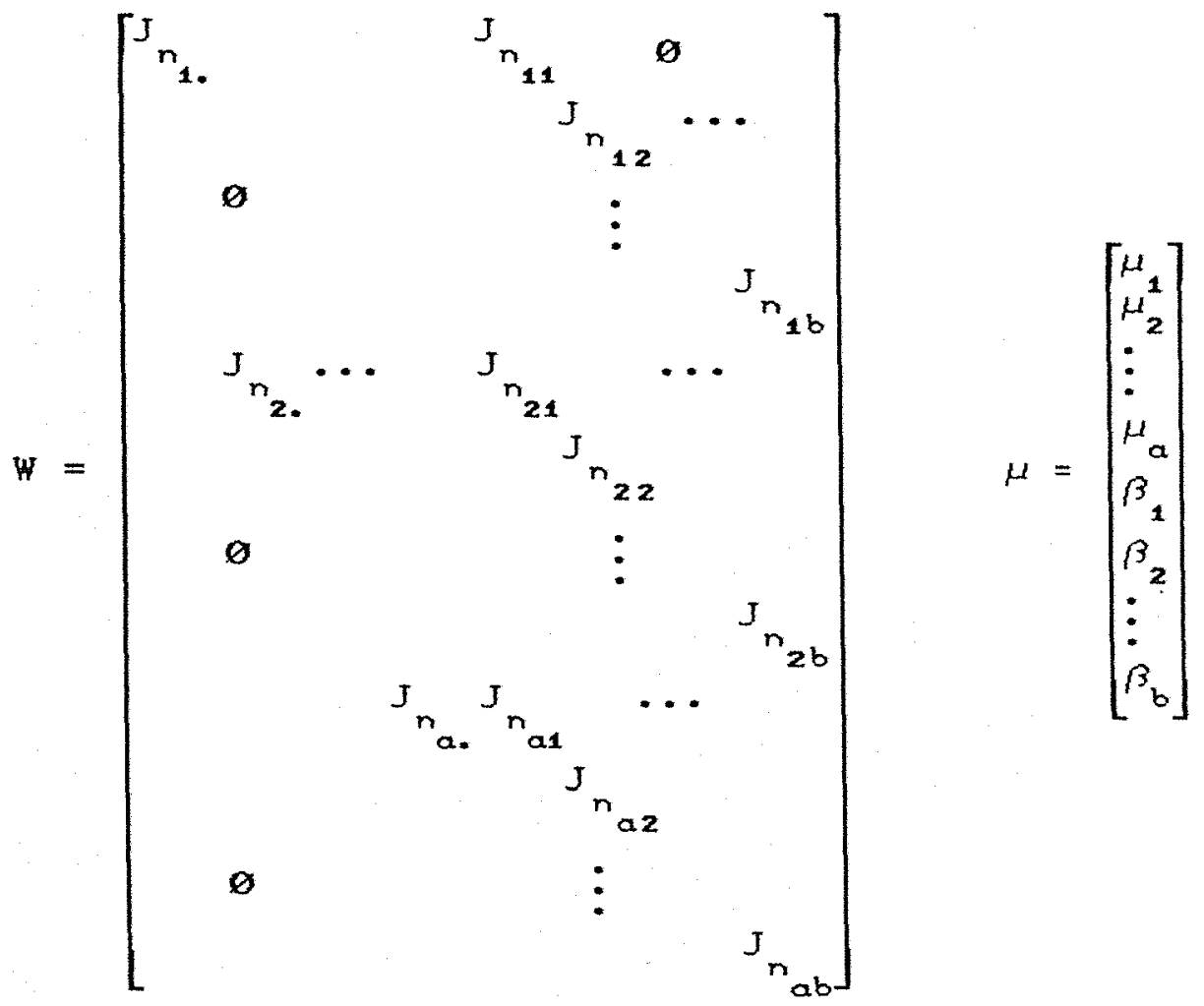

As matrizes, construídas dessa forma, são válidas caso não exista casela vazia, caso contrário, os elementos contendo caselas vazias devem ser eliminados. 0 
próximo capitulo tem o objetivo de esclarecer qualquer dúvida sobre as construçóes das hipóteses.

\section{2.6. QUADRO DA ANÁLISE DE VARI ÂNCIA}

Um esquema da análise de variância é obtido e pode ser visto no Quadro 4.

Quadro 4 - Análise de Variancia do modelo com interacão

\begin{tabular}{|c|c|c|c|}
\hline c. $\mathrm{V}$. & G. L. & S.Q. & $F$ \\
\hline LINHAS & $(a-1)$ & S.Q. $\mathrm{Ho}^{(2)}$ & $Q M^{(L)} / Q M R E S$ \\
\hline COLUNAS & $(b-1)$ & S.Q. $\mathrm{Ho}^{(\mathrm{C})}$ & $O M^{(C)} / O M R E S$ \\
\hline INTERAC̆ÃO & $(a-1)(b-1)-t$ & S.Q. Ho ${ }^{(x)}$ & $\left.Q M^{(I}\right) / Q M R E S$ \\
\hline RESÍDUO & $\Delta_{1}$ & $\Delta \mathbf{2}$ & \\
\hline
\end{tabular}

onde: a é o número de linhas da Quadro 2 ;

bé o número de col unas da Quadro 2 ;

t é o nứmero de caselas vazias;

$\Delta_{1} e \Delta_{2}$ são indicadores obtidos por diferenca;

QM é o quadrado médio dado por SQHo/posto de B';

QMres é dado por $\Delta z / \Delta 1$;

SQHo representam as somas de quadrados associadas a cada hipótese já apresentada.

Evidentemente, se o modelo linear não contiver interacão, a terceira linha do quadro 4 deve ser el iml nada. 


\subsubsection{PROJETORES ORTOGONAIS}

Dentro daquilo que já foi mencionado, IEMMA (1993) discute a relação entre a construcão de projetores ortogonais e hipóteses mais comuns sobre linhas e colunas. Assim, tem-se resumidamente o enfoque principal dentro do contexto desse trabal ho.

Seja um modelo linear $y=X \theta+e$, dado em (4).

Nesse contexto, é bem sabido que o sistema de equacões normais $X^{\prime} X \theta=X^{\prime} Y$, sempre consistente, fornece solucões aproximadas de mínimos quadrados para $y=x \theta$, em geral inconsistente, dadas por $\hat{\theta}=(X, X)^{a} X^{\prime} Y$. É bem sabido, também, que se $x$ não tem posto coluna completo, então o sistema de equacoóes normais é indeterminado e $\hat{\theta}$ não tem valor por si só, mas sim através de $x$, pois $\hat{y}=x \hat{\theta}$, invariante para qual quer $\hat{\theta}$ solucão das equacões normais, é a aproximacão de mínimos quadrados para o vetor y das observacôes.

Por outro lado, é imediato verificar que $\hat{y}=x \hat{\theta}=P y$, onde $P=X(X, X)^{a} X$, é o projetor ortogonal de $y$ sobre - espaco gerado pelas colunas de X. Assim, com pode ser observado na $f i g u r a 1$, o vetor $y \in R^{n}$ é decomposto na soma de dois vetores pertencentes a subespacos ortogonais: $\hat{y}=P y$ pertencente a $C(X)$ e $\hat{e}=y-\hat{y}=(I-P) y$ pertencente ao complemento ortogonal do espaco coluna de $x, C^{\perp}(x)$. 
Figura 1 - Projeção ortogonal do vetor y sobre o espaco gerado pelas colunas de $X$.

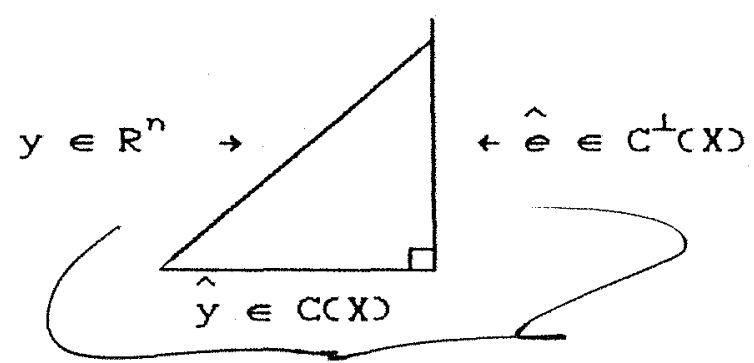

Então, dada a ortogonalidade podemos utilizar

- teorema de Pitágoras, obtendo a decomposicão da análise de $\operatorname{variancia}\|y\|^{2}=\left|\hat{y}\left\|^{2}+\mid \hat{e}\right\|^{2}\right.$, onde $\|y\|^{2}=y^{\prime} y=$ $\Sigma y^{2}$ a soma de quadrados total não corrigida; $\left.|| \hat{y}\right|^{2}=$ ||$P y||^{2}=y^{\prime} P y$ é a soma de quadrados dos parâmetros e $\left.|\hat{e}|\right|^{2}$ $=y^{\prime}(I-P) y$ é a soma de quadrados do resíduo.

A obtencão de $P$ é trivial pois $X$ é a matriz conhecida do delineamento. Desse modo, a forma quadrática y'Py que traduz a soma de quadrados dos parâmetros, em termos das observacões, é facilmente determinada. Tal simplicidade, no entanto, não é verificada na obtencão de projetores ortogonais associados a hipóteses mais especificas como por exemplo hipóteses sobre linhas, colunas e interacão, principalmente se existem caselas vazias.

3.2. 8. NOTACÃO RC ,

Tomando como base o trabalho de IEMMA (1991). - possivel descrever sucintamente a notacão RC $)$. Para tanto, faz-se necessário descrever algumas caractertzacões 
que o modelo-s pode assumir, conforme 0 interesse do pesquisador. Assim, parametrizando sucessivamente desde o modelo mais simples até o modelo com dois fatores e interacão, tem-se:

$$
\begin{gathered}
y_{i}=\mu+e_{i} \\
y_{i j}=\mu+\alpha_{i}+e_{i j} \\
y_{i j}=\mu+\beta_{j}+e_{i j} \\
y_{i j k}=\mu+\alpha_{i}+\beta_{j}+e_{i j k} \\
y_{i j k}=\mu+\alpha_{i}+\beta_{j}+\gamma_{i j}+e_{i j k}
\end{gathered}
$$

As somas de quadrados associadas aos modelos apresentados podem ser convenientemente descritas através da notacão RC 3 .

De modo geral, para o modelo $y=x \theta+e$, tem-se:

$$
R(\theta)=\hat{\theta} \cdot X^{\prime} y=S \cdot Q \cdot \text { Parâmetros }
$$

que é a soma de quadrados devida a todos os parâmetros do modelo adotado. Através de parametrizaçôes sucessivas e de subtracões pode-se obter as somas de quadrados de interesse. Assim, por exemplo, para a caracterização (12.1), a soma de quadrados dos parâmetros do modelo pode ser obtida por:

$$
R(\mu)=\hat{\theta} ; x_{1}^{\prime} y=\text { Correção }
$$

onde $x_{1}$ é um vetor de "uns" referente à primeira coluna da matriz X (matriz delineamento), ou seja, a coluna associada 
ao parâmetro $\mu$. Agora, utilizando-se (12. 2), tem-se:

$$
\mathrm{R}(\mu, \alpha)=\hat{\theta} ; \mathrm{x}_{2}^{\prime} \mathrm{y}
$$

onde $x_{2}$ é uma matriz de ordem $\left.C_{n} \times a+1\right)$, que dentro deste trabalho se refere às colunas $1,2,3, \ldots, a+1$ da matriz $X$, ou seja, as colunas associadas aos parâmetros $\mu$ e $\alpha$.

Assim, com base em (13) e (14) pode-se obter a soma de quadrados de linhas, ajustada após $\mu$, ignorandose $\beta$ e $\gamma$ :

$$
R(\alpha \mid \mu)=R(\mu, \alpha)-R(\mu)=\sum_{i} \frac{A_{i}^{2}}{n_{i}}-C
$$

que é bem conhecida dos usuários de estatistica.

De modo análogo obtém-se qualquer soma de quadrados de interesse, por exemplo:

$$
\begin{gathered}
R(\mu, \beta)=\hat{\theta}, X_{3}^{\prime} y \\
R(\beta \mid \mu)=R(\mu, \beta)-R(\mu) \\
R(\mu, \alpha, \beta)=\hat{\theta} \cdot X, y \\
R(\alpha \mid \mu, \beta)=R(\mu, \alpha, \beta)-R(\mu, \beta) \\
R(\beta \mid \mu, \alpha)=R(\mu, \alpha, \beta)-R(\mu, \alpha) \\
R(\gamma \mid \mu, \alpha, \beta)=R(\mu, \alpha, \beta, \gamma)-R(\mu, \alpha, \beta)
\end{gathered}
$$

e assim por diante.

\section{2. 9. PACOTES ESTATISTICOS}

Os pacotes estatisticos utilizados para a análise de cada uma das situacóes criadas para os exemplos foram: o SAS (Statistical Analyses System), mais 
especificamente 0 PROC GLM CGeneral Linear Model Procedure), e o STATGRAPHICS (Statistical Graphics System). o uso de tais pacotes se justifica, pois ambos têm sido uni versalmente utilizados.

Para proceder a análise de dados através do PROC GLM é necessárto que se faca um programa informando, além dos dados, o tipo de modelo a ser usado e o tipo de hipótese para criar o quadro da análise de variancia. No caso do PROC GLM, têm-se quatro tipos de hipóteses CI, II, $I I \cap I V D$

- STATGRAPHIC.S, versão 7.0, fornece apenas dois tipos de hipótese (I e III) e, ao contrário do GLM, não há necessidade de se programar. Todas as opcões são apresentadas na tela.

Dentro desse contexto, as hipóteses do tipo III e IV São obtidas utilizando-se o modelo $\Sigma$. 0 modelo $\Sigma$ é um modelo ilnear superparametrizado, com restricões do tipo "soma igual a zero" e pode ser representado por:

$$
y=2 \theta+e
$$

Assim, por exemplo, em relaç̃o ao modelo (12.5), tem-se:

$$
y_{i j k}=\mu^{0}+\alpha_{i}^{0}+\beta_{j}^{0}+\gamma_{i j}^{0}+e_{i j k}
$$

onde

$$
a_{i}^{0}=a_{i}-\frac{\sum a_{i}}{a} \Rightarrow \sum \alpha_{i}^{0}=0 ;
$$


$\beta_{j}^{0}=\beta_{j}-\frac{\Sigma \beta_{j}}{b} \Rightarrow \sum \beta_{j}^{0}=0$

$\gamma_{i j}^{0}=\gamma_{i j}-\frac{\sum_{i} \gamma_{i j}}{a}-\frac{\sum_{j} \gamma_{i j}}{b}-\frac{\sum_{i j} \gamma_{i j}}{a b}$

então,

$$
\sum_{i} \gamma_{i j}^{0}=0, \forall j \text { e } \sum_{j} \gamma_{i j}^{0}=0, \forall i
$$

Dessa forma, as hipóteses sobre linhas e colunas ficam:

$$
H_{0}: \alpha_{i}^{0}=0, \forall 1 \text { e Ho: } \beta_{j}^{0}=0, \forall j
$$

onde $\alpha^{\circ}$ e $\beta^{\circ}$ são os parâmetros do modelo restrito, como em (15.1).

A importância do modelo $\Sigma$ está na obtenção da soma de quadrados para um parâmetro ajustado para todos os outros, por exemplo, considerando um modelo com dois fatores e interação, tem-se:

$$
\left.\left.\left.\operatorname{RC} \alpha^{\circ} \mid \mu^{\circ}, \beta^{\circ}, \gamma^{\circ}\right) ; \operatorname{RC} \beta^{\circ} \mid \mu^{\circ}, \alpha^{\circ}, \gamma^{\circ}\right) ;\left.\operatorname{RC} \gamma^{\circ}\right|^{\circ}, \alpha^{\circ}, \beta^{\circ}\right)
$$

em Iugar do ajuste sequencial, que pode ser utilizado para obtencão das hipóteses do tipo I e II, da forma como foi apresentada em 3.2 .8 .

Em resumo, os quadros de análise de variância fornecidos pelos dois pacotes podem ser apresentados como nos Quadros 5 a 7 . 
Quadro 5 - Quadro para a hipótese do tipo I

\begin{tabular}{ll}
\hline Fonte de Variação & $R C)$ \\
\hline Linha (não ajustada) & $R(\alpha \mid \mu)$ \\
Col una (ajustada) & $R(\beta \mid \mu, \alpha)$ \\
Interacão (L*C) & $R(\gamma \mid \mu, \alpha, \beta)$ \\
\hline
\end{tabular}

Quadro 6 - Quadro para a hipótese do tipo II

\begin{tabular}{ll}
\hline Fonte de Variacão & $R C)$ \\
\hline Linha (ajustada) & $R(\alpha \mid \mu, \beta)$ \\
Coluna (ajustada) & $R(\beta \mid \mu, \alpha)$ \\
Interacão (L*C) & $R(\gamma \mid \mu, \alpha, \beta)$ \\
\hline
\end{tabular}

Quadro 7 - Quadro para a hipótese do tipo III

\begin{tabular}{ll}
\hline Fonte de Variacão & $R C)$ \\
\hline Linha & $\left.R C \alpha^{\circ} \mid \mu^{\circ}, \beta^{\circ}, \gamma^{\circ}\right)$ \\
Coluna & $\left.R C \beta^{\circ} \mid \mu^{\circ}, \alpha^{\circ}, \gamma^{\circ}\right)$ \\
Interacão $(L * C)$ & $R(\gamma \mid \mu, \alpha, \beta)$ \\
\hline
\end{tabular}

Os quadros referentes ao modelo sem interação, na verdade, são idêntidos aos quadros acima, desprezando, logicamente, o efeito da interacão. No próximo capítulo são esclarecidos outros detalhes sobre os pacotes aqui ut $11 \pm z$ ados. 


\section{RESULTADOS E DISCUSSÃo}

A apresentacão dos resultatos, fornecidos pelos pacotes estatísticos, é feita no quadro de análise de variância proposto por Fisher.

A solucão para o vetor de parâmetros do modelo linear proposto é obtida através da solucão de Mínimos Quadrados.

As Somas de Quadrados vistas nos quadros de análise de variância, são obtidas pela imposicão das "matrizes hipóteses" B" matrizes que esclarecem o tipo de hipótese testada.

Cada uma das hipóteses testadas está relacionada com os quatro tipos de Funcões Estimáveis dadas pelo PROC GLM do SAS, ou seja, tipos I, II, III e IV.

Como já comentado no capitulo anterior, dois exemplos são utilizados para auxiliar na análise dos dados feita pelos dois pacotes estatisticos aqui estudados e criar condicões de discernimento entre todos os tipos de hipóteses. Dessa forma, as peculiaridades de cada hipótese ficará evidenciada. A seguir temos os dois exemplos.

\section{1. EXEMPLO 1}

Conforme o item 3.1.1. no presente trabalho. os dados são adaptados e analisados desde um modelo bal anceado até um modelo desbalanceado com caselas vazias, 
todos na presenca de interacão. Apresentam-se, a seguir, cinco casos que podem ser encontrados em análises de experimentos.

\subsubsection{CASO A1 - Dados bal anceados}

1. O MODELO LINEAR

O modelo de médias de caselas fica:

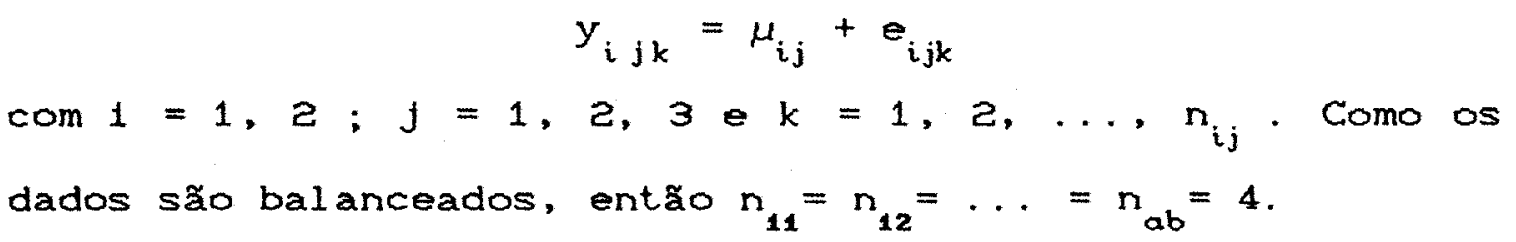

Comparando-se com o modelo superparametrizado,

tem-se:

$$
\begin{gathered}
y_{i j k}=\mu+\alpha_{i}+\beta_{j}+\gamma_{i j}+e_{i j k}=\mu_{i j}+e_{i j k}, \operatorname{ass} 1 m, \\
\mu_{i j}=\mu+\alpha_{i}+\beta_{j}+\gamma_{i j}
\end{gathered}
$$

Com base no Quadro 2 , pode-se construlr o

Quadro 8 para o caso A1 que vem a seguir.

\begin{tabular}{|c|c|c|}
\hline \multicolumn{3}{|c|}{ COLUNAS } \\
\hline 1 & 2 & 3 \\
\hline$\mu_{11}^{(4)}$ & $\mu_{12}^{44\}}$ & $\mu_{19}^{\langle 4\rangle}$ \\
\hline
\end{tabular}

Quadro 8 - Quadro do modelo de méd1 as - Caso A1

LINHAS

2

\begin{tabular}{lll}
$\mu_{21}^{(4)}$ & $\mu_{22}^{(4)}$ & $\mu_{23}^{(4)}$ \\
\hline
\end{tabular}


2. AS MATRIZES

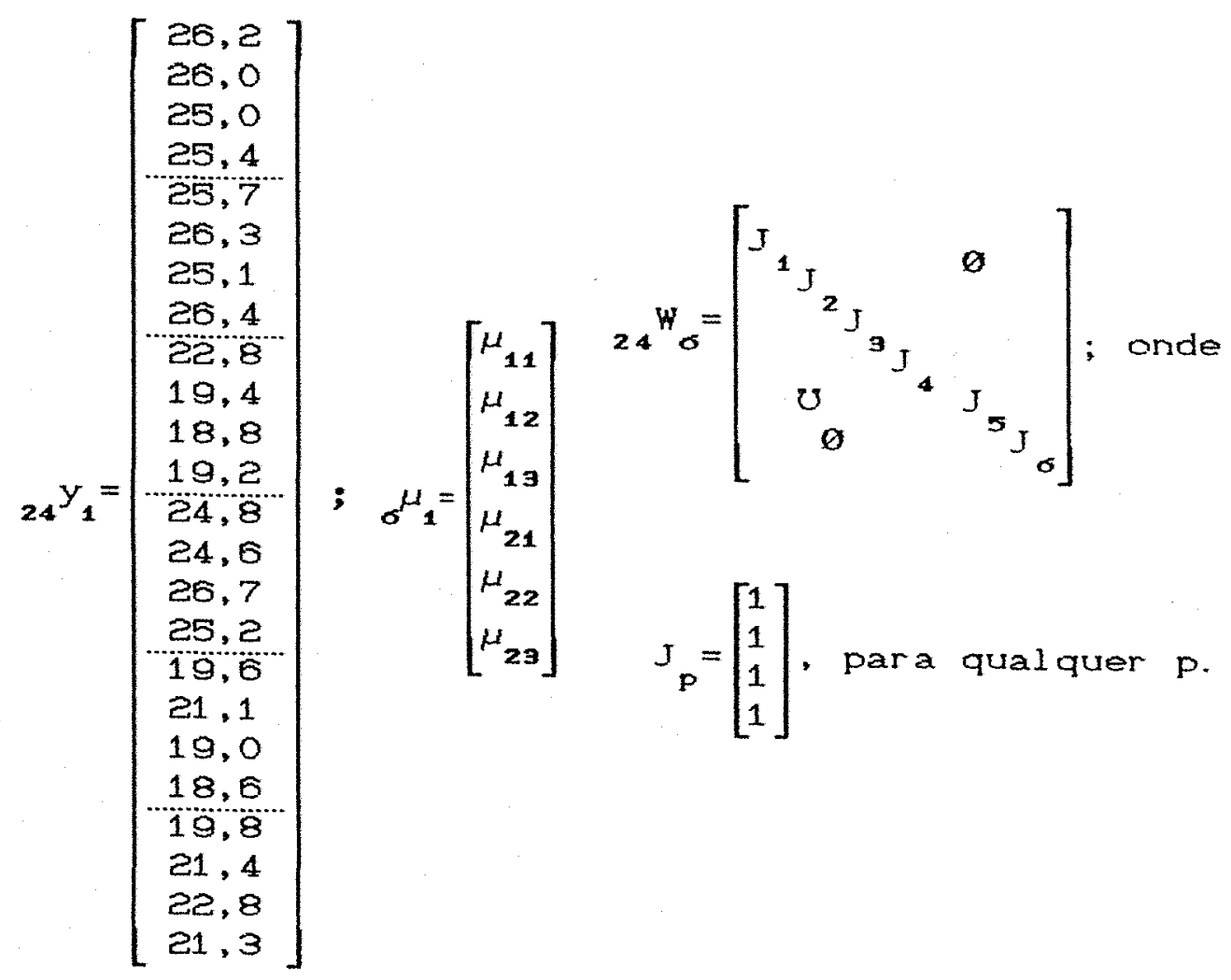

$$
\begin{aligned}
& \text { Assim, (W'w) })^{-1} \text { tem a forma, } \\
& \left(W^{\prime} W^{-1}=\frac{1}{4}\left[\begin{array}{llllll}
1 & & & & & \\
& 1 & & & 8 & \\
& & 1 & & & \\
& & & 1 & & \\
& 0 & & & 1 & \\
& & & & & 1
\end{array}\right]=\frac{1}{4} I_{\langle\sigma\rangle}\right.
\end{aligned}
$$

Então, pode-se escrever a matriz $\left(W^{3} W^{-1}\right.$ na

forma

$$
(W \cdot W\rangle^{-1}=\frac{1}{k} I_{\langle a b\rangle}
$$

onde $k$ é o número de repeticões por tratamento cpara o

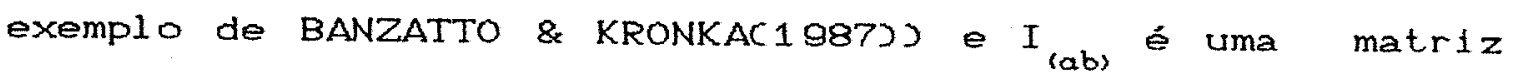
identidade de ordem (ab), se o experimento é bal anceado. 
De acordo com (7) ou (11), tem-se,

$$
\hat{\mu}=\frac{1}{4}\left[\begin{array}{r}
102,6 \\
103,5 \\
80,2 \\
101,3 \\
78,3 \\
85,3
\end{array}\right]
$$

Agora, por (9), encontram-se as somas de quadrados para as hipóteses formuladas.

\section{HIPÓTESES ESTATÍSTICAS}

Cabe agora um lembrete que pode ser encontrado facilmente na literatura correlata, digamos, KUTNER (1974): ao se trabalhar com dados balanceados, a análise de dados é feita de forma simples e as hipóteses do tipo I, II, III e IV são equi valentes.

Através de uma simples exposicão dessas hipóteses essas afirmacões podem ser comprovadas, assim:

3.1. Hipóteses sobre Li nhas ou Espécies 3.1.1. Tipo I

$$
\mathrm{Ho}^{(1)}: \frac{4 \mu_{11}+4 \mu_{12}+4 \mu_{13}}{12}=\frac{4 \mu_{21}+4 \mu_{22}+4 \mu_{23}}{12} \Rightarrow
$$$$
\Rightarrow \quad \mu_{11}+\mu_{12}+\mu_{13}=\mu_{21}+\mu_{22}+\mu_{29}
$$ 
3.1.2. Tipo II

$H_{0}^{(2)}: \frac{4 \mu_{11}+4 \mu_{12}+4 \mu_{13}}{12}=\frac{4 \bar{C}_{1}+4 \bar{C}_{2}+4 \bar{C}_{3}}{12} \Rightarrow$

$\Rightarrow \mu_{11}+\mu_{12}+\mu_{19}=\bar{C}_{1}+\bar{C}_{2}+\bar{C}_{3}=\frac{4 \mu_{11}+4 \mu_{21}}{8}+\frac{4 \mu_{12}+4 \mu_{22}}{8}+$

$+\frac{4 \mu_{19}+4 \mu_{29}}{8} \Rightarrow \mu_{11}+\mu_{12}+\mu_{13}=\mu_{21}+\mu_{22}+\mu_{23}=H_{0}^{(1)}$

3.1.3. Tipo III

$$
\begin{aligned}
& H_{0}^{(3)}=\frac{\mu_{11}+\mu_{12}+\mu_{13}}{3}=\frac{\mu_{21}+\mu_{22}+\mu_{29}}{3} \Rightarrow \\
& \Rightarrow \quad \mu_{11}+\mu_{12}+\mu_{13}=\mu_{21}+\mu_{22}+H_{23}=H_{0}^{3\rangle}=H_{0}^{(2)}=H_{0}^{(1)}
\end{aligned}
$$

Na construção da matriz $B^{*}$, há apenas 1 grau de 1 iberdade, pois existem apenas duas espécies estudadas, ou B' tem apenas 1 linha 1 inearmente independente CL.I..

Cada coluna de $B^{\prime}$ está associada com os coeficientes dos parâmetros do modelo. Desta forma, a Matriz Hipótese, é:

$$
\begin{gathered}
B_{L}^{\prime}=\left[\begin{array}{ccccccc}
\mu_{11} & \mu_{12} \mu_{13} & \mu_{21} & \mu_{22} & \mu_{23} \\
\uparrow & 1 & 1 & 1 & -1 & -1 & -1
\end{array}\right] \text { assim, } \\
B_{L}^{\prime} \hat{\mu}=\frac{1}{4}[21,4] ; \quad\left[B_{L}^{\prime} W^{*} W W^{-1} B_{L}\right]^{-1}=\frac{2}{3} \\
\therefore \text { SQLinha }=\frac{1}{4}\left[\begin{array}{r}
21 \\
4
\end{array}\right]\left[\frac{2}{3}\right] \frac{1}{4}[21,4]=\frac{11449}{600}=19,0817
\end{gathered}
$$


3. 2. Hipóteses sobre Colunas ou Rectpientes

De modo análogo às hipóteses sobre Linhas, todas as hipóteses nesse caso serão da forma:

$H_{0}^{(C)}: \frac{\mu_{11}+\mu_{21}}{2}=\frac{\mu_{12}+\mu_{22}}{2}=\frac{\mu_{13}+\mu_{23}}{2}$

Neste caso, B' tem duas linhas L.I., pois há três recipientes. Então, há dois g. 1. .

Matriz Hipótese: $B_{C}^{\prime}=\left[\begin{array}{rrrrrr}1 & -1 & 0 & 1 & -1 & 0 \\ 1 & 0 & -1 & 1 & 0 & -1\end{array}\right]$, ou $\mathrm{B}_{\mathrm{C}}^{\prime}=\left[\begin{array}{rrrrrr}1 & -1 & 0 & 1 & -1 & 0 \\ 0 & 1 & -1 & 0 & 1 & -1\end{array}\right]$, ou $\mathrm{B}_{\mathrm{c}}^{\prime}=\left[\begin{array}{llllll}1 & 0 & -1 & 1 & 0 & -1 \\ 0 & 1 & -1 & 0 & 1 & -1\end{array}\right]$

e há outras que levam a hipóteses equi valentes.

Logicamente, as três matrizes testam a mesma hipótese, ou seja, a hipótese de diferenca significativa entre os três recipientes. Em outras palavras, as hipóteses são equivalentes, fornecendo, portanto, a mesma soma de quadrados.

Conforme (9) a soma de quadrados fica,

$$
\mathrm{B}_{\mathrm{c}}^{\prime} \hat{\mu}=\frac{1}{4}\left[\begin{array}{c}
22,1 \\
38,4
\end{array}\right] ; \quad\left[\mathrm{B}_{\mathrm{c}}^{*}\left(w^{\prime} w^{-1} \mathrm{~B}_{\mathrm{c}}\right]^{-1}=\frac{4}{12}\left[\begin{array}{rr}
4 & -2 \\
-2 & 4
\end{array}\right]\right.
$$




$$
\begin{gathered}
\text { SQcoluna }=\frac{1}{4}[22,138,4] \frac{4}{12}\left[\begin{array}{rr}
4 & -2 \\
-2 & 4
\end{array}\right] \frac{1}{4}\left[\begin{array}{l}
22,1 \\
38,4
\end{array}\right] \\
\therefore \text { SQcoluna }=\frac{111433}{1200}=92,8608
\end{gathered}
$$

3. 3. Hipótese sobre a interacão

$$
\begin{aligned}
& H_{0}^{(I)}:\left\{\begin{array}{l}
\mu_{11}+\mu_{22}=\mu_{12}+\mu_{21} \\
\mu_{11}+\mu_{23}=\mu_{13}+\mu_{21}
\end{array},\right. \text { ou } \\
& H_{0}^{(I)}:\left\{\begin{array}{l}
\mu_{11}+\mu_{22}=\mu_{12}+\mu_{21} \\
\mu_{12}+\mu_{23}=\mu_{19}+\mu_{22}
\end{array},\right. \text { ou } \\
& H_{0}^{(I)}:\left\{\begin{array}{l}
\mu_{11}+\mu_{23}=\mu_{13}+\mu_{21} \\
\mu_{12}+\mu_{23}=\mu_{13}+\mu_{22}
\end{array}\right.
\end{aligned}
$$

De modo análogo ao item anterior, apresentam-se para $B^{\prime}$, dentre outras, três formas, ou seja, três hipóteses equivalentes que testam a significância do efeito da interacão.

Veja que $\mathrm{Ho}^{(x)}$ tem duas linhas, indicando dois g. 1. para interação, o que concorda com o quadro da análise de variancia mostrado anteriormente. Isto é, $(a-1)(b-1)-t=$ $1 \times 2-0=2$ (ver ELSTON \& BUSH, 1964 e IEMMA, 1991$).$

$$
\begin{gathered}
\text { A matriz } B_{I}^{\prime} \text { pode ser da forma: } \\
B_{I}^{\prime}=\left[\begin{array}{rrrrrr}
1 & -1 & 0 & -1 & 1 & 0 \\
1 & 0 & -1 & -1 & 0 & 1
\end{array}\right] ; \text { assim, } \\
B_{I}^{\prime} \hat{\mu}=\frac{1}{4}\left[\begin{array}{r}
-23,9 \\
6,4
\end{array}\right] ; \quad\left[B_{I}^{\prime}\left(W^{\prime} W^{-1} B_{I}\right]^{-1}=\frac{4}{12}\left[\begin{array}{rr}
4 & -2 \\
-2 & 4
\end{array}\right]\right.
\end{gathered}
$$




$$
\begin{gathered}
\therefore \mathrm{SQH}^{(\mathbf{I})}=\frac{1}{4}[-23,96,4] \frac{4}{12}\left[\begin{array}{rr}
4 & -2 \\
-2 & 4
\end{array}\right] \frac{1}{4}\left[\begin{array}{r}
-23,9 \\
6,4
\end{array}\right] \Rightarrow \\
\Rightarrow \mathrm{SQH}^{(1)}=\frac{76513}{1200}=63,7608
\end{gathered}
$$

Pode-se agora montar o quadro da análise de variancia para o Caso A1.

Quadro 1.A1 - Análise de Variância de acordo com o Caso A1

\begin{tabular}{lccc} 
F.V. & G.L. & S.Q. & F \\
\hline LINHAS & $(a-1)=1$ & $19,081 \overline{6}$ & $14,88^{* *}$ \\
COLUNAS & $(b-1)=2$ & 92,8608 & $36,20^{* *}$ \\
INTERAC̆̃O & $(a-1)(b-1)-t=2$ & 63,7608 & $24,85^{* *}$ \\
RESÍDUO & $\Delta \mathbf{1}=18$ & 23,0900 & \\
\hline & $(n-1)=23$ & $198,79 \overline{3}$
\end{tabular}

Verifica-se que o teste $F$ para a Interacão LxC fol significativo, Indicando existir uma dependência entre os fatores: Linhas (Espécies) e Colunas (Recipientes). Assim, qualquer conclusão que se deseje colher do Quadro 1. Al, em relação aos efeitos principais, será mascarada pelo efeito da interacão. Portanto, é necessário que se faca um desdobramento da interacão, o que pode ser feito de duas maneiras. A primeira, estudando o comportamento das espécies dentro de cada recipiente, a a segunda, os recipientes dentro de cada espécie.

A fim de enfocar a necessidade de se escolher corretamente as "matrizes hipóteses", estuda-se, como ilustração, a segunda manetra. E os cálculos para uma correta análise são vistos agora: 
A hipótese $H^{\prime}{ }^{1}$ ? recipientes dentro da espécie citriodora (E. .

$$
\begin{gathered}
H_{0}^{(1)}:\left\{\begin{array}{l}
\mu_{11}=\mu_{12} \\
\mu_{11}=\mu_{13}
\end{array} \Rightarrow B_{1}^{\prime}=\left[\begin{array}{cccccc}
1 & -1 & 0 & 0 & 0 & 0 \\
1 & 0 & -1 & 0 & 0 & 0
\end{array}\right] ;\right. \text { assim, } \\
B_{1}^{\prime} \hat{H}=\frac{1}{4}\left[\begin{array}{l}
-0,9 \\
22,4
\end{array}\right] ; \quad\left[B_{1}^{\prime}\left(W^{\prime} W^{-1} B_{1}\right]^{-1}=\frac{4}{3}\left[\begin{array}{cc}
2 & -1 \\
-1 & 2
\end{array}\right]\right. \\
\therefore S_{Q H o}^{(1)}=\frac{1}{4}[-0,9 \quad 22,4] \frac{4}{3}\left[\begin{array}{cc}
2 & -1 \\
-1 & 2
\end{array}\right] \frac{1}{4}\left[\begin{array}{c}
-0,9 \\
22,4
\end{array}\right] \Rightarrow \\
\Rightarrow S Q H o=\frac{52273}{600}=87,121 \overline{6}
\end{gathered}
$$

A hipótese $\mathrm{H}_{\circ}^{(2)}$ : reclpientes dentro da espécie grandis (E2).

$$
\begin{aligned}
& H_{0}^{(2)}:\left\{\begin{array}{l}
\mu_{21}=\mu_{22} \\
\mu_{21}=\mu_{23}
\end{array} \Rightarrow B^{*}=\left[\begin{array}{llllll}
0 & 0 & 0 & 1 & -1 & 0 \\
0 & 0 & 0 & 1 & 0 & -1
\end{array}\right] ;\right. \text { assim, } \\
& B^{\prime} \hat{\mu}=\frac{1}{4}\left[\begin{array}{c}
23 \\
16
\end{array}\right] ;\left[B^{\prime}\left(W^{\prime} W\right)^{-1} B\right]^{-1}=\frac{4}{3}\left[\begin{array}{cc}
2 & -1 \\
-1 & 2
\end{array}\right] \\
& \therefore \mathrm{SOH}^{(2)}=\frac{1}{4}[23 \quad 16] \frac{4}{3}\left[\begin{array}{cc}
2 & -1 \\
-1 & 2
\end{array}\right] \frac{1}{4}\left[\begin{array}{l}
23 \\
16
\end{array}\right] \Rightarrow \\
& \Rightarrow \mathrm{SQHo}^{(2)}=\frac{41700}{600}=69,50
\end{aligned}
$$

- quadro da análise de variância é:

Quadro 2. Al - Quadro do desdobramento da interacão para estudar o comportamento dos recipientes dentro de cada espécie

\begin{tabular}{cccccc} 
& F.V. & G.L. & S.Q. & $F$ \\
\hline L & d. & $C_{1}$ & 2 & $87,121 \overline{6}$ & $33,96^{* *}$ \\
L & d. $C_{2}$ & 2 & 69,5000 & $27,09^{* *}$ \\
\hline
\end{tabular}


Portanto, conclui-se que os três recipientes têm efeitas diferentes sobre o desenvolvimento de mudas das duas espécies. Um teste de comparacão múltipla poderia ser aplicado para a conclusão final.

Os resultados, através do PROC GLM podem ser obtidos como a seguir:

DATA;

INPUT L C y @@;

CARDS;

11 26. 2

11 26. 0

11 25. 0

11 25. 4

1 ᄅ 25.7

1226.3

12 25. 1

12 26. 4

13 2. 8

1319.4

1318.8

1319.2

2 124.8

2124.6

2 1 26.7

2 1 25.2

2 219.6

2221.1

2 219.0

ᄅ 218.6

2 319.8

2321.4

23 22. 8

I 321.3

PROC GLM;

CLASS L C;

MODEL $y=L C$ L*C SOLUTION S1 SE S3 S4;

RUN; 
Apresentam-se, agora, as saídas do PROC GLM do SAS para os quatro tipos de Somas de Quadrados.

Quadro 3. Al - Quadro da análise de variancia preliminar

\begin{tabular}{lrrrr} 
Source & DF & $\begin{array}{c}\text { Sum of } \\
\text { Squares }\end{array}$ & $\begin{array}{r}\text { Mean } \\
\text { Square }\end{array}$ & F Value \\
\hline Model & 5 & 175.7033333 & 35.1406667 & 27.39 \\
Error & 18 & 23.0900000 & 1.2827778 & \\
\hline Total & 23 & 198.7933333 & &
\end{tabular}

Quadro 4. Al - Quadro da análise de variância para a hipótese do tipo I

\begin{tabular}{lcccc} 
Source & DF & Type I SS & Mean Square & F Value \\
\hline L & 1 & 19.08166667 & 19.08166667 & 14.88 \\
C & 2 & 92.86083333 & 46.43041667 & 36.20 \\
L*C & 2 & 63.76083333 & 31.88041667 & 24.85 \\
\hline
\end{tabular}

Quadro 5. Al - Quadro da análise de variância para a hipótese do tipo II

\begin{tabular}{lccccc} 
Source & DF & Type II SS & Mean Square & F Value \\
\hline L & 1 & 19.08166667 & 19.08166667 & 14.88 \\
C & 2 & 92.86083333 & 46.43041667 & 36.20 \\
L*C & 2 & 63.76083333 & 31.88041667 & 24.85 \\
\hline
\end{tabular}

Quadro B. A1 - Quadro da análise de variancia para a hipótese do tipo III

\begin{tabular}{lcccc} 
Source & DF & Type III SS & Mean Square & F Value \\
\hline L & 1 & 19.08166667 & 19.08166667 & 14.88 \\
C & 2 & 92.86083333 & 46.43041667 & 36.20 \\
L*C & 2 & 63.76083333 & 31.88041667 & 24.85 \\
\hline
\end{tabular}


Quadro 7.A1 - Quadro da análise de variancia para a hipótese do tipo IV

\begin{tabular}{lcccc} 
Source & DF & Type IV SS & Mean Square & F Val ue \\
\hline L & 1 & 19.08166667 & 19.08166667 & 14.88 \\
C & 2 & 92.86083333 & 46.43041667 & 36.20 \\
L*C & 2 & 63.76083333 & 31.88041667 & 24.85 \\
\hline
\end{tabular}

Como ilustracão, a saída para o STATGRAPHICS, para as hipóteses dos tipos I e III é vista no Quadro 4. A1'. Note que há a informacão do número de caselas vazias existentes.

Quadro 4. A1"- Quadro da Análise de variância para a hipótese do tipo I

\begin{tabular}{lcc} 
Source of variation & Sum of Squares & d.f \\
\hline MAIN EFFECTS & & \\
L: Espécies & 19.08167 & 1 \\
C: Recipientes & 92.86083 & 2 \\
INTERACTIONS & 63.76083 & 2 \\
LC & 23.09000 & 18 \\
RESI DUAL & 198.79333 & 19 \\
\hline TOTAL CCORRECTEDS &
\end{tabular}

O missing values have been excluded.

All F-ratios are based on the residual mean square error.

Através de uma simples observacão, conclut-se

que todas as somas de quadrados são tdênticas. Isto ocorre, justamente, por se tratar de um conjunto de dados bal anceados. Assim, a análise dos dados é de fácll obtencão - Interpretacão, como relataram vários pesquisadores, dentre eles, YATES, já em 1934.

É fundamental que se note, desde já, que se as somas de quadrados obtidas forem iguais, as "matrizes 
hipóteses" $B^{\prime}$ são, também, 1dênticas. Portanto, as hipóteses testadas pelas somas de quadrados do tipo I. II, III e IV săo equi valentes. Assim.

Para 1 inhas

$H_{0}^{(L)}=H_{0}^{(1)}=H_{0}^{(2)}=H_{0}^{(3)}=H_{0}^{(4)}: \mu_{12}+\mu_{12}+\mu_{13}=\mu_{21}+\mu_{22}+\mu_{29}$

Para col unas

$H_{0}^{(L)}=H_{0}^{(1)}=H_{0}^{(2)}=H_{0}^{(3)}=H_{0}^{(4)}: \mu_{11}+\mu_{21}=\mu_{12}+\mu_{22}=\mu_{19}+\mu_{29}$

4.1.2. Caso A2 - Dados desbalanceados sem casela vazla

Quadro 9 - Esquema do modelo de médias para o Caso A2, conforme descrito no Quadro 2.

COLUNAS

\begin{tabular}{|c|c|c|}
\hline 1 & 2 & 3 \\
\hline$\mu_{11}^{(4)}$ & $\mu_{12}^{(4)}$ & $\mu_{19}^{(2)}$ \\
\hline
\end{tabular}

LINHAS

$2 \mu_{21}^{(1)} \quad \mu_{22}^{(9)} \quad \mu_{29}^{(2)}$

As matrizes são da forma:

$$
{ }_{10} y_{1}=\left[\begin{array}{c}
26,2 \\
26,0 \\
25,0 \\
25,4 \\
25,7 \\
26,3 \\
25,1 \\
28,4 \\
18,8 \\
19,2 \\
24,6 \\
19,6 \\
19,0 \\
18,6 \\
21,4 \\
22,8
\end{array}\right] ; \quad \sigma_{1}=\left[\begin{array}{l}
\mu_{11} \\
\mu_{12} \\
\mu_{19} \\
\mu_{21} \\
\mu_{22} \\
\mu_{23}
\end{array}\right]
$$


Pelas expressões dadas em (6), tem-se:

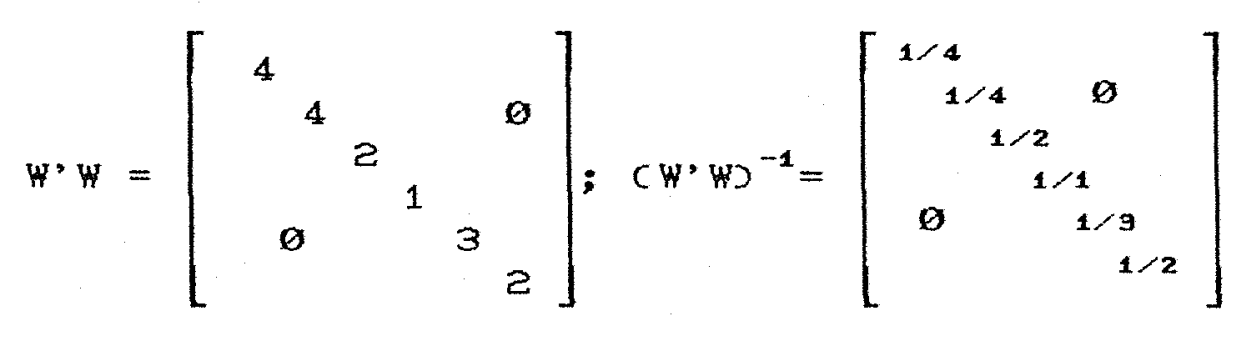

Assim como o Caso $\mathrm{Al}$, o estimador de mínimos quadrados para $\mu$ é:

$$
\hat{\mu}=\left[\begin{array}{c}
102,6 / 4 \\
103,5 / 4 \\
38,0 / 2 \\
24,6 / 1 \\
57,2 / 3 \\
44,2 / 2
\end{array}\right]
$$

Agora as somas de quadrados dadas por (9)

São:

PARA LINHAS

a) Tipo I

$$
\begin{gathered}
H_{0}^{(1)}: \frac{4 \mu_{11}+4 \mu_{12}+2 \mu_{13}}{10}=\frac{\mu_{21}+3 \mu_{22}+2 \mu_{23}}{6} \text {, então, } \\
B_{1}^{\prime}=\left[\frac{4}{10} \frac{4}{10} \frac{2}{10}-\frac{1}{6}-\frac{3}{6}-\frac{2}{6}\right] \\
\therefore \quad S_{0 H}^{(1)}=43,6054=\mathrm{R}(\alpha \mid \mu)
\end{gathered}
$$

Note que essa hipótese é de dificil interpretacão. Os coeficientes de cada um dos parâmetros do modelo-M podem ser confusos para o usuário. Para ressaltar tal fato a hipótese através do modelo-s, modelo mais conhecido pelos pesquisadores, é também vista a seguir: 
$H_{0}^{(1)}:\left\{\begin{array}{l}\alpha_{1}-\alpha_{2}+\frac{7}{3 O_{1}}-\frac{1}{5} \beta_{2}-\frac{2}{15} \beta_{9}+\frac{2}{5} \gamma_{11}+\frac{2}{5} \gamma_{12}+\frac{1}{5} \gamma_{13}-\frac{1}{\sigma^{\gamma}} \gamma_{21}- \\ -\frac{1}{2} \gamma_{22}-\frac{1}{3} \gamma_{23}=0\end{array}\right.$

Assim, fica claro para qualquer pesquisador que a hipótese testada não é aquela que alguns pesquisadores estão acostumados a testar, ou seja, Ho: $\alpha_{1}-\alpha_{2}=0$. Mesmo assim, para se testar uma hipótese próxima a esta é preciso que se imponham restricões paramétricas ao modelo linear.

\section{Observando-se a expressão da hipótese} $H^{(1)}$, verifica-se que as sugestões do trabal ho de Snedecor \& Cox (1935) eram, no mínimo, estranhas, pois ao contrário do que é dito no referido artigo, os dois efeitos principais estão envolvidos na hipótese formulada.

b) Tipo II

Pode-se utilizar $\mathrm{Ho}^{(2)}$ mostrada em (B) do item 3.2.4.1. para contrução da hipótese do tipo II. Assim,

$\sum_{j}^{3} n_{i j} \mu_{i j}=n_{i 1} \mu_{i 1}+n_{i z} \mu_{i z}+n_{i 3} \mu_{i 3}$

para $i=1 \Rightarrow 4 \mu_{11}+4 \mu_{12}+2 \mu_{13}$

para $1=2 \Rightarrow \mu_{21}+3 \mu_{22}+2 \mu_{29}$

$\sum_{i \cdot j}^{2} \sum^{3} \frac{n_{i j} n_{i} \cdot j H_{i} \cdot j}{n_{* j}} \Rightarrow$

$\Rightarrow \sum_{i}^{2} \frac{n_{i 1} n_{i-1} \mu_{i+1}}{n \cdot 1}+\frac{n_{i 2} n_{i}-2 \mu_{i-2}}{n_{2}}+\frac{n_{i 3} n_{i \cdot 3} \mu_{i}-3}{n \cdot 3}=$ $=\frac{n_{i 1}\left(n_{11} \mu_{11}+n_{21} \mu_{21}\right)}{n \cdot 1}+\frac{\left.n_{i 2} C_{12} \mu_{12}+n_{22} \mu_{22}\right)}{n_{0}}+\frac{n_{i 9} C_{19} \mu_{19}+n_{23} \mu_{29}}{n_{0}}$ 
para $i=1 \Rightarrow \frac{4\left(4 \mu_{11}+\mu_{21}\right)}{5}+\frac{4\left(4 \mu_{12}+3 \mu_{22}\right)}{7}+\frac{2\left(2 \mu_{19}+2 \mu_{23}\right)^{2}}{4}$ $\operatorname{para} 1=2 \Rightarrow \frac{1\left(4 \mu_{11}+\mu_{21}\right)}{5}+\frac{3 C 4 \mu_{12}+3 \mu_{22}}{7}+\frac{2\left(2 \mu_{19}+2 \mu_{23}\right.}{4}$

Assim, Igualando-se as expressões, por exemplo, para $i=1$, encontra-se:

$H_{0}^{(2)}: \frac{4}{5} \mu_{11}+\frac{12}{7} \mu_{12}+\mu_{13}-\frac{4}{5} \mu_{21}-\frac{12}{7} \mu_{22}-\mu_{23}=0$

A matriz $B_{2}^{\prime}$ pode ser escrita como:

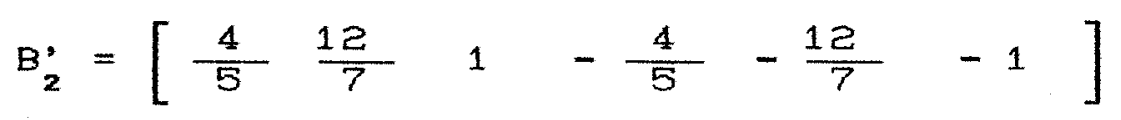

Desta forma, pode-se obter $\mathrm{SOH}^{\{2\}}$ :

$$
\left.S Q H_{0}^{(2)}=25,2043=R C \alpha \mid \mu, \beta\right)
$$

Existem outras hipóteses do tipo II, mas todas equivalentes à $H_{0}^{(2)}$. Uma delas pode ser construída fazendo, por exemplo, $1=2$.

A construcão de $B_{2}^{\prime}$ a partir da hipótese $H_{0}^{\{2\}}$ não é tão simples. Um modo mais fácil e prático pode ser encontrado no trabal ho de IEMMA (1991, p. 38), que consiste em:

1) tomar o 1 . membro da igualdade de $\mathrm{Ho}^{(1)}$ como o 1. membro de $\mathrm{Ho}^{(2)}$. 
ii) o $2^{\circ}$ membro de $H_{0}^{(2)}$ é obtido pela substituicão das médias ponderadas de colunas na posicão correspondente do 1 - membro.

$$
\begin{aligned}
& \text { Portanto, a "nova" } \mathrm{Ho}^{(2)} \text { será: } \\
& \mathrm{Ho}^{(2)}: \frac{4 \mu_{11}+4 \mu_{12}+2 \mu_{13}}{10}=\frac{4 \overline{\mathrm{C}}_{1}+4 \overline{\mathrm{C}}_{2}+2 \overline{\mathrm{C}}_{9}}{10} \Rightarrow
\end{aligned}
$$

onde $\bar{C}_{j}$ é a média ponderada da coluna $j$.

$$
4 \mu_{11}+4 \mu_{12}+2 \mu_{19}=4 \cdot \frac{4 \mu_{11}+\mu_{21}}{5}+4 \cdot \frac{4 \mu_{12}+3 \mu_{22}}{7}+2 \cdot \frac{2 \mu_{13}+2 \mu_{23}}{4}
$$

Depois de simplificadas as expressões, encontra-se a mesma hipótese $\mathrm{Ho}^{(2)}$, como era de se esperar. Novamente, assim como para a hipótese do tipo I, a hipótese é de dificil entendimento. Veja para o modelo superparametrizado como fica a hipótese:

$$
H_{0}^{(2)}: \frac{123}{35} \alpha_{1}-\frac{123}{35} \alpha_{2}+\frac{4}{5} \gamma_{11}+\frac{12}{7} \gamma_{12}+\gamma_{13}-\frac{4}{5} \gamma_{21}-\frac{12}{7} \gamma_{22}-\gamma_{29}=0
$$

Pelo simples exame da hipótese $H_{0}^{(2)}$, nota-se que a sugestão dada no trabalho de Snedecor \& Cox (1935) é concordante, porém, ELSTON \& BUSH (1964) especificam melhor
a situação.
c) IIPO III

Usando-se CCS do item 3.2.4.1. a hipótese é:

$$
H_{0}^{(3)}: \frac{\mu_{11}+\mu_{12}+\mu_{13}}{3}=\frac{\mu_{21}+\mu_{22}+\mu_{23}}{3} \text { ou }
$$




$$
\begin{aligned}
& \mathrm{Ho}^{(3)}: \mu_{11}+\mu_{12}+\mu_{13}=\mu_{21}+\mu_{22}+\mu_{23} \text {, então, } \\
& \mathrm{B}_{3}^{\prime}=\left[\begin{array}{llllllll}
3 & 1 & 1 & 1 & -1 & -1 & -1 & 1
\end{array}\right. \\
& \left.\Rightarrow \mathrm{SQH}_{0}^{(3)}=7,9912=\operatorname{RCa} \alpha^{\circ} \mid \mu^{\circ}, \beta^{\circ}, \gamma^{\circ}\right)
\end{aligned}
$$

caracterizada:

$\mathrm{Ho}^{(3)}: 3 a_{1}-3 \alpha_{2}+\gamma_{11}+\gamma_{12}+\gamma_{13}-\gamma_{21}-\gamma_{22}-\gamma_{23}=0$

d) Tipo IV

Como foi discutido em (D) do item 3.2.4.1., espera-se nesse caso que $S \mathrm{SHo}^{(3)}=\mathrm{SOH}_{0}^{(4)}$, pois não há casela vazia. Assim, $H_{\circ}^{(3)}=H_{o}^{(4)}$.

As saídas do SAS comprovam o fato, como pode ser visto nos Quadros 4. A2 e 5. A2. Para isso, a nova programação é igual a do caso A1, com a eliminação das observaçốes perdidas. Assim:

DATA;

INPUT L C Y @@;

CARDS;

11 26. 2

11 26. 0

11 25. 0

11 25. 4

12 2 25.7

12 26. 3

12 25.1

12 26. 4

1318.8

13 19.2

2124.6

2219.6

2 219.0

2. 2 18.6

2 321.4

23 22. 8

PROC GLM;

CLASS L C;

MODEL $y=L C L * C / S O L U T I O N$ S1 Se $S 3$ S4;

RUN; 
Quadro 1. Ae - Quadro da análise de variância preliminar

\begin{tabular}{lrrrrr} 
Source & DF & $\begin{array}{c}\text { Sum of } \\
\text { Squares }\end{array}$ & $\begin{array}{c}\text { Mean } \\
\text { Square }\end{array}$ & F Value \\
Model & 5 & 143.4702083 & 28.6940417 & 80.51 \\
Error & 10 & 3.5641667 & 0.3564167 & \\
\hline Total & 15 & 147.0343750 & &
\end{tabular}

Quadro 2. AZ - Quadro da análise de variância para a hipótese do tipo I

\begin{tabular}{lcrrr} 
Source & DF & Type I SS & Mean Square & F Value \\
\hline$L$ & 1 & 43.60537500 & 43.60537500 & 122.34 \\
$C$ & 2 & 35.11412195 & 17.55706098 & 49.26 \\
$L * C$ & 2 & 64.75071138 & 32.37535569 & 90.84 \\
\hline
\end{tabular}

Quadro 3.A2 - Quadro da análise de variância para a hipótese do tipo II

\begin{tabular}{lcccc} 
Source & DF & Type II SS & Mean Square & F Value \\
\hline L & 1 & 25.20426481 & 25.20426481 & 70.72 \\
C & 2 & 35.11412195 & 17.55706098 & 49.26 \\
L*C & 2 & 64.75071138 & 32.37535569 & 90.84 \\
\hline
\end{tabular}

Quadro 4. Ae - Quadro da análise de variância para a hipótese do tipo III

\begin{tabular}{lcrrr} 
Source & DF & Type III SS & Mean Square & F Value \\
\hline L & 1 & 7.99120098 & 7.99120098 & 22.42 \\
C & 2 & 37.25445122 & 18.62722561 & 52.26 \\
L*C & 2 & 64.75071138 & 32.37535569 & 90.84 \\
\hline
\end{tabular}

Quadro 5. A2 - Quadro da análise de variancia para a hipótese do tipo IV

\begin{tabular}{lrrrr} 
Source & DF & Type IV SS & Mean Square & F Value \\
\hline L & 1 & 7.99120098 & 7.99120098 & 22.42 \\
C & 2 & 37.25445122 & 18.62722561 & 52.26 \\
$L * C$ & 2 & 64.75071138 & 32.37535569 & 90.84 \\
\hline
\end{tabular}




$$
\text { Vê-se que para o caso Az, quando existe }
$$

desbalanceamento, as somas de quadrados são distintas. Há uma equivalência entre as hipóteses dos tipos III $e$ IV. Porém, as hipóteses dos tipos I, II e III não são equivalentes.

A ordem de entrada dos fatores é essencial para a análise. o caso em questão estuda a ordenacão L, C e LxC. Dessa forma, as $S Q$ dos quadros $2 . A 2$ e 3. Ae para $C$ são as mesmas, pois a hipótese associada é do tipo II. Isso sempre ocorre. Ou seja, a 2olinha dos quadros de análise de variancia para $S Q$ tipo I e $S Q$ tipo II, testam a mesma hipótese para o segundo fator na ordenacão do modelo.

Devido ao avanco que se observa na informática, fica praticamente inaceitável que pacotes estatísticos não estabelecam, claramente, meios para que seus usuários saibam qual a hipótese que realmente se está testando.

No caso do SAS, o indicativo de quals hipóteses estão sendo testadas é dado através da forma das funcơes estimáveis. Porém, estas não são de fácil entendimento, até mesmo para estatisticos, quanto mais, para os usuários esporádicos. Detalhes sobre o tema podem ser obtidos em MONDARDO (1994). 
4.1.3. Caso $A 3$ - Uma casela vazia e demals dados balanceados Quadro 10 - Esquema do modelo de médias para o caso A3, conforme Quadro 2 .

LINHAS

\begin{tabular}{|c|c|c|}
\hline \multicolumn{3}{|c|}{ COLUNAS } \\
\hline 1 & 2 & 3 \\
\hline$\checkmark$ & $\mu_{12}^{(4)}$ & $\mu_{19}^{(4)}$ \\
\hline
\end{tabular}

$2 \quad \mu_{21}^{(4)} \quad \mu_{22}^{(4)} \quad \mu_{29}^{(4)}$

onde $\gamma$ indica a ocorrêncla da casela vazia.

A construcão das matrizes $\&$ análoga aos casos anteriores, exceto, pela coluna correspondente a casela vazia $\mu_{11}$.

Deste modo, as matrizes ficam:

$$
{ }_{20}{ }_{1}=\left[\begin{array}{c}
25,7 \\
26,3 \\
25,1 \\
26,4 \\
22,8 \\
19,4 \\
18,8 \\
19,2 \\
24,8 \\
24,6 \\
28,7 \\
25,2 \\
19,6 \\
21,1 \\
19,0 \\
18,6 \\
19,8 \\
21,4 \\
22,8 \\
21,3
\end{array}\right]
$$$$
{ }_{5} \mu_{1}=\left[\begin{array}{l}
\mu_{12} \\
\mu_{19} \\
\mu_{21} \\
\mu_{22} \\
\mu_{29}
\end{array}\right]
$$

$$
\left(W^{\prime} W\right)^{-1}=\frac{1}{4} I_{(s)}
$$$$
\hat{\mu}=\frac{1}{4}\left[\begin{array}{r}
103,5 \\
80,2 \\
101,3 \\
78,3 \\
85,3
\end{array}\right]
$$

Como nos casos anteriores, obtêm-se as hipóteses para cada um dos efeitos do modelo: 
PARA LINHAS

a) Tipo I

$$
\begin{aligned}
& \mathrm{H}^{(1 *)}: \frac{4 \mu_{12}+4 \mu_{19}}{8}=\frac{4 \mu_{21}+4 \mu_{22}+4 \mu_{29}}{1 \mathrm{Z}} \\
& \begin{array}{ccccc}
\mu_{12} & \mu_{19} & \mu_{21} & \mu_{22} & \mu_{29} \\
\uparrow & \uparrow & \uparrow & \uparrow & \uparrow
\end{array} \\
& \Rightarrow B_{1 *}^{\prime}=\left[\begin{array}{lllll}
1 / 2 & 1 / 2 & -1 / 3 & -1 / 3 & -1 / 3
\end{array}\right]
\end{aligned}
$$

Para o modelo-s:

$H_{0}^{(1 *)}: 6 \alpha_{1}-6 \alpha_{2}-2 \beta_{1}+\beta_{2}+\beta_{9}+3 \gamma_{12}+3 \gamma_{19}-2 \gamma_{21}-2 \gamma_{22}-2 \gamma_{23}=0$

$$
\therefore \mathrm{SQHo}^{(1 *)}=3,78075=\mathrm{R}(\alpha \mid \mu)
$$

o asterisco (*), a partir de agora, indica que se trata de hipóteses na presenca de, pelo menos, uma casela vazia.

b) Tipo II

$$
\begin{gathered}
H_{0}^{(2 *)}: \frac{4 \mu_{12}+4 \mu_{19}}{8}=\frac{4 \bar{C}_{2}+4 \bar{C}_{9}}{8} \Rightarrow \\
\Rightarrow B_{2 *}^{\prime}=\left[\begin{array}{llllllll}
1 & 1 & 0 & -1 & -1
\end{array}\right]
\end{gathered}
$$

Pelo model o-S:

$H_{0}^{(2 *)}: 2 \alpha_{1}-2 \alpha_{2}+\gamma_{12}+\gamma_{19}-\gamma_{22}-\gamma_{29}=0$

$$
\left.\therefore \quad \mathrm{SQHo}^{(2 *)}=25,250625=\mathrm{RC} \alpha \mid \mu, \beta\right)
$$


c) Tipo III

Devido a dificuldade de se construir as hipóteses do tipo III, especialmente na presenca de caselas vazias, um método simples e prático foi desenvolvido nesse trabalho para solucionar tal transtorno. Esse método serve para qualquer situacão, inclusive quando aparecem caselas vazias. Dessa forma, a hipótese fica assim construida:

$\mathrm{Ho}^{\left\{9^{*}\right)}: \mu_{21}+\mu_{22}+\mu_{29}=C_{1}+C_{2}+C_{3}$

onde: $C_{1}=\frac{\mu_{21}}{1} ; c_{2}=\frac{\mu_{12}+\mu_{22}}{2} ; c_{9}=\frac{\mu_{19}+\mu_{29}}{2}$

ou seja, $C_{j}$ é a média aritmética simples das médias populacionais das caselas da coluna j. Portanto, substituindo-se convenientemente os valores de $C_{j}$ no segundo membro da expressão de $\mathrm{Ho}^{(9 *)}$, encontra-se:

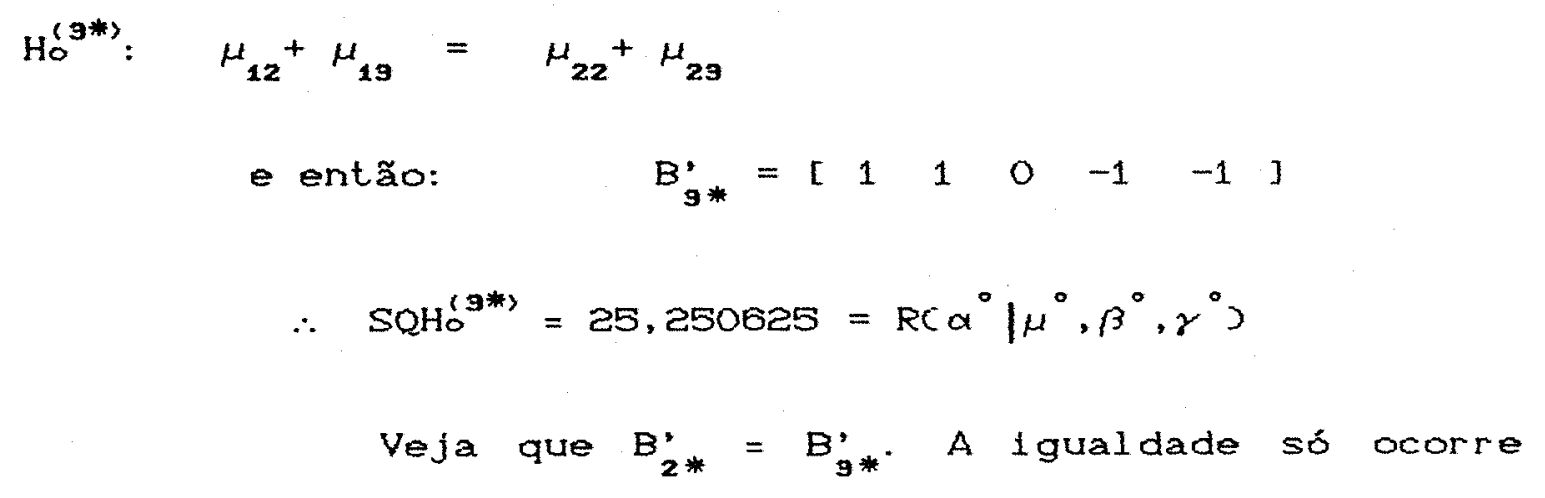
devido ao balanceamento. No caso A4 $15 s 0$ pode ser verificado.

d) Tipo IV

A hipótese do tipo IV para linhas é 
construída da seguinte forma:

$1)$ comparam-se as médias $\mu_{i j}$ dentro da mesma coluna, iniciando-se a comparacão sempre pela última linha;

2) essa comparacão deve formar um contraste entre os $\mu_{i j}$, de maneira que este tenha um maior número de médias;

3) na contrução dos contrastes, o fator limitante para um grande número de médias será a casela vazla.

Assim, no exemplo, a hipótese do tipo IV para 1 inhas fica ldêntica a do tipo III. Pols,

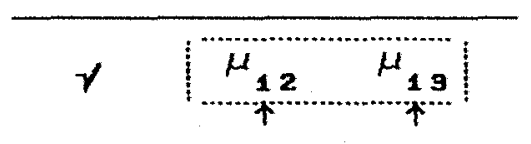

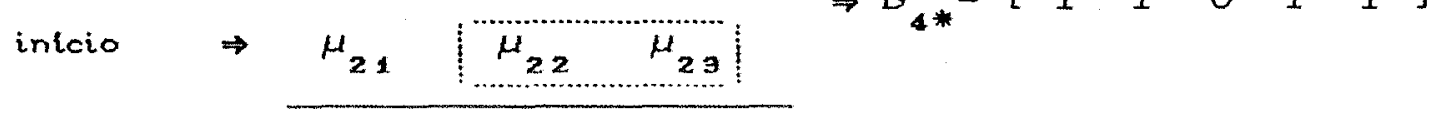

Veja, que no exemplo em questão, as hipóteses dos tipos II, III e IV não contêm $\mu_{\mathbf{2 1}}$ ou seja, a espécie grandis plantada no saco pequeno não está sendo comparada com os demais tratamentos. Essa seria a diferenca principal entre os tipos de hipóteses que o GLM (tIpo IV) e o STATGRAPHICS (tipo III) fornecem, quando há casela vazia. Mas o STATGRAPHICS não executa a análise, se o modelo contém interação e casela vazia, conjuntamente.

É bom salientar que a ausência de casela $\mu_{21}$ no contraste da hipótese do tipo III năo é regra geral. Ou melhor, a hipotese tipo III não "discrimina" necessariamente as caselas que estão na mesma coluna cou IInhas de uma casela vazia. Isto só ocorreu porque há 
apenas dois nivels para o primeiro fator.

- manual do STATGRAPHICS, por sua vez, não comenta claramente as diferencas entre a $S Q I$ e a $S Q$ III. Além disso, não resolve qualquer caso onde envolva, conjuntamente, caselas vazias e interacão.

Uma observacão interessante é que uma versão anterior, versão 2.6, utilizava, apenas as hipóteses do tipo II e seu manual não comentava este fato. Além disso. executava, para algumas situacões, a análise contento interacão com caselas vazias. E, quanto à mudanca da hipótese do tipo II para as opcóes de hipóteses dos tipos I e III da atual versão, não se encontra nenhuma justificativa no atual manual.

Para o caso das hipóteses sobre colunas, nota-se que a única diferenca está na hipótese do tipo IV, sendo, portanto, $\mathrm{SQHo}_{0}^{\left(1^{*}\right)}=\mathrm{SOHo}^{\left(2^{*}\right)}=\mathrm{SQH}_{0}^{\left(3^{*}\right)}$, pois as hipóteses são equivalentes e podem ser contruídas através de $B_{2 *}^{\prime *}$

$$
\mathrm{B}_{2 *}^{\prime}=\left[\begin{array}{rrrrr}
3 & -3 & -2 & 4 & -2 \\
-3 & 3 & -2 & -2 & 4
\end{array}\right]
$$

Efetuando-se os cálculos, obtém-se a $\mathrm{SQHo}^{(2 *)}$ para colunas, de modo similar a soma de quadrados para 1 inhas.

$$
\therefore \mathrm{SOHO}^{(1 *)}=\mathrm{SQH}_{0}^{(2 *)}=\mathrm{SOHO}^{\left(3^{*}\right)}=79,980625
$$

Já a $\mathrm{SQHo}^{\left(4^{*}\right)}$ é obtida com o auxíl10 da matriz 
$B_{4 *}^{*}$ dada por:

$$
B_{4 *}^{*}=\left[\begin{array}{rrrrr}
1 & -1 & 0 & 1 & -1 \\
0 & 0 & 1 & 0 & -1
\end{array}\right] ; \text { pots }
$$

intcio

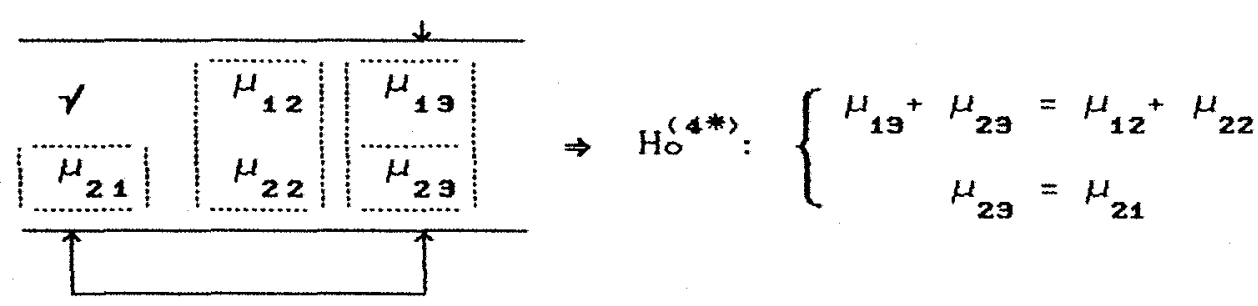

$$
\therefore \mathrm{SQHO}^{(4 *)}=36,9207
$$

Convém lembrar que a matriz hipótese ligada à interacão $B_{5 *}^{\prime}$ tem, agora, apenas uma linha, ao invés de duas, como no caso anterior. Isso se deve à casela vazia, pols, tem-se para a interação $(a-1)(b-1)-t=(2-1)(3-1)-1=$ 19.1

Pelo esquema de médias populacionals, fica evidente a única interacão que é estimável nesse exemplo. Então:

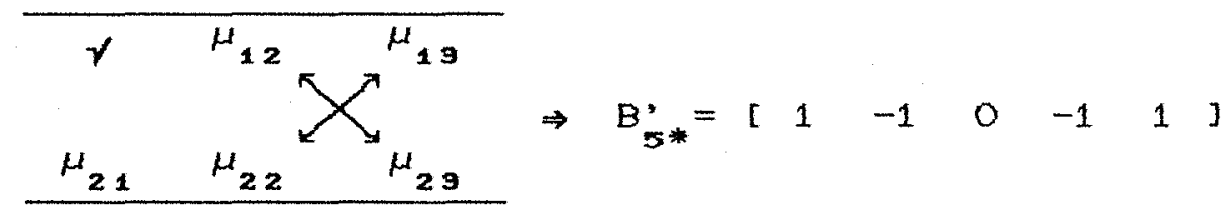

$$
\therefore \text { SQinteracão }=57,380625=R(\gamma \mid \mu, \alpha, \beta)
$$

Apresentam-se, a seguir, os resultados fornecldos pelo PROC GLM para o caso A3. 
Quadro 1.A3 - Quadro da análise de variância preliminar

\begin{tabular}{lrrrrr} 
Source & DF & $\begin{array}{l}\text { Sum of } \\
\text { Squares }\end{array}$ & $\begin{array}{c}\text { Mean } \\
\text { Square }\end{array}$ & F Value \\
\hline Model & 4 & 141.1420000 & 35.2855000 & 23.86 \\
Error & 15 & 22.1800000 & 1.4786667 & \\
\hline Total & 19 & 163.3220000 & &
\end{tabular}

Quadro 2.A3 - Quadro da análise de variancia para a hipótese do tipo I

\begin{tabular}{lcrrrr} 
Source & DF & Type I SS & Mean Square & F Value \\
\hline L & 1 & 3.78075000 & 3.78075000 & 2.56 \\
C & 2 & 79.98062500 & 39.99031250 & 27.04 \\
L*C & 1 & 57.38062500 & 57.38062500 & 38.81 \\
\hline
\end{tabular}

Quadro 3. A3 - Quadro da análise de variância para a hipótese do tipo II

\begin{tabular}{lcccc} 
Source & DF & Type II SS & Mean Square & F Value \\
\hline L & 1 & 25.25062500 & 25.25062500 & 17.08 \\
C & 2 & 79.98062500 & 39.99031250 & 27.04 \\
L*C & 1 & 57.38062500 & 57.38052500 & 38.81 \\
\hline
\end{tabular}

Quadro 4.A3 - Quadro da análise de variância para a hipótese do tipo III

\begin{tabular}{lcccc} 
Source & DF & Type III SS & Mean Square & F Value \\
\hline L & 1 & 25.25062500 & 25.25062500 & 17.08 \\
C & 2 & 79.98062500 & 39.99031250 & 27.04 \\
L*C & 1 & 57.38062500 & 57.38062500 & 38.81 \\
\hline
\end{tabular}

Quadro 5. A3 - Quadro da análise de variância para a

\begin{tabular}{lcccc} 
Source & DF & hipótese do tipo IV & \\
\hline Type IV SS & Mean Square & F Value \\
C & $1 *$ & 25.25062500 & 25.25062500 & 17.08 \\
L*C & $2 *$ & 36.92071429 & 18.46035714 & 12.48 \\
\hline
\end{tabular}


Note que a salda do PROC GLM para os quadros de análise de vartância não indicam se há casela vazia. É preciso que o usuário esteja atento aos g.l. da interacão. Mesmo assim, é impossível afirmar qual a casela vazia. Já o STATGRAPHICS comenta, abaixo do quadro de análise de variância, o número de caselas vazias e também não indica quals são. Para tanto, é necessário que as observacóes ausentes sejam informadas pelo codigo de "missing" que é Igual a -32768. Porém, a saída do STATGRAPHICS, para esse exemplo, não ocorre devido a presenca da casela vazia. A tela do computador informa a seguinte mensagem de erro:

Multifactor Analysis of Variance

Data: MUDAS

Factors: A: EUCAL

B: RECIP

C:

D:

E:

$F$ :

G:

H:

I :

J:

Covar 1 ates:

(optional)

Means plot: LSD Confldence level: 95 Range test: LSD Ignore interactions higher than order: 2 Sum of squares: Type I ERROR: $A B$ is confounded with other effects. 1 Help eEdit 3Savscr 4Prtscr 50pts 6Go 7Vars 8Cmd 9Device $10 Q u i t$ INPUT STATGRAPHICS Vers.7.0 DISPI ay ANOVA 
4.1.4. Caso A4 - Dados desbal anceados com uma casela vazia Quadro 11 - Esquema do modelo de médias para o caso A4, conforme o Quadro 2 .

COLUNAS

\begin{tabular}{|c|c|c|}
\hline 1 & 2 & 3 \\
\hline$\gamma^{\prime}$ & $\mu_{12}^{(4)}$ & $\mu_{19}^{(2)}$ \\
\hline
\end{tabular}

LINHAS

$\mu_{22}^{(9)} \quad \mu_{23}^{(2)}$

onde $\gamma$ indica a casela vazia.

Pode-se, a seguir, construir as matrizes analogamente ao caso $\mathbf{A B}$ :

$$
{ }_{12} y_{1}=\left[\begin{array}{c}
25,7 \\
26,3 \\
25,1 \\
26,4 \\
18,8 \\
19,2 \\
\cdots 24,8 \\
19,6 \\
19,0 \\
18,6 \\
21,4 \\
22,8
\end{array}\right]
$$

A matriz $W$ e vetor $\mu$ deste caso såo Idênticos ao do caso A3. A única diferenca se encontra no desbal anceamento. Portanto, a soluczo de minimos quadrados do vetor de médias é:

$$
\hat{s_{1}}=\left[\begin{array}{c}
103,5 / 4 \\
38 / 2 \\
24,6 / 1 \\
57,2 / 3 \\
44,2 / 2
\end{array}\right]
$$

Em seguida, apresentam-se as hipoteses: 
PARA LINHAS

a) Tipo I

$H_{0}^{(1 *)}: \frac{4 \mu_{12}+2 \mu_{13}}{6}=\frac{\mu_{21}+3 \mu_{22}+2 \mu_{29}}{6} \Rightarrow$

$$
\begin{gathered}
\mu_{21} \\
\Rightarrow B_{1^{*}}^{\prime}=\left[\begin{array}{lllll}
4 & 2 & -1 & -3 & -2
\end{array}\right] \\
\therefore \text { SoHo } \\
\text { Observe que essa hipótese leva em }
\end{gathered}
$$
consideracão a casela $\mu_{21}$. Nos demais tipos, isso não acontece. Como pode ser visto a seguir.

b) Tipo II

$H^{(2 *)}: \quad \frac{4 \mu_{12}+2 \mu_{13}}{6}=\frac{4 \bar{C}_{2}+2 \bar{C}_{9}}{6} \Rightarrow$

$$
\begin{gathered}
\Rightarrow \mathrm{B}_{2^{*}}^{\prime}=\left[\begin{array}{lllll}
6 / 7 & 1 / 2 & 0 & -6 / 7 & -1 / 2
\end{array}\right] \\
\therefore \quad \mathrm{SQHo}^{\left(2^{*}\right)}=27,067669=\mathrm{R}(\alpha \mid \mu, \beta)
\end{gathered}
$$

c) Tipo III

$H_{0}^{(9 *)}: \frac{\mu_{12}+\mu_{19}}{2}=\frac{\mu_{22}+\mu_{29}}{2} \Rightarrow$

$$
\begin{gathered}
\mu_{21} \\
\Rightarrow B_{3 *}^{\prime}=\left[\begin{array}{llllll} 
& 1 & 1 & 0 & -1 & -1
\end{array}\right] \\
\left.\therefore \operatorname{SQHo}^{(9 *)}=8,6853=\operatorname{RCa} \alpha^{\circ}, \mu^{\circ}, \gamma^{\circ}\right)
\end{gathered}
$$

d) Tipo IV

$$
\text { É equivalente à } \mathrm{Ho}^{\left(3^{*}\right)} \text {. }
$$


Lembrando-se do caso A3, fol dito que as somas de quadrados tipos II e III eram iguais, pois, exceto pela casela vazia, os dados eram balanceados. Porém, vê-se que, para o caso em estudo, as somas de quadrados diferem. Dai, reforca-se a importâncla que deve ser dada à escolha do tipo de hipótese, no procedimento de um teste estatistico.

As hipóteses para colunas fornecidas pelo PROC GLM são obtidas como segue.

a) Para os quadros 1.A4 e 2.A4

$$
\begin{aligned}
& H_{0}^{(2 *)}:\left\{\begin{aligned}
\frac{4 \mu_{12}+3 \mu_{22}}{7} & =\frac{4 \bar{L}_{1}+3 \bar{L}_{2}}{7} \Rightarrow \\
\mu_{21} & =\bar{L}_{2}
\end{aligned} \Rightarrow\right. \\
& \Rightarrow \quad \mathrm{B}_{2 *}^{\prime}=\left[\begin{array}{ccccc}
4 / 3 & -4 / 3 & -1 / 2 & 3 / 2 & -1 \\
0 & 0 & 5 & -3 & -2
\end{array}\right] \\
& \therefore \mathrm{SOH}_{0}^{(2 *)}=27,6088=\mathrm{RC} \beta \mid \mu, \alpha
\end{aligned}
$$

b) Para o quadro 3. A4

$$
\begin{aligned}
& H_{0}^{(9 *)}:\left\{\begin{array}{l}
\mu_{12}+\mu_{22}=\mu_{13}+\mu_{29} \\
\mu_{22}+\mu_{29}=2 \mu_{21}
\end{array}\right. \text { ou } \\
& H_{0}^{(3 *)}:\left\{\begin{array}{l}
\mu_{12}+\mu_{22}=L_{1}+L_{2} \\
\mu_{22}+\mu_{29}=L_{2}+L_{9}
\end{array}\right. \\
& \Rightarrow \quad \mathrm{B}_{\mathbf{3} *}^{*}=\left[\begin{array}{rrrrr}
1 & -1 & 0 & 1 & -1 \\
0 & 0 & -2 & 1 & 1
\end{array}\right] \\
& \left.\therefore \quad \operatorname{SOH}^{\left(3^{*}\right)}=21,4065=\operatorname{RC} \beta^{\circ} \mid \mu^{\circ}, \alpha^{\circ}, \gamma^{\circ}\right)
\end{aligned}
$$


c) Para o quadro $4 . A 4$

$$
\begin{gathered}
H_{0}^{(4 *)}:\left\{\begin{aligned}
\mu_{12}+\mu_{22}= & \mu_{13}+\mu_{23} \\
\mu_{23} & =\mu_{21}
\end{aligned}\right. \\
\Rightarrow B_{4 *}^{\prime}=\left[\begin{array}{rrrrr}
1 & -1 & 0 & 1 & -1 \\
0 & 0 & 1 & 0 & -1
\end{array}\right] \\
\therefore \operatorname{SQH}^{(4 *)}=10,5549
\end{gathered}
$$

Finalmente, a soma de quadrados para

interaçao é obtida de maneira idêntica ao caso anterior.

Então, ainda se tem 1 g.1. para a interacão. E

$B_{5 *}^{\prime}=\left[\begin{array}{llllll}1 & -1 & 0 & -1 & 1\end{array}\right]$. Assim,

$\mu_{11}+\mu_{12}+\mu_{13}=\mu_{21}+\mu_{22}+\mu_{23}$

$\Rightarrow \quad$ SQinteração $=62,0053 ;$ para qualsquer dos quadros de análise de variâneia.

Os quadros do GLM vêm a seguir.

Quadro 1. A4 - Quadro da análise de variância preliminar

$$
\text { Sum of Mean }
$$

\begin{tabular}{lrrrrr} 
Source & DF & Squares & Square & F Value \\
\hline Model & 4 & 109.6350000 & 27.4087500 & 72.29 \\
Error & 7 & 2.6541667 & 0.3791667 & \\
\hline Total & 11 & 112.2891667 & &
\end{tabular}

Quadro 2.A4 - Quadro da análise de variancia para a

$$
\text { hipótese do tipo I }
$$

\begin{tabular}{lcccc} 
Source & DF & Type I SS & Mean Square & F Value \\
\hline L & 1 & 20.02083333 & 20.02083333 & 52.80 \\
C & 2 & 27.60885965 & 13.80442982 & 36.41 \\
L*C & 1 & 62.00530702 & 62.00530702 & 163.53 \\
\hline
\end{tabular}


Quadro 3. A4 - Quadro da análise de variancia para a hipótese do tipo II

\begin{tabular}{lcccc} 
Source & DF & Type II SS & Mean Square & F Value \\
\hline L & 1 & 27.06766917 & 27.08766917 & 71.39 \\
C & 2 & 27.60885965 & 13.80442982 & 36.41 \\
L*C & 1 & 62.00530702 & 62.00530702 & 163.53 \\
\hline
\end{tabular}

Quadro 4. A4 - Quadro da análise de variância para a hipótese do tipo III

\begin{tabular}{lrrrr} 
Source & DF & Type III SS & Mean Square & F Value \\
\hline L & 1 & 8.68530702 & 8.68530702 & 22.91 \\
C & 2 & 21.40651639 & 10.70325820 & 28.23 \\
L*C & 1 & 62.00530702 & 62.00530702 & 163.53 \\
\hline
\end{tabular}

Quadro 5. A4 - Quadro da análise de variancia para a hipótese do tipo IV

\begin{tabular}{lcrrr} 
Source & DF & Type IV SS & Mean Square & F Value \\
\hline L & $1 *$ & 8.68530702 & 8.68530702 & 22.91 \\
C & $2 *$ & 10.55495098 & 5.27747549 & 13.92 \\
L*C & 1 & 62.00530702 & 62.00530702 & 163.53 \\
\hline
\end{tabular}

4.1.5. Caso A5 - Dados desbalanceados com duas caselas vazias

Quadro 12 - Esquema do modelo de médias para o caso A5, conforme o Quadro 2 .

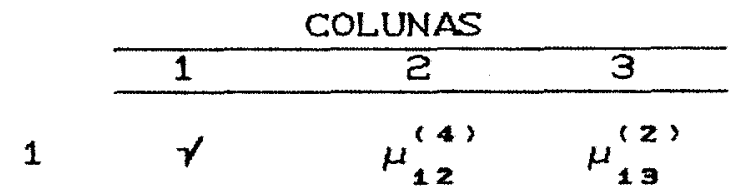

LINHAS

$2 \quad \mu_{21}^{(1)} \quad \mu_{22}^{(3)} \quad \gamma$

onde $\gamma$ indica a ocorrência da casela vazia.

Eliminando-se, coerentemente, as caselas vazias $\mu_{11} e \mu_{23}$, podem-se construir as matrizes para a obtenção das somas de quadrados. As matrizes ficam: 


$$
10^{H}=\left[\begin{array}{llll}
1 & 0 & 0 & 0 \\
1 & 0 & 0 & 0 \\
1 & 0 & 0 & 0 \\
1 & 0 & 0 & 0 \\
0 & 1 & 0 & 0 \\
0 & 1 & 0 & 0 \\
0 & 0 & 1 & 0 \\
0 & 0 & 0 & 1 \\
0 & 0 & 0 & 1 \\
0 & 0 & 0 & 1
\end{array}\right] \quad\left(W^{\prime} w^{-1}=\left[\begin{array}{rrr}
1 / 4 & & \\
1 / 2 & 0 \\
0 & 1 & 1 / 3
\end{array}\right]\right.
$$

As hipóteses são dadas a segulr.

PARA LINHAS

a) Tipo I

$$
\begin{gathered}
H_{0}^{(1 *)}: \frac{4 \mu_{12}+2 \mu_{13}}{6}=\frac{\mu_{21}+3 \mu_{22}}{4} \Rightarrow \\
\Rightarrow B_{1 *}^{\prime}=[4,3 \text { 2, } 3 \text {-1, } 2-3,2] \\
\left.\therefore S Q H^{(1 *)}=23,562 \bar{C}=\mathrm{RCa} / \mu\right)
\end{gathered}
$$

b) TIpo II

$$
\begin{aligned}
& H_{0}^{(2 *)}: \frac{4 \mu_{12}+2 \mu_{13}}{6}=\frac{4 \bar{C}_{2}+2 \bar{C}_{3}}{6} \Rightarrow \\
& \Rightarrow B_{2 *}^{*}=\left[\begin{array}{lllll}
12 / 7 & 0 & 0 & -12 / 7
\end{array}\right] \\
& \left.\therefore \quad \mathrm{SQHo}^{(2 *)}=79,462976=\mathrm{RC} \alpha \mid \mu, \beta\right) \\
& \mathrm{Ho}^{(3 *)}: \mu_{21}+\mu_{22}=\mathrm{C}_{1}+\mathrm{C}_{2} \\
& \mathrm{Ho}^{\left(9^{*}\right)}: \mu_{12}=\mu_{22} \quad \Rightarrow B_{9 *}^{\prime}=\left[\begin{array}{lllllll}
1 & 1 & 0 & -1 & -1
\end{array}\right] \\
& \therefore \mathrm{SQHo}^{(3 *)}=79,462976
\end{aligned}
$$

$$
\mathrm{Ho}^{(4 *)}=\mathrm{Ho}^{(9 *)}
$$


Vê-se que a hipótese tipo I é a única que compara, conjuntamente, todos os tratamentos (caselas) existentes, ao contrário das demais hipóteses, que não assumem em seus contrastes os tratamentos que pertencem a colunas contendo caselas vazias.

PARA COLUNAS

Todos os quadros de análise de variâcia fornecem as mesmas somas de quadrados para colunas, isso devido à posicão em que se encontram as duas caselas vazias.

A soma de quadrados corresponde à hipótese:

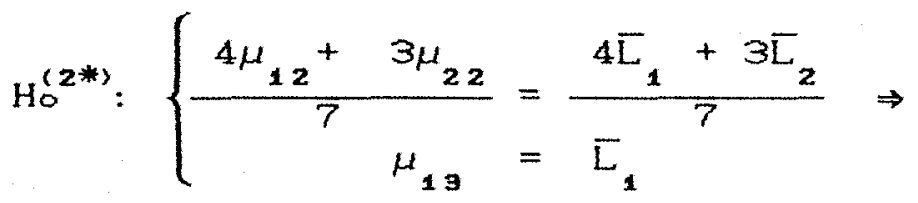

$$
\begin{aligned}
& \Rightarrow B_{2 *}^{\prime}=\left[\begin{array}{cccc}
4 / 3 & -4 / 3 & -3 / 4 & 3 / 4 \\
4 & -4 & 0 & 0
\end{array}\right] \\
& \left.\therefore \mathrm{SQHo}^{(2 *)}=85,9841 \overline{\mathrm{\sigma}}=\mathrm{RC} \beta \mid \mu, \alpha\right)
\end{aligned}
$$

Surge agora uma situacão interessante. Pois, é impossivel encontrar ao menos um constraste para a interacão que relactone as médias de caselas, o que concorda com o número de g.1. dado por $(2-1)(3-2)-2=0$. Conclui-se, portanto, que o efeito da interacão não pode ser medido. Convém ressaltar que a ausência do teste para interacão não deve ser utilizada como um critério de escolha entre um modelo com e um modelo sem interacão. Pols, não há, no caso, funcóes estimávels e, portanto, 
testáveis sobre qualquer componente da interacão.

$$
\text { Os resultados podem ser vistos a seguir. }
$$

Quadro 1.AS - Quadro da análise de variância prelíminar

\begin{tabular}{lrrrrr} 
& & & Sum of & Mean \\
Source & DF & Squares & Square & F Value \\
\hline Model & 3 & 109.5468333 & 36.5156111 & 130.87 \\
Error & 6 & 1.6741667 & 0.2790278 & \\
\hline Total & 9 & 111.2210000 & &
\end{tabular}

Quadro 2. A5 - Quadro da análise de variância para a hipótese do tipo I

\begin{tabular}{lcrcc} 
Source & DF & Type I SS & Mean Square & F Value \\
\hline L & 1 & 23.56266667 & 23.56266667 & 84.45 \\
C & 2 & 85.98416667 & 42.99208333 & 154.08 \\
L*C & 0 & 0.00000000 &. &. \\
\hline
\end{tabular}

Quadro 3.A5 - Quadro da análise de variância para a hipótese do tipo II

\begin{tabular}{lcrcr} 
Source & DF & Type II SS & Mean Square & F Value \\
\hline L & 1 & 79.46297619 & 79.46297619 & 284.79 \\
C & 2 & 85.98416667 & 42.99208333 & 154.08 \\
L*C & 0 & 0.00000000 & &. \\
\hline
\end{tabular}

Quadro 4.A5 - Quadro da análise de variância para a hipótese do tipo III

\begin{tabular}{lcccc} 
Source & DF & Type III SS & Mean Square & F Value \\
\hline L & 1 & 79.46297619 & 79.46297619 & 284.79 \\
C & 2 & 85.98416667 & 42.99208333 & 154.08 \\
L*C & 0 & 0.00000000 &. &. \\
\hline
\end{tabular}

Quadro 5.A5 - Quadro da análise de variancia para a hipótese do tipo IV

\begin{tabular}{lcccc} 
Source & DF & Type IV SS & Mear Square & F Value \\
\hline L & 1 & 79.46297619 & 79.46297619 & 284.79 \\
C & 2 & 85.98416667 & 42.99208339 & 154.08 \\
L*C & 0 & 0.00000000 & &. \\
\hline
\end{tabular}




\section{2. EXEMPLO 2}

Conforme o 1tem 3.1.2., este exemplo \& criado para se evitarem casos particulares. Pols, acredita-se que tals casos não são de relevante importancla. Artigos como de OVERALL \& SPIEGEL (1969), e BURDICK (1979), tratam da equivalência entre algumas hipóteses em casos particulares. como a proporclonalidade entre os nfvels dos fatores. Porém, é evidente que, se um pesquisador sabe o que se está testando, de maneira geral, saberá também o que se está testando nesses casos particulares. Desse modo, qualquer informacão a mais julga-se ser irrelevante.

Os sete casos criados nessa secão têm, como objetivo principal, proporctonar ao leltor condicóes para que ele possa, de forma fáll e pratica, construir as hipóteses relacionadas a cada uma daquel as fornectas pelo PROC GLM. E assim, consequentemente, poder escolher, convenientemente, a melhor para seu interesse.

4.2.1. Caso B1 - Com interaçio sem casela vazia

Pelo Quadro 2, tem-se: 
Quadro 13 - Esquema do modelo de médias para o caso B1, conforme o Quadro 2 .

COLUNAS

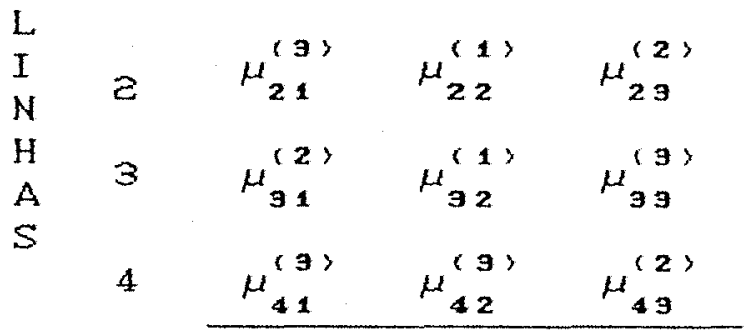

1

$\begin{array}{ccc}1 & 2 & 3 \\ \mu_{11}^{(4)} & \mu_{12}^{(3)} & \mu_{13}^{(2)}\end{array}$

De maneira análoga ao caso $\mathrm{Al}$, pode-se encontrar a solucão de mínimos quadrados para o vetor de parâmetros por (7).

$$
1^{\mu} 1=\left[\begin{array}{r}
73 \\
66 \\
106 \\
76 \\
69 \\
111 \\
65 \\
62 \\
99 \\
64 \\
57 \\
94
\end{array}\right]
$$

Agora por (9), obtém-se:

PARA LINHAS

a) Tipo I

$$
H_{0}^{(1)}:\left\{\begin{array}{l}
\frac{3 \mu_{21}+\mu_{22}+2 \mu_{29}}{9}=\frac{2 \mu_{91}+\mu_{92}+3 \mu_{99}}{6} \\
\frac{3 \mu_{21}+\mu_{22}+2 \mu_{23}}{9}=\frac{3 \mu_{41}+3 \mu_{42}+2 \mu_{43}}{8} \\
\frac{3 \mu_{21}+\mu_{22}+2 \mu_{23}}{9}=\frac{4 \mu_{11}+3 \mu_{12}+2 \mu_{13}}{9}
\end{array} \Rightarrow\right.
$$




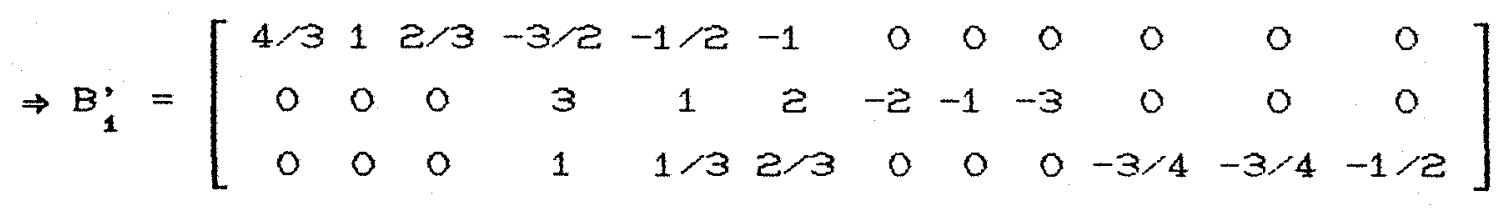

$$
\therefore \operatorname{SQH}^{(1)}=1173,090517=\mathrm{R}(a \mid \omega)
$$

Pelo modelo-s:

$H_{0}:\left\{\begin{array}{l}3 \alpha_{1}-3 \alpha_{2}-\frac{1}{6} \beta_{1}+\frac{1}{2} \beta_{2}-\frac{1}{3} \beta_{3}+\frac{4}{3} \gamma_{11}+\gamma_{12}+\frac{2}{3} \gamma_{19}-\frac{3}{2} \gamma_{21}-\frac{1}{2} \gamma_{22} \gamma_{29}=0 \\ 6 \alpha_{2}-6 \alpha_{9}+\beta_{1}-\beta_{9}+3 \gamma_{21}+\gamma_{22}+2 \gamma_{23}-2 \gamma_{91}-\gamma_{92}-3 \gamma_{33}=0 \\ 2 \alpha_{2}-2 \alpha_{4}+\frac{1}{4} \beta_{1}-\frac{2}{3} \beta_{2}+\frac{1}{6} \gamma_{9}+\gamma_{21}+\frac{1}{3} \gamma_{22}+\frac{2}{3} \gamma_{23}-\frac{3}{4} \gamma_{11}-\frac{3}{4} \gamma_{12}-\frac{1}{2} \gamma_{49}=0\end{array}\right.$

Note a dificuldade de entendimento da hipótese mostrada pelo modelo-s. Porém, é bom ficar atento que o problema principal não está, na verdade, na interpretacão da hipótese, mas sim que vários usuários desses pacotes nem imaginam o que estão testando.

b) Tipo II

$$
H_{0}^{\{2)}:\left\{\begin{array}{c}
4 \mu_{11}+3 \mu_{12}+2 \mu_{13}=4 \bar{C}_{1}+3 \bar{C}_{2}+2 \bar{C}_{9} \\
3 \mu_{21}+\mu_{22}+2 \mu_{29}=3 \bar{C}_{1}+3 \bar{C}_{2}+2 \bar{C}_{9} \\
2 \mu_{31}+\mu_{92}+3 \mu_{39}=2 \bar{C}_{1}+\bar{C}_{2}+3 \bar{C}_{3} \\
B_{1}^{\prime}=
\end{array}\right.
$$

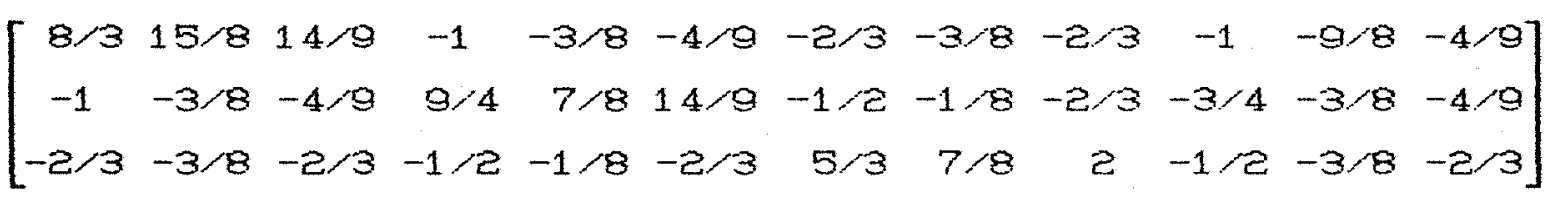$$
\therefore \quad \mathrm{SOH}_{0}^{(2)}=794,4675=\mathrm{R}(\alpha \mid \mu, \beta)
$$ 
Pelo modelo-s:

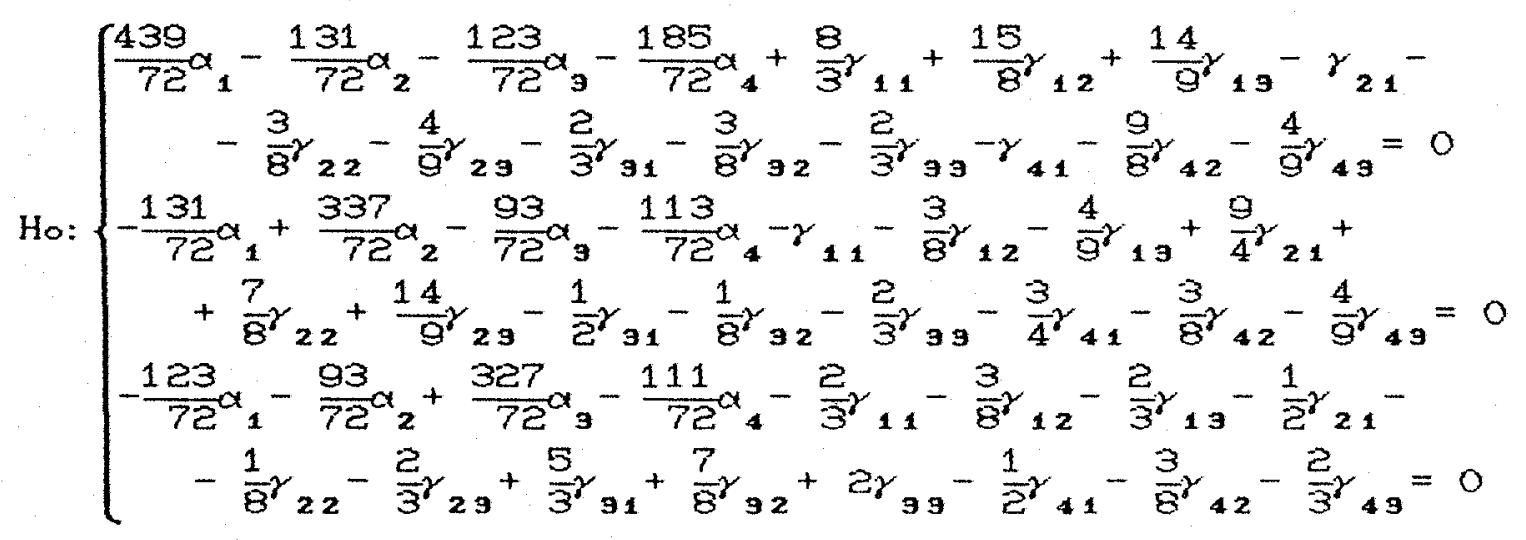

Pela observacão da hipótese Ho, fica difícll esperar que um pesquisador não iniciado em estatística possa interpretar corretamente esta hipótese.

c) Tipo III

$$
\begin{aligned}
& H_{0}^{(3)}:\left\{\begin{array}{l}
\mu_{11}+\mu_{12}+\mu_{19}=\mu_{21}+\mu_{22}+\mu_{23} \\
\mu_{11}+\mu_{12}+\mu_{13}=\mu_{31}+\mu_{32}+\mu_{93} \\
\mu_{11}+\mu_{12}+\mu_{13}=\mu_{41}+\mu_{42}+\mu_{43}
\end{array} \Rightarrow\right. \\
& \Rightarrow \mathrm{B}^{\prime}=\left[\begin{array}{rrrrrrrrrrrr}
1 & 1 & 1 & -1 & -1 & -1 & 0 & 0 & 0 & 0 & 0 & 0 \\
1 & 1 & 1 & 0 & 0 & 0 & -1 & -1 & -1 & 0 & 0 & 0 \\
1 & 1 & 1 & 0 & 0 & 0 & 0 & 0 & 0 & -1 & -1 & -1
\end{array}\right]
\end{aligned}
$$

Pelo modelo-s:

$H_{0}:\left\{\begin{array}{l}3 a_{1}-3 a_{2}+\gamma_{11}+\gamma_{12}+\gamma_{19}-\gamma_{21}-\gamma_{22}-\gamma_{29}=0 \\ 3 a_{1}-3 a_{9}+\gamma_{11}+\gamma_{12}+\gamma_{19}-\gamma_{91}-\gamma_{92}-\gamma_{99}=0 \\ 3 a_{1}-3 a_{4}+\gamma_{11}+\gamma_{12}+\gamma_{19}-\gamma_{41}-\gamma_{42}-\gamma_{43}=0\end{array}\right.$ 


$$
\left.\therefore \quad \mathrm{SOH}_{0}^{(3)}=719,241602=\mathrm{SQH}^{(4)}=\operatorname{RCQ} \alpha^{\circ} \mid \mu^{\circ}, \beta^{\circ}, \gamma^{\circ}\right)
$$

Essa igualdade ocorre, novamente, pois não há

casela vazia.

PARA COLUNAS

$$
\text { Usando o mesmo ractocínio dos casos }
$$

anteriores.

a) Para os quadros $1 . \mathrm{B} 1$ e 2. B1

$$
\begin{aligned}
& H_{0}^{(2)}:\left\{\begin{array}{l}
3 \mu_{12}+\mu_{22}+\mu_{32}+3 \mu_{42}=3 L_{1}+L_{2}+L_{9}+3 L_{4} \\
2 \mu_{13}+2 \mu_{29}+3 \mu_{33}+2 \mu_{43}=2 L_{1}+2 L_{2}+3 L_{3}+2 E_{4}
\end{array}\right. \\
& B_{2}^{\prime}=
\end{aligned}
$$

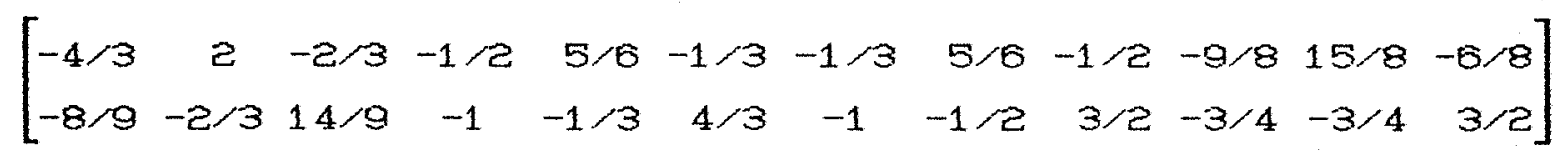

$$
\left.\therefore \quad \mathrm{SQHo}^{(2)}=7511,787014=\mathrm{RC} \beta \mid \mu, \infty\right)
$$

Pelo modelo-s:

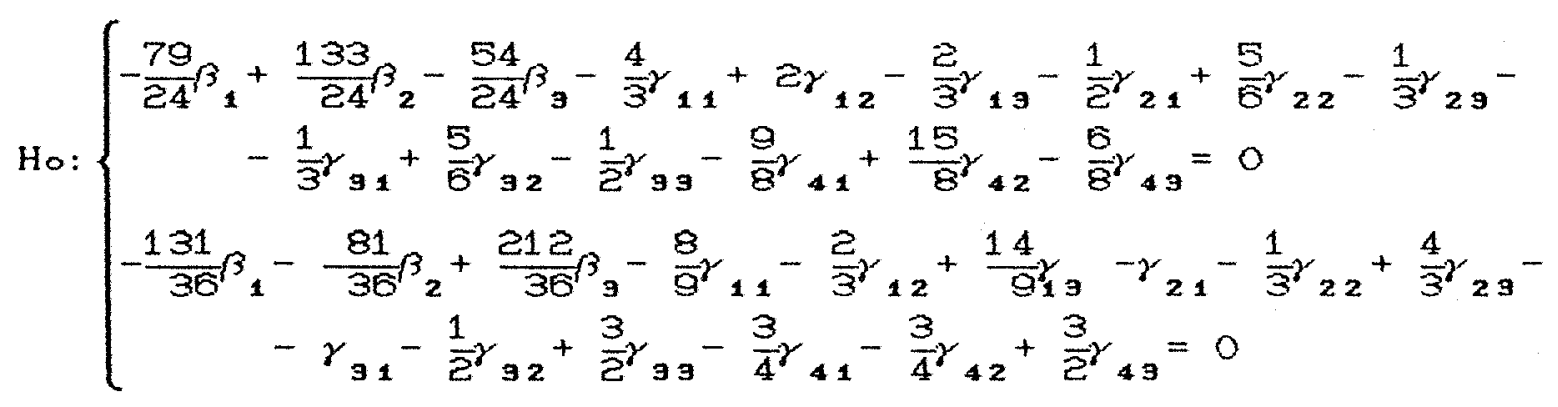

Novamente, note a dificuldade de se interpre-

tar a hipótese. 
b) Para os quadros $3 . \mathrm{B} 1=4 . \mathrm{B} 1$

$H_{0}^{(3)}:\left\{\begin{array}{l}\mu_{11}+\mu_{21}+\mu_{91}+\mu_{41}=\mu_{12}+\mu_{22}+\mu_{32}+\mu_{42} \\ \mu_{11}+\mu_{21}+\mu_{91}+\mu_{41}=\mu_{13}+\mu_{29}+\mu_{39}+\mu_{49}\end{array}\right.$

$\Rightarrow \mathrm{B}_{\mathbf{3}}^{\prime}=\left[\begin{array}{rrrrrrrrrrrr}1 & -1 & 0 & 1 & -1 & 0 & 1 & -1 & 0 & 1 & -1 & 0 \\ 1 & 0 & -1 & 1 & 0 & -1 & 1 & 0 & -1 & 1 & 0 & -1\end{array}\right]$

$$
\left.\therefore \quad \mathrm{SQH}_{0}^{(3)}=7279,546239=S \mathrm{SHo}^{(4)}=\mathrm{RC} \alpha^{\circ} \mid \mu^{\circ}, \beta^{\circ}, \gamma^{\circ}\right)
$$

ou pelo modelo-s:

$H o:\left\{\begin{array}{l}4 \beta_{1}-4 \beta_{2}+\gamma_{11}-\gamma_{12}+\gamma_{21}-\gamma_{22}+\gamma_{31}-\gamma_{32}+\gamma_{41}-\gamma_{42}=0 \\ 4 \beta_{1}-3 \beta_{3}+\gamma_{11}-\gamma_{13}+\gamma_{21}-\gamma_{29}+\gamma_{91}-\gamma_{99}+\gamma_{41}-\gamma_{43}=0\end{array}\right.$

Verifica-se que a dificuldade de interpretacão das hipóteses é visível. Os coeficientes dos parâmetros do modelo são extremamente confusos e as ponderacões existentes também criam um obstáculo para uma melhor compreensão da hipótese. Novamente, ressalta-se aqui que o grande problema constste no fato de que o pesquisador desconhece a hipótese que está sendo testada.

PARA INTERACÃO

Como a interação possui $3 \times 2=6 \mathrm{~g} .1$. , a matriz hipótese tem 6 linhas L.I., da forma:

$$
B^{\prime}=\left[\begin{array}{rrrrrrrrrrrr}
1 & -1 & 0 & -1 & 1 & 0 & 0 & 0 & 0 & 0 & 0 & 0 \\
1 & 0 & -1 & -1 & 0 & 1 & 0 & 0 & 0 & 0 & 0 & 0 \\
1 & -1 & 0 & 0 & 0 & 0 & -1 & 1 & 0 & 0 & 0 & 0 \\
1 & -1 & 0 & 0 & 0 & 0 & 0 & 0 & 0 & -1 & 1 & 0 \\
1 & 0 & -1 & 0 & 0 & 0 & 0 & 0 & 0 & -1 & 0 & 1 \\
1 & 0 & -1 & 0 & 0 & 0 & -1 & 0 & 1 & 0 & 0 & 0
\end{array}\right]
$$


As saídas do PROC GLM são como seguem:

Quadro 1. B1 - Quadro da análise de variância preliminar

\begin{tabular}{lcrrr} 
Source & DF & $\begin{array}{c}\text { Sum of } \\
\text { Squares }\end{array}$ & $\begin{array}{r}\text { Mean } \\
\text { Square }\end{array}$ & F Value \\
\hline Model & 11 & 8710.965517 & 791.905956 & 58.03 \\
Error & 17 & 232.000000 & 13.647059 & \\
\hline Total & 28 & 8942.965517 & &
\end{tabular}

Quadro 2.B1 - Quadro da análise de variancla para a hipótese do tipo I

\begin{tabular}{lrrrrr} 
Source & DF & Type I SS & Mean Square & F Value \\
\hline L & 3 & 1173.090517 & 391.030172 & 28.65 \\
C & 2 & 7511.787014 & 3755.893507 & 275.22 \\
L*C & 6 & 26.087986 & 4.347998 & 0.32 \\
\hline
\end{tabular}

Quadro 3.B1 - Quadro da análise de variancia para a hipótese do tipo II

\begin{tabular}{lrrrr} 
Source & DF & Type II SS & Mean Square & F Value \\
\hline L & 3 & 794.467570 & 264.822523 & 19.41 \\
C & 2 & 7511.787014 & 3755.893507 & 275.22 \\
L*C & 6 & 26.087986 & 4.347998 & 0.32 \\
\hline
\end{tabular}

Quadro 4.B1 - Quadro da análise de variancia para a hipótese do tipo III

\begin{tabular}{lrrrr} 
Source & DF & Type III SS & Mean Square & F Value \\
\hline L & 3 & 719.241602 & 239.747201 & 17.57 \\
C & 2 & 7279.546239 & 3639.773120 & 266.71 \\
L*C & 6 & 26.087986 & 4.347998 & 0.32 \\
\hline
\end{tabular}


Quadro 5.B1 - Quadro da análise de variancla para a hipótese do tipo IV

\begin{tabular}{lrrrr} 
Source & DF & Type IV SS & Mean Square & F Value \\
\hline L & 3 & 719.241602 & 239.747201 & 17.57 \\
C & 2 & 7279.546239 & 3639.773120 & 266.71 \\
L*C & 6 & 26.087986 & 4.347998 & 0.32 \\
\hline
\end{tabular}

4. 2. 2. Caso B2 - Sem Interação sem casela vazia

Quadro 14 - Esquema do modelo de médias para o caso BZ, conforme Quadro 3.

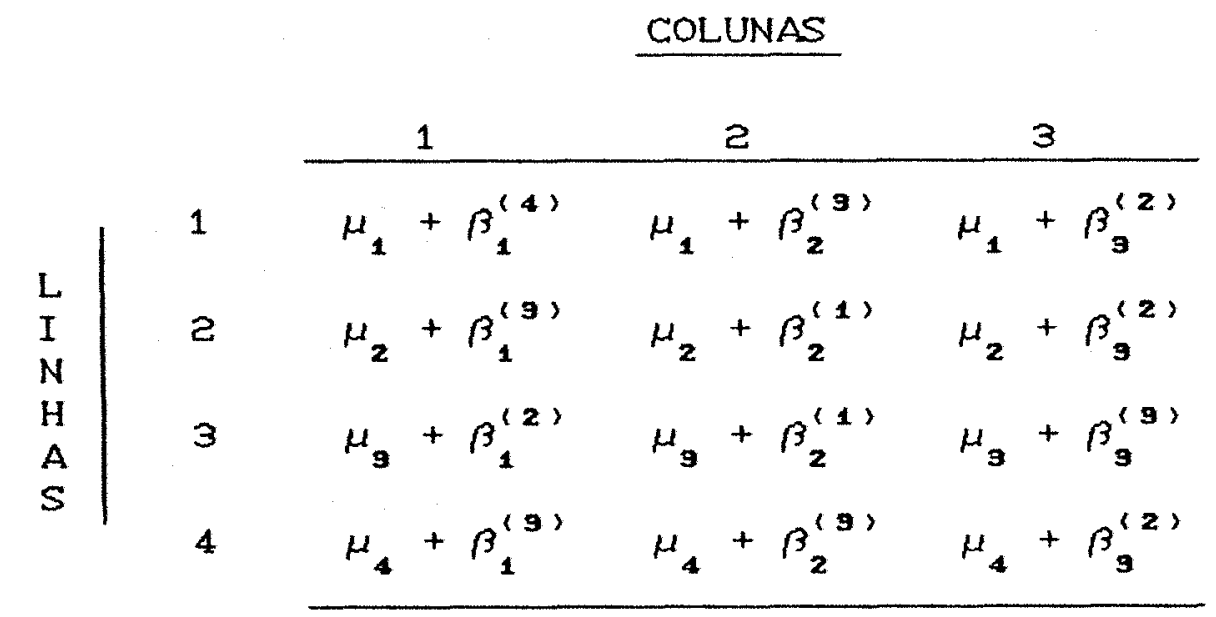

As matrizes são da forma: 


$$
{ }_{20}=\left[\begin{array}{lllllll}
1 & 0 & 0 & 0 & 1 & 0 & 0 \\
1 & 0 & 0 & 0 & 1 & 0 & 0 \\
1 & 0 & 0 & 0 & 1 & 0 & 0 \\
1 & 0 & 0 & 0 & 1 & 0 & 0 \\
1 & 0 & 0 & 0 & 0 & 1 & 0 \\
1 & 0 & 0 & 0 & 0 & 1 & 0 \\
1 & 0 & 0 & 0 & 0 & 1 & 0 \\
1 & 0 & 0 & 0 & 0 & 0 & 1 \\
1 & 0 & 0 & 0 & 0 & 0 & 1 \\
0 & 1 & 0 & 0 & 1 & 0 & 0 \\
0 & 1 & 0 & 0 & 1 & 0 & 0 \\
0 & 1 & 0 & 0 & 1 & 0 & 0 \\
0 & 1 & 0 & 0 & 0 & 1 & 0 \\
0 & 1 & 0 & 0 & 0 & 0 & 1 \\
0 & 1 & 0 & 0 & 0 & 0 & 1 \\
0 & 0 & 1 & 0 & 1 & 0 & 0 \\
0 & 0 & 1 & 0 & 1 & 0 & 0 \\
0 & 0 & 1 & 0 & 0 & 1 & 0 \\
0 & 0 & 1 & 0 & 0 & 0 & 1 \\
0 & 0 & 1 & 0 & 0 & 0 & 1 \\
0 & 0 & 1 & 0 & 0 & 0 & 1 \\
0 & 0 & 0 & 1 & 1 & 0 & 0 \\
0 & 0 & 0 & 1 & 1 & 0 & 0 \\
0 & 0 & 0 & 1 & 1 & 0 & 0 \\
0 & 0 & 0 & 1 & 0 & 1 & 0 \\
0 & 0 & 0 & 1 & 0 & 1 & 0 \\
0 & 0 & 0 & 1 & 0 & 1 & 0 \\
0 & 0 & 0 & 1 & 0 & 0 & 1 \\
0 & 0 & 0 & 1 & 0 & 0 & 1
\end{array}\right] ; \mu_{1}=\left[\begin{array}{l}
\mu_{1} \\
\mu_{2} \\
\mu_{3} \\
\mu_{4} \\
\beta_{1} \\
\beta_{2} \\
\beta_{3}
\end{array}\right]
$$

$$
\gamma_{1}=\left[\begin{array}{c}
515,1958 \\
519,0000 \\
508,5181 \\
505,4174 \\
-442,4226 \\
-448,6597 \\
-409,5312
\end{array}\right]
$$

As matrizes, construídas dessa forma, são válidas caso não exista casela vazia. Como no exemplo 1 , os elementos contendo caselas vazias devem ser eliminados.

Agora, as somas de quadrados podem ser obtidas de maneira usual por $(9)$ e as hipóteses são: 
PARA LINHAS

a) Tipo I

Genericamente, a hipótese é da forma,

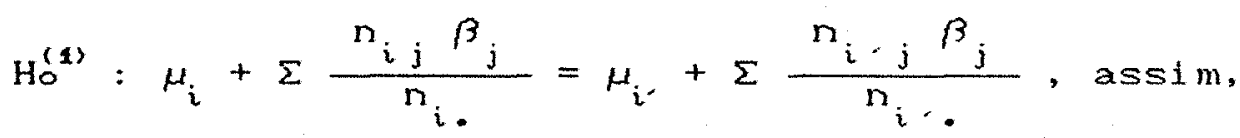

$H_{0}^{(1)}:\left\{\begin{array}{l}\mu_{1}+\frac{4 \beta_{1}+3 \beta_{2}+2 \beta_{3}}{\theta}=\mu_{2}+\frac{3 \beta_{1}+\beta_{2}+2 \beta_{3}}{\beta} \\ \mu_{9}+\frac{2 \beta_{1}+\beta_{2}+3 \beta_{3}}{6}=\mu_{2}+\frac{3 \beta_{1}+\beta_{2}+2 \beta_{3}}{6} \\ \mu_{4}+\frac{3 \beta_{1}+3 \beta_{2}+2 \beta_{3}}{8}=\mu_{2}+\frac{3 \beta_{1}+\beta_{2}+2 \beta_{3}}{6}\end{array}\right.$

$$
\begin{aligned}
& \mu_{1} \mu_{2} \mu_{9} \mu_{4} \beta_{1} \quad \beta_{2} \beta_{3} \\
& \Rightarrow B_{1}^{\prime}=\left[\begin{array}{ccccccc}
\downarrow & \downarrow & \downarrow & \downarrow & \downarrow & \downarrow & \downarrow \\
-1 & 1 & 0 & 0 & 1 / 18 & -1 / 6 & 1 / \theta \\
0 & 6 & -6 & 0 & 1 & 0 & -1 \\
0 & 1 & 0 & -1 & 1 / 8 & -5 / 24 & 1 / 12
\end{array}\right] \\
& \left.\therefore \mathrm{SQHo}^{(1)}=1173,090517=\mathrm{RC} \alpha \mid \mu\right)
\end{aligned}
$$

Note que o contraste possui os dois efeitos (variedade e solo). Assim, essa hipótese deve ser vista com cautela para testar os efeitos principais isoladamente. Isso é válido para qualquer caso onde a análise é feita pela soma de quadrados tipo. I, pois, sendo esta 
não-ajustada para colunas (variedade), os efeitos de linhas (solo) sempre estarão presentes.

b) Tipo II

A hipótese tipo II pode ser escrita por,

$H_{0}^{(2)}: \mu_{i}+\sum \frac{n_{i j} \beta_{j}}{n_{i}}=\sum \frac{n_{i j} \bar{C}_{j}}{n_{i}}$,

- pode ser mostrado, algebricamente, que essa hipótese sempre recai na seguinte hipótese:

$H_{0}^{(2)}: \quad \mu_{i}=\mu_{i,}$, portanto.

$H_{0}^{(2)}: \mu_{1}=\mu_{2}=\mu_{3}=\mu_{4} \Rightarrow H_{0}^{(2)}: \alpha_{1}=a_{2}=\alpha_{9}=a_{4}$

$$
B_{2}^{\prime}=\left[\begin{array}{rrrrrrr}
1 & -1 & 0 & 0 & 0 & 0 & 0 \\
1 & 0 & -1 & 0 & 0 & 0 & 0 \\
1 & 0 & 0 & -1 & 0 & 0 & 0
\end{array}\right]
$$$$
\left.\therefore \mathrm{SQHo}^{(2)}=794,46757=\mathrm{SQHo}^{(3)}=\mathrm{SOH}_{0}^{(4)}=\mathrm{RC} \alpha \mid \mu, \beta\right)
$$

Por melo de simples observacão, as três últimas colunas da matriz hipótese são nulas, devido ao ajuste, indicando a não "interferência" do efeito das variedades. Assim, com o modelo não contém interacão e não há casela vazia, o efeito de solos pode ser testado isoladamente. Isto também pode ser visto nos casos BB e B7. 
Se o modelo utilizado não contiver interacão, a soma de quadrados tipo II sempre será idêntica às somas de quadrados dos tipos III e IV, independentemente da quantidade e da posicão das caselas vazias. Isso pode ser observado através dos casos deste exemplo.

\section{PARA COLUNAS}

Como já fol comentado anterformente, as somas de quadrados do segundo fator da ordenacão A,B são iguals para os tipos I e II. Forém, agora, como a hipótese tipo II é equivalente às dos tipos III e IV, todas as hipóteses fornecidas pelo PROC GLM serão identicas. E são da forma:

$$
\begin{gathered}
H_{0}^{(2)}: \beta_{1}=\beta_{2}=\beta_{9} \Rightarrow B_{2}=\left[\begin{array}{ccccccc}
0 & 0 & 0 & 0 & 1 & -1 & 0 \\
0 & 0 & 0 & 0 & 1 & 0 & -1
\end{array}\right] \\
\therefore \quad S O H O^{(2)}=7511,787014=S O H O^{(1)}=S O H_{0}^{(3)}=\mathrm{SOH}^{(4)}
\end{gathered}
$$

Os resultados do PROC GLM comprovam os comentários:

Quadro 1. Be - Quadro da análise de variancia preliminar Sum of Mean

\begin{tabular}{lrrrrr} 
Source & DF & Squares & Square & F Value \\
\hline Model & 5 & 8684.877531 & 1736.975506 & 154.79 \\
Error & 23 & 258.087986 & 11.221217 & \\
\hline Total & 28 & 8942.965517 & &
\end{tabular}


Quadro 2.BZ - Quadro da análise de variancia para a hipótese do t1po I

\begin{tabular}{lrrrrr} 
Source & DF & Type I SS & Mean Square & F Value \\
\hline L & 3 & 1173.090517 & 391.030172 & 34.85 \\
C & 2 & 7511.787014 & 3755.893507 & 334.71 \\
\hline
\end{tabular}

\begin{tabular}{lccccc} 
Quadro 3.Be & - Quadro da análise de variância para a \\
& hipótese do tipo II & & \\
Source & DF & Type II SS & Mean Square & F Value \\
\hline L & 3 & 794.467570 & 264.822523 & 23.60 \\
C & 2 & 7511.787014 & 3755.893507 & 334.71 \\
\hline
\end{tabular}

Quadro 4.Be - Quadro da análise de variancia para a hipótese do tipo III

\begin{tabular}{lrrrrr} 
Source & DF & Type III SS & Mean Square & F Value \\
\hline L & 3 & 794.467570 & 264.822523 & 23.60 \\
C & 2 & 7511.787014 & 3755.893507 & 334.71 \\
\hline
\end{tabular}

Quadro 5.BZ - Quadro da análise de variância para a hipótese do tipo IV

\begin{tabular}{lrrrrr} 
Source & DF & Type IV SS & Mean Square & F Value \\
L & 3 & 794.467570 & 264.822523 & 23.60 \\
C & 2 & 7511.787014 & 3755.893507 & 334.71 \\
\hline
\end{tabular}




\section{2. 3. Caso B3 - Com interaçăo uma casela vazia}

Quadro 15 - Esquema do modelo de médias para o caso B3, conforme o Quadro 2 .

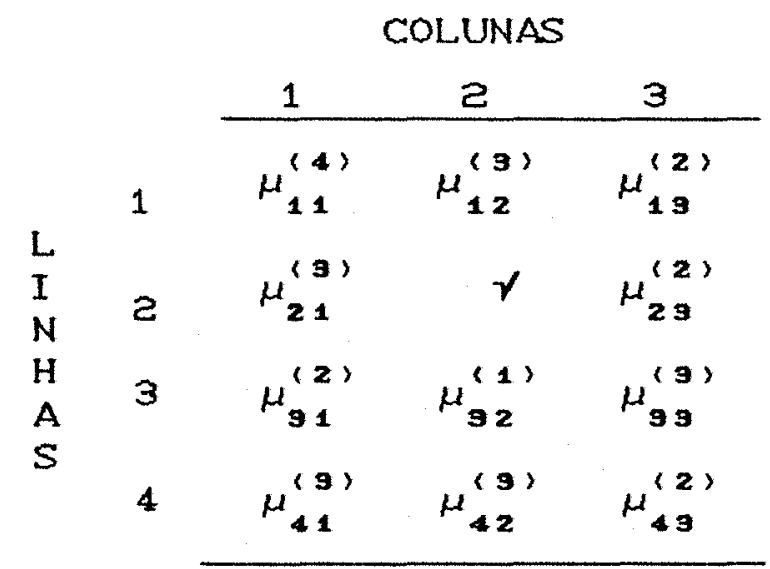

onde $\gamma$ indica a presenca da casela vazia.

As hipóteses, então são:

PARA LINHAS

a) Tipo I

$$
\begin{aligned}
& H_{0}^{(1 *)}:\left\{\begin{array}{l}
\frac{3 \mu_{21}+2 \mu_{29}}{5}=\frac{4 \mu_{11}+3 \mu_{12}+2 \mu_{19}}{9} \\
\frac{3 \mu_{21}+2 \mu_{29}}{5}=\frac{2 \mu_{91}+\mu_{92}+3 \mu_{93}}{8} \\
\frac{3 \mu_{21}+2 \mu_{23}}{5}=\frac{3 \mu_{41}+3 \mu_{42}+2 \mu_{49}}{8}
\end{array}\right.
\end{aligned}
$$

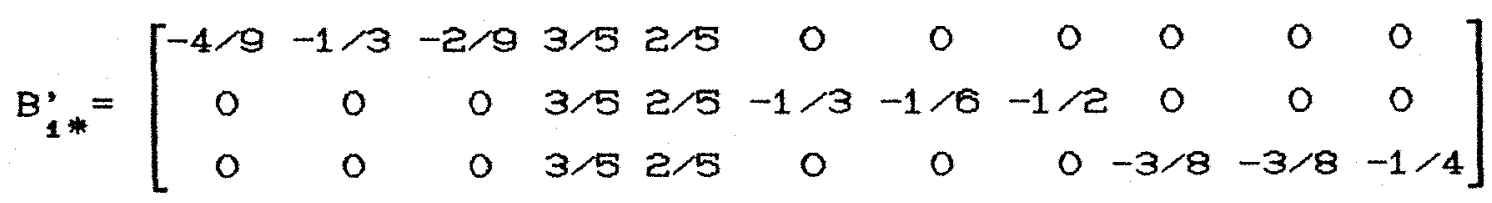

$$
\begin{aligned}
& \therefore \mathrm{SOH}_{0}^{(1 *)}=1467,275397=\mathrm{R}(\alpha \mid \mu)
\end{aligned}
$$


Imaginando-se essa mesma hipótese para o modelo-s, a dificuldade de entendimento é ainda maior.

b) Tipo II

$$
H o^{(2 *)}:\left\{\begin{array}{l}
3 \mu_{21}+2 \mu_{29}=3 \bar{c}_{1}+2 \bar{c}_{3} \\
2 \mu_{31}+\mu_{32}+3 \mu_{39}=2 \bar{c}_{1}+\bar{c}_{2}+3 \bar{c}_{3} \\
3 \mu_{41}+3 \mu_{42}+2 \mu_{43}=3 \bar{c}_{1}+3 \bar{c}_{2}+2 \bar{c}_{3}
\end{array}\right.
$$

$$
\mathrm{B}_{2 *}^{,}=
$$

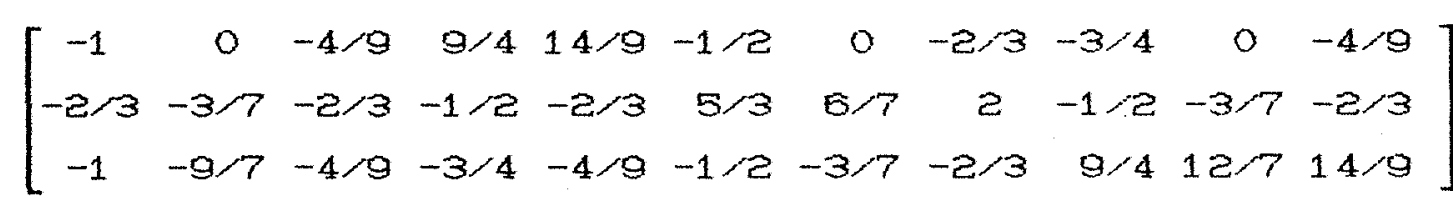

$$
\therefore \mathrm{SQHo}^{(2 *)}=1015,455769=\mathrm{R}(\alpha \mid \mu, \beta)
$$

c) Tipo III

$$
H_{0}^{(9 *)}:\left\{\begin{array}{l}
\mu_{11}+\mu_{12}+\mu_{13}=c_{1}+c_{2}+c_{9} \\
\mu_{21}+\mu_{23}=c_{1}+c_{9} \\
\mu_{91}+\mu_{32}+\mu_{99}=c_{1}+c_{2}+c_{9}
\end{array} \Rightarrow\right.
$$

$$
\begin{gathered}
\Rightarrow \mathrm{B}^{\prime} *=\left[\begin{array}{rrrrrrrrrrr}
9 & 8 & 9 & -3 & -3 & -3 & -4 & -3 & -3 & -4 & -3 \\
-3 & -4 & -3 & -3 & -3 & 9 & 8 & 9 & -3 & -4 & -3 \\
-3 & 0 & -3 & 9 & 9 & -3 & 0 & -3 & -3 & 0 & -3
\end{array}\right] \\
\left.\therefore \operatorname{SQHo}^{(3 *)}=1088,762780=\mathrm{RCa} \alpha^{\circ}, \beta^{\circ}, \gamma^{\circ}\right)
\end{gathered}
$$


d) Tipo IV

$$
\begin{aligned}
& H_{0}^{(4 *)}:\left\{\begin{array}{l}
\mu_{41}+\mu_{42}+\mu_{43}=\mu_{91}+\mu_{92}+\mu_{99} \\
\mu_{41}+\mu_{49}=\mu_{21}+\mu_{23} \Rightarrow \\
\mu_{41}+\mu_{42}+\mu_{49}=\mu_{11}+\mu_{12}+\mu_{13}
\end{array} \Rightarrow\right. \\
& \Rightarrow \quad B_{*}^{\prime}=\left[\begin{array}{rrrrrrrrrrr}
0 & 0 & 0 & 0 & 0 & -1 & -1 & -1 & 1 & 1 & 1 \\
0 & 0 & 0 & -1 & -1 & 0 & 0 & 0 & 1 & 0 & 1 \\
-1 & -1 & -1 & 0 & 0 & 0 & 0 & 0 & 1 & 1 & 1
\end{array}\right] \\
& \therefore \mathrm{SOH}^{(4 *)}=993,945202
\end{aligned}
$$

PARA COLUNAS

a) Quadros 2. B3 e $3 . \mathrm{B} 3$

$$
\begin{aligned}
& H_{0}^{(2 *)}:\left\{\begin{array}{l}
3 \mu_{12}+\mu_{92}+3 \mu_{42}=3 \bar{L}_{1}+\bar{L}_{9}+3 \bar{L}_{4} \\
4 \mu_{11}+3 \mu_{21}+2 \mu_{91}+3 \mu_{41}=4 L_{1}+3 L_{2}+2 L_{9}+3 L_{4}
\end{array}\right. \\
& B_{2 *}^{\prime}= \\
& {\left[\begin{array}{ccccccccccc}
-4 / 3 & 2 & -2 / 3 & 0 & 0 & -1 / 3 & 5 / 6 & -1 / 2 & -9 / 8 & 15 / 8 & -3 / 4 \\
20 / 9 & -4 / 3 & -8 / 9 & 6 / 5 & -6 / 5 & 4 / 3 & -1 / 3 & -1 & 15 / 8 & -9 / 8 & -3 / 4
\end{array}\right]} \\
& \left.\therefore \quad \operatorname{SQHo}^{(2 *)}=5635,624816=\mathrm{RC} \beta \mid \mu, \alpha\right)
\end{aligned}
$$


b) Quadro 4.83

$$
\begin{aligned}
& H_{0}^{\left\{3^{*}\right)}:\left\{\begin{array}{l}
\mu_{12}+\mu_{32}+\mu_{42}=L_{1}+L_{3}+L_{4} \\
\mu_{11}+\mu_{21}+\mu_{91}+\mu_{41}=L_{1}+L_{2}+L_{9}+L_{4}
\end{array}\right. \\
& \mathbf{B}_{\mathbf{9} *}^{\prime}=
\end{aligned}
$$

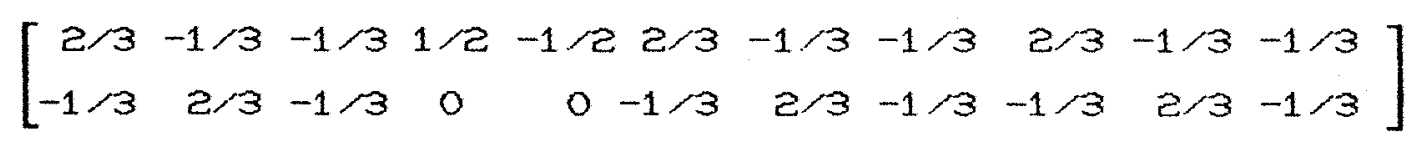

$$
\begin{aligned}
& \left.\therefore \quad \mathrm{SQHo}^{\left(3^{*}\right)}=552 \mathrm{e}, 290036=\mathrm{RC} \alpha^{\circ} \mid \mu^{\circ}, \beta^{\circ}, \gamma^{\circ}\right)
\end{aligned}
$$

c) Quadro 5. B3

$$
\begin{aligned}
& \mathrm{H}_{0}^{(4 *)}:\left\{\begin{array}{l}
\mu_{13}+\mu_{99}+\mu_{43}=\mu_{12}+\mu_{92}+\mu_{42} \\
\mu_{13}+\mu_{29}+\mu_{99}+\mu_{49}=\mu_{11}+\mu_{21}+\mu_{91}+\mu_{41}
\end{array}\right. \\
& \Rightarrow \mathrm{B}_{4 *}^{\prime}=\left[\begin{array}{rrrrrrrrrrr}
0 & -1 & 1 & 0 & 0 & 0 & -1 & 1 & 0 & -1 & 1 \\
-1 & 0 & 1 & -1 & 1 & -1 & 0 & 1 & -1 & 0 & 1
\end{array}\right] \\
& \therefore \mathrm{SQH}^{(4 *)}=5345,866434
\end{aligned}
$$

Os quadros do SAS ficam:

Quadro 1.B3 - Quadro de análide de variancla preliminar

$$
\text { Sum of }
$$

Mean

\begin{tabular}{lrrrr} 
Source & DF & Squares & Square & F Value \\
\hline Model & 10 & 7413.630952 & 741.363095 & 82.19 \\
Error & 17 & 153.333333 & 9.019608 & \\
\hline Total & 27 & 7566.964286 & &
\end{tabular}


Quadro Z.B3 - Quadro da análise de variâncla para a hipótese do tipo I

\begin{tabular}{lrrrrr} 
Source & DF & Type I SS & Mean Square & F Value \\
\hline L & 3 & 1467.275397 & 489.091799 & 54.23 \\
C & 2 & 5635.624816 & 2817.812408 & 312.41 \\
L*C & 5 & 310.730739 & 62.146148 & 6.89 \\
\hline
\end{tabular}

Quadro 3. B3 - Quadro da análise de variancia para a hipótese do tipo II

\begin{tabular}{lrrrrr} 
Source & DF & Type II SS & Mean Square & F Value \\
\hline L & 3 & 1015.455769 & 338.485256 & 37.53 \\
C & 2 & 5635.624816 & 2817.812408 & 312.41 \\
L*C & 5 & 310.730739 & 62.146148 & 6.89 \\
\hline
\end{tabular}

Quadro 4.B3 - Quadro da análise de variância para a hipótese do tipo III

\begin{tabular}{lrrrr} 
Source & DF & Type III SS & Mean Square & F Value \\
\hline L & 3 & 1088.762780 & 362.920927 & 40.24 \\
C & 2 & 5522.290038 & 2761.145018 & 306.13 \\
L*C & 5 & 310.730739 & 62.146148 & 6.89 \\
\hline
\end{tabular}

Quadro 5.B3 - Quadro da análise de variancia para a hipótese do tipo IV

\begin{tabular}{lrrrr} 
Source & DF & Type IV SS & Mean Square & F Value \\
\hline L & $3 *$ & 993.945202 & 331.315067 & 36.73 \\
$C$ & $2 *$ & 5345.866434 & 2672.933217 & 296.35 \\
L*C & 5 & 310.730739 & 62.146148 & 6.89 \\
\hline
\end{tabular}




\section{2. 4. Caso B4 - Sem interaçăo com uma casela vazia}

Quadro 16 - Esquema do modelo de médias para o caso B4, conforme o Quadro 3.

\section{COLUNAS}

\begin{tabular}{|c|c|c|c|c|c|c|}
\hline & & 1 & & 2 & & 3 \\
\hline & 1 & $\mu_{1}+\beta_{1}^{(4)}$ & $\mu_{1}$ & $+\beta_{2}^{(3)}$ & $\mu_{1}$ & $+\beta_{9}^{(2)}$ \\
\hline & 2 & $\mu_{2}+\beta_{1}^{(9)}$ & & $\gamma$ & $\mu_{2}$ & $+\beta_{9}^{(2)}$ \\
\hline & 3 & $\mu_{3}+\beta_{1}^{(2)}$ & $\mu_{\mathbf{3}}$ & $+\beta_{2}^{(1)}$ & $\mu_{3}$ & $+\beta_{3}^{(9)}$ \\
\hline & 4 & $\mu_{4}+\beta_{1}^{(3)}$ & $\mu_{4}$ & $+\beta_{2}^{(9)}$ & $\mu_{4}$ & $+\beta_{3}^{(2)}$ \\
\hline
\end{tabular}

onde $\gamma$ indica a casela vazia.

Para se obter a matriz W', basta eliminar a coluna da matriz W" do caso Be. que contenha as observacóes da casela (2, 2), ou seja, a coluna 13. Como a coluna 13 contém apenas uma abservação, então $W^{\prime}$ tem ordem $7 \times 28$.

Já para o vetor $y$, o procedimento é análogo. Retira-se a 11 nha 13. Dai, y tem ordem $28 \times 1$.

Diante dessas informaçóes, é possivel determinar o vetor de solucão de mínimos quadrados. Então, $\hat{\mu}_{1}=\left[\begin{array}{l}\hat{\mu}_{1} \\ \hat{\mu}_{2} \\ \hat{\mu}_{3} \\ \hat{\mu}_{4} \\ \hat{\beta}_{1} \\ \hat{\beta}_{2} \\ \hat{\beta}_{3}\end{array}\right] \Rightarrow \hat{\mu}=\left[\begin{array}{r}445,8356 \\ 450,0000 \\ 439,2046 \\ 436,0454 \\ -373,1573 \\ -379,1211 \\ -340,2640\end{array}\right]$ 
Assim, as hipóteses ficam:

PARA LINHAS

a) Tipo I

$H_{0}^{(1 *)}:\left\{\begin{array}{l}\mu_{1}+\frac{4 \beta_{1}+3 \beta_{2}+2 \beta_{3}}{9}=\mu_{2}+\frac{3 \beta_{1}+2 \beta_{3}}{5}+2 \beta_{9} \\ \mu_{3}+\frac{2 \beta_{1}+\beta_{2}+3 \beta_{3}}{6}=\mu_{2}+\frac{3 \beta_{1}}{5}+2 \beta_{9} \\ \mu_{4}+\frac{3 \beta_{1}+3 \beta_{2}+2 \beta_{9}}{8}=\mu_{2}+\frac{3 \beta_{1}}{6}\end{array}\right.$

$$
\begin{aligned}
& \mu_{1} \mu_{2} \mu_{3} \mu_{4} \beta_{1} \quad \beta_{2} \beta_{3} \\
& \Rightarrow B_{1 *}^{\prime}=\left[\begin{array}{rrrrrcc}
\downarrow & \downarrow & \downarrow & \downarrow & \downarrow & \downarrow & \downarrow \\
-1 & 1 & 0 & 0 & 7 / 45 & -1 / 3 & 8 / 45 \\
0 & 1 & -1 & 0 & 4 / 15 & -1 / 6 & -1 / 10 \\
0 & 1 & 0 & -1 & 9 / 40 & -3 / 8 & 3 / 20
\end{array}\right]
\end{aligned}
$$

$H_{0}^{(1 *)}:\left\{\begin{array}{l}-\alpha_{1}+\alpha_{2}+\frac{7}{45} \beta_{1}-\frac{1}{3} \beta_{2}+\frac{8}{45} \beta_{3}=0 \\ a_{2}-\alpha_{3}+\frac{4}{15} \beta_{1}-\frac{1}{6} \beta_{2}-\frac{1}{10} \beta_{3}=0 \\ a_{2}-\alpha_{4}+\frac{9}{40} \beta_{1}-\frac{3}{8} \beta_{2}-\frac{3}{20} \beta_{3}=0\end{array}\right.$

$$
\therefore \mathrm{SQH}^{(1 *)}=1457,339280=\mathrm{RC} \text { a } / 1 \mathrm{H}
$$

b) Tipo II

Como comentado no caso BZ, a hipótese tipo II sempre será, no modelo sem interacão, equivalente às hipóteses do tipo III e IV. Porém, para reforçar essa ldéla, providenciam-se os cálculos algébricos para se chegar a essa afirmacão. Notar-se-á que essa igualdade é 
válida, até para um grande número de caselas vazias.

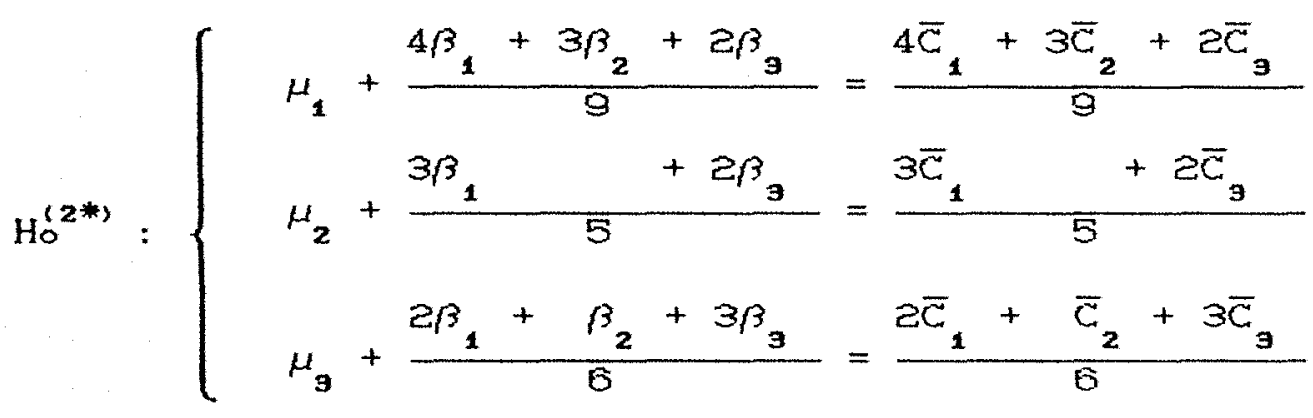

onde: $\bar{c}_{1}=\frac{4 \mu_{1}+3 \mu_{2}+2 \mu_{9}+3 \mu_{4}+12 \beta_{1}}{12}$

$$
\begin{aligned}
& \bar{c}_{2}=\frac{3 \mu_{1}+\mu_{3}+3 \mu_{4}+7 \beta_{2}}{7} \\
& \bar{c}=\frac{2 \mu_{1}+2 \mu_{2}+3 \mu_{3}+2 \mu_{4}+9 \beta_{3}}{9}
\end{aligned}
$$

Assim,

1. Iinha da hipótese:

$9 \mu_{1}+4 \beta_{1}+3 \beta_{2}+2 \beta_{3}=4 \overline{\mathrm{C}}_{1}+3 \overline{\mathrm{C}}_{2}+2 \overline{\mathrm{C}}_{3}=$

$=\frac{193 \mu_{1}+91 \mu_{2}+111 \mu_{3}+173 \mu_{4}+252 / \beta_{1}+189 \beta_{2}+126 / 3}{63} \Rightarrow$

$567 \mu_{1}+252 \beta_{1}+189 \beta_{2}+126 \beta_{3}=$

$=193 \mu_{1}+91 \mu_{2}+111 \mu_{9}+173 \mu_{4}+252 \beta_{1}+189 \beta_{2}+126 \beta_{9} \Rightarrow$

$\Rightarrow-374 \mu_{1}+91 \mu_{2}+111 \mu_{9}+173 \mu_{4}=0$

Portanto, a 1 . Iinha da matriz hipótese fica:

$\mu_{1} \mu_{2} \quad \mu_{3} \quad \mu_{4} \beta_{1} \beta_{2} \beta_{9}$

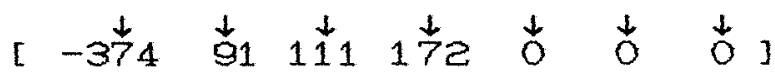


De manefra similar, pode-se obter as duas

Iinhas restantes. Assim, a matriz hipótese tem a forma:

$$
\begin{aligned}
& \begin{array}{lllllll}
\mu_{1} & \mu_{2} & \mu_{3} & \mu_{4} & \beta_{1} & \beta_{2} & \beta_{3}
\end{array} \\
& \Rightarrow B_{i *}^{*}=\left[\begin{array}{rcrcccc}
\downarrow & \downarrow & \downarrow & \downarrow & \downarrow & \downarrow & \downarrow \\
-374 & 91 & 111 & 12 & 0 & 0 & 0 \\
52 & -137 & 42 & 43 & 0 & 0 & 0 \\
74 & 49 & -190 & 67 & 0 & 0 & 0
\end{array}\right] \\
& \therefore \operatorname{SOHO}^{(2 *)}=748,681312=R(a \mid \mu, \beta)
\end{aligned}
$$

c) Tipo III

Utilizando-se o método desenvolvido neste trabalho, a hipótese do tipo III fica:

$H_{0}^{(9 *)}:\left\{\begin{array}{l}\mu_{1}+\frac{\beta_{1}+\beta_{2}+\beta_{3}}{3}=\frac{C_{1}+C_{2}+C_{9}}{3}+\beta_{3}=\frac{C_{1}+C_{9}}{2} \\ \mu_{2}+\frac{\beta_{1}}{2} \\ \mu_{3}+\frac{\beta_{1}+\beta_{2}+\beta_{3}}{3}=\frac{C_{1}+C_{2}+C_{3}}{3}\end{array}\right.$

onde: $C_{1}=\frac{\mu_{1}+\mu_{2}+\mu_{9}+\mu_{4}+4 \beta_{1}}{4}$

$C_{2}=\frac{\mu_{1}+\mu_{3}+\mu_{4}+3 \beta_{2}}{3}$

$c_{3}=\frac{\mu_{1}+\mu_{2}+\mu_{3}+\mu_{4}+4 \beta_{3}}{4}$

$$
B^{*}=\left[\begin{array}{rrrrrrr}
-13 & 3 & 5 & 5 & 0 & 0 & 0 \\
1 & -3 & 1 & 1 & 0 & 0 & 0 \\
5 & 3 & -13 & 5 & 0 & 0 & 0
\end{array}\right]
$$


d) Tipo IV

Pelo mesmo raciocinio de $B 3$, a hipótese tipo

IV, agora, é:

$H_{0}^{(4 *)}:\left\{\begin{array}{l}\mu_{4}=\mu_{3} \\ \mu_{4}=\mu_{2} \\ \mu_{4}=\mu_{1}\end{array} \Rightarrow B_{4}^{\prime}=\left[\begin{array}{rrrrrrr}0 & 0 & -1 & 1 & 0 & 0 & 0 \\ 0 & -1 & 0 & 1 & 0 & 0 & 0 \\ -1 & 0 & 0 & 1 & 0 & 0 & 0\end{array}\right]\right.$

Efetuando-se os cálculos para a obtenção das respectivas somas de quadrados, verifica-se, mais uma vez, que os resultados são os mesmos.

É fundamental perceber que as hipóteses para - efelto A (Solos) não contém os efeitos de B (Variedades), portanto, há uma diferenca das três últimas hipóteses em relação à primeira, do tipo I, pois, essa contém os efeitos de colunas, ou seja, o efeito das variedades.

PARA COLUNAS

Verifica-se, também, que todas as hipóteses são equivalentes em relação ao fator variedades. Deste modo, apresenta-se a hipótese do tipo IV, pois acredita-se que seja a de maior facilidade de compreensão. Ou seja,

$$
\begin{gathered}
H_{0}^{\left(4^{*}\right)}:\left\{\begin{array}{c}
\beta_{1}=\beta_{2} \\
\beta_{1}=\beta_{3}
\end{array} \Rightarrow B_{4 *}^{*}=\left[\begin{array}{ccccccc}
0 & 0 & 0 & 0 & 1 & -1 & 0 \\
0 & 0 & 0 & 0 & 1 & 0 & -1
\end{array}\right]\right. \\
\therefore \text { SQHo }^{(4)}=7146,786471
\end{gathered}
$$


Observa-se, então, que se o modelo proposto não considera a interacão, as hipóteses dos tipos II, III e IV são equivalentes, consequentemente, o objetivo do teste é o mesmo. Dentro desse contexto, comparando-se o caso B3 com o presente, a única diferenca está justamente na escolha do modelo: o primeiro, com interacão e o segundo, sem.

Assim, vê-se que o caso B3, modelo com interacão, não testa isoladamente, nem o efeito do fator Solo, muito menos o efeito do fator Variedade. Isto é, não é um modelo apropriado para tomada de decisóes sobre efeltos principais. Já o segundo modelo permite essa tomada de decisão, devido à ausência de interacão.

Os resultados for necidos pelo PROC GLM São da

forma:

Quadro 1.B4 - Quadro da análise de variancia preliminar

\begin{tabular}{lrrrr} 
& & Sum of & Mean & \\
Source & DF & Squares & Square & F Value \\
\hline Model & 5 & 8604.125756 & 1720.825151 & 148.12 \\
Error & 22 & 255.588529 & 11.617660 & \\
\hline Total & 27 & 8859.714286 & &
\end{tabular}

Quadro Z.B4 - Quadro da análise de variancia para a hipótese do tipo I

\begin{tabular}{lrrrr} 
Source & DF & Type I SS & Mean Square & F Value \\
\hline L & 3 & 1457.339286 & 485.779762 & 41.81 \\
C & 2 & 7146.786471 & 3573.393235 & 307.58 \\
\hline
\end{tabular}


Quadro 3.B4 - Quadro da análise de variancia para a hipótese do tipo II

\begin{tabular}{lrrrrr} 
Source & DF & Type II SS & Mean Square & F Value \\
\hline L & 3 & 748.681312 & 249.560437 & 21.48 \\
C & 2 & 7146.786471 & 3573.393235 & 307.58 \\
\hline
\end{tabular}

Quadro 4.B4 - Quadro da análise de variância para a hipótese do tipo III

\begin{tabular}{lrrrrr} 
Source & DF & Type III SS & Mean Square & F Value \\
\hline L & 3 & 748.681312 & 249.560437 & 21.48 \\
C & 2 & 7146.786471 & 3573.393235 & 307.58 \\
\hline
\end{tabular}

Quadro 5.B4 - Quadro da análise de varlância para a hipótese do tipo IV

\begin{tabular}{lrrrr} 
Source & DF & Type IV SS & Mean Square & F Value \\
\hline L & 3 & 748.681312 & 249.560437 & 21.48 \\
C & 2 & 7146.786471 & 3573.393235 & 307.58 \\
\hline
\end{tabular}

A saida do STATGRAPHICS, por exemplo, para as hipóteses dos tipos I e III, que correspondem aos quadros 2. B4 e 4.B4, são apresentadas nos quadros $2 . B 4^{\prime}$ e $4 . B 4^{\prime}$.

Quadro 2.B4'- Quadro da análise de variancia para a hipótese do tipo I

$\begin{array}{lcc}\text { Source of variation } & \text { Sum of square } & \text { d.f } \\ \text { MAIN EFFETCS } & & \\ \text { L: LINHAS } & 1457.33929 & 3 \\ \text { C: COLUNAS } & 7146.78647 & 2\end{array}$

\begin{tabular}{lcc} 
RESI DUAL & 255.58853 & 22 \\
\hline TOTAL CCORRECTED) & 8859.71429 & 27 \\
\hline
\end{tabular}

1 missing values have been excl uded.

All F-ratios are based on the residual mean square error. 
Quadro 4. B4"- Quadro da análise de variáncia para a hipótese do tipo III

\begin{tabular}{|c|c|c|}
\hline Source of variation & Sum of & d. $f$ \\
\hline \multicolumn{3}{|l|}{ MAIN EFFETCS } \\
\hline L: LINHAS & 748.68131 & 3 \\
\hline C: COLUNAS & 7146.78647 & 2 \\
\hline RESI DUAL & 255.58853 & 22 \\
\hline TOTAL (CORRECTED) & 8859.71429 & 27 \\
\hline
\end{tabular}

$1 \mathrm{missing}$ values have been excluded.

All F-ratios are based on the residual mean square error.

Observe, como já comentado anteriormente, que - STATGRAPHICS fornece abaixo dos quadros o número de caselas vazias existentes.

4.2.5. Caso B5 - Com interação e com duas caselas vazias Quadro 17 - Esquema do modelo de médias para o caso B5, conforme o Quadro 2 .

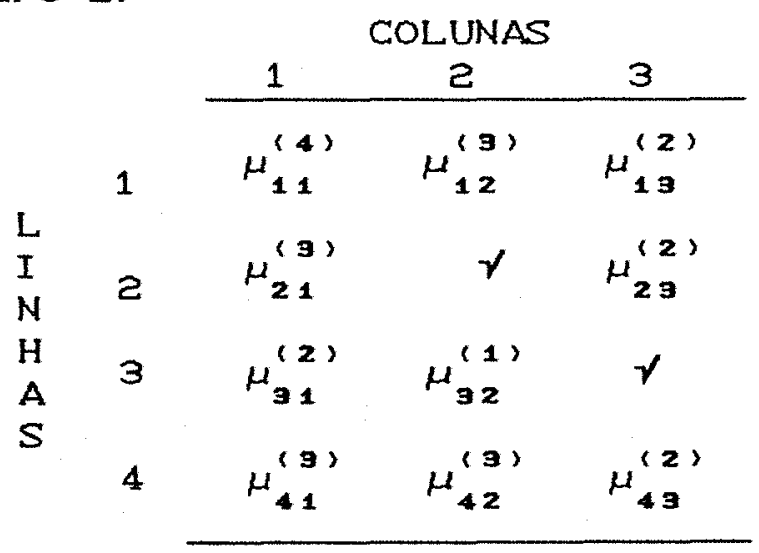

onde $\gamma$ indica a casela vazia.

As hipóteses, então são: 
PARA LINHAS

a) İpo I

$$
\begin{aligned}
& H_{0}^{\prime * 2}:\left\{\begin{array}{l}
\frac{2 \mu_{31}+\mu_{32}}{3}=\frac{3 \mu_{21}+2 \mu_{23}}{3} \\
\frac{2 \mu_{31}+\mu_{32}}{3}=\frac{3 \mu_{41}+3 \mu_{42}+2 \mu_{49}}{8} \\
\frac{2 \mu_{91}+\mu_{92}}{3}=\frac{4 \mu_{11}+3 \mu_{12}+2 \mu_{13}}{8}
\end{array} \Rightarrow\right.
\end{aligned}
$$

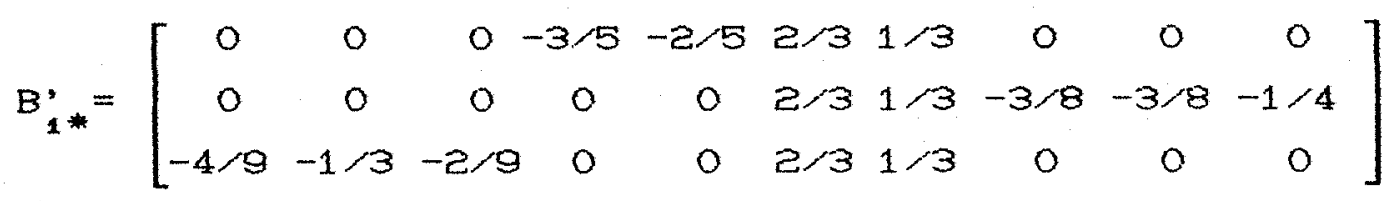

$$
\begin{aligned}
& \therefore \quad \mathrm{SQH}^{(1 *)}=1853,1250=\mathrm{R}(\alpha \mid \mu)
\end{aligned}
$$

b) Tipo II

$$
H \sigma^{2 *)}:\left\{\begin{array}{l}
3 \mu_{21}+2 \mu_{23}=3 \bar{C}_{1}+2 \bar{C}_{3} \\
2 \mu_{31}+\mu_{32}=2 \bar{C}_{1}+\overline{C_{2}} \\
3 \mu_{41}+3 \mu_{42}+2 \mu_{49}=3 \bar{C}_{1}+3 \bar{C}_{2}+2 \bar{C}_{9}
\end{array}\right.
$$

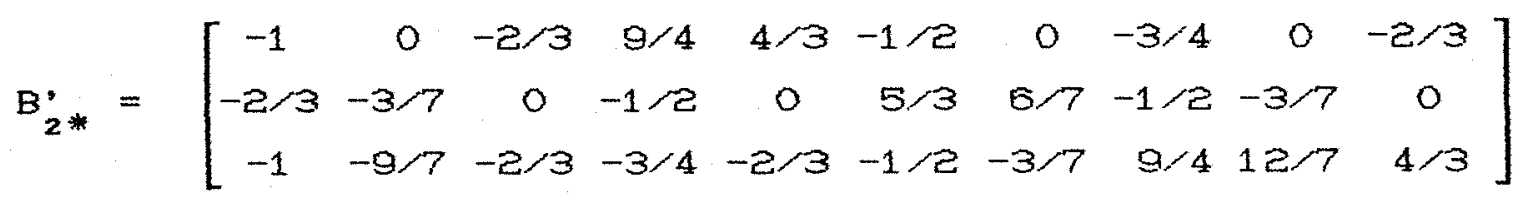

$$
\therefore \mathrm{SQHo}^{(2 *)}=705,154358=\mathrm{R}(\alpha \mid \mu, \beta)
$$


c) Tipo III

$$
\begin{aligned}
& H_{0}^{(3 *)}:\left\{\begin{array}{l}
\mu_{21}+\mu_{23}=c_{1}+C_{3} \\
\mu_{91}+\mu_{32}=c_{1}+C_{2} \\
\mu_{41}+\mu_{42}+\mu_{43}=C_{1}+C_{2}+C_{3}
\end{array} \Rightarrow\right. \\
& \Rightarrow_{9 *}^{\prime}=\left[\begin{array}{rrrrrrrrrr}
-3 & 0 & -4 & 9 & 8 & -3 & 0 & -3 & 0 & -4 \\
-3 & -4 & 0 & -3 & 0 & 9 & 8 & -3 & -4 & 0 \\
-3 & -4 & -4 & -3 & -4 & -3 & -4 & 9 & 8 & 8
\end{array}\right] \\
& \left.\therefore \mathrm{SOH}^{(3 *)}=715,710684=\mathrm{RC} \alpha^{\circ} \mid \mu^{\circ}, \beta^{\circ}, \gamma^{\circ}\right)
\end{aligned}
$$

Veja que ao contrário do exemplo 1 , todos os parâmetros do modelo estão presentes na hipótese $\mathrm{Ho}^{(3 * \text { ? }}$, concordando dessa forma com o comentário feito para o caso A3.

d) T1po IV

$$
\begin{aligned}
& H_{0}^{(4 *)}:\left\{\begin{array}{l}
\mu_{41}+\mu_{42}=\mu_{31}+\mu_{32} \\
\mu_{41}+\mu_{49}=\mu_{21}+\mu_{23} \Rightarrow \\
\mu_{41}+\mu_{42}+\mu_{49}=\mu_{11}+\mu_{12}+\mu_{13}
\end{array}\right. \\
& \Rightarrow \quad B_{4 *}^{*}=\left[\begin{array}{rrrrrrrrrr}
0 & 0 & 0 & 0 & 0 & -1 & -1 & 1 & 1 & 0 \\
0 & 0 & 0 & -1 & -1 & 0 & 0 & 1 & 0 & 1 \\
-1 & -1 & -1 & 0 & 0 & 0 & 0 & 1 & 1 & 1
\end{array}\right] \\
& \therefore \mathrm{SQHO}^{(4 *)}=643,905093
\end{aligned}
$$


PARA COLUNAS

a) Quadros 2. B5 e $3 . \mathrm{BS}$

$H_{0}^{(2 *)}:\left\{\begin{array}{l}3 \mu_{12}+\mu_{32}+3 \mu_{42}=3 L_{1}+\bar{L}_{3}+3 \bar{L}_{4} \\ 2 \mu_{19}+2 \mu_{29}+2 \mu_{49}=2 \bar{L}_{1}+2 \bar{L}_{2}+2 \bar{L}_{4}\end{array}\right.$

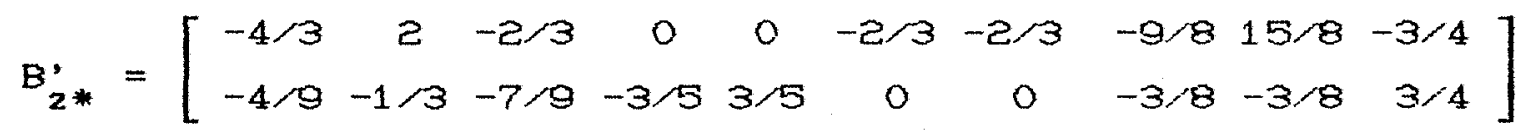

$$
\therefore \mathrm{SQHo}^{(2 *)}=5309,315073=R(\alpha \mid \mu, \beta)
$$

b) Quadro 4.85

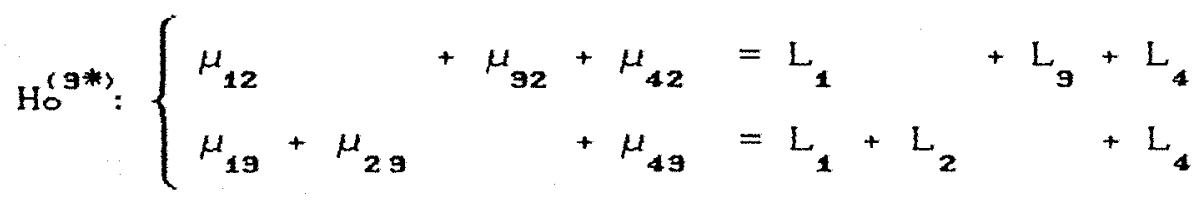

$$
\begin{aligned}
& \Rightarrow \mathrm{B}_{3^{*}}=\left[\begin{array}{cccccccccc}
-1 / 3 & 2 / 3 & -1 / 3 & 0 & 0 & -1 / 2 & 1 / 2 & -1 / 3 & 2 / 3 & -1 / 3 \\
-1 / 3 & -1 / 3 & 2 / 3 & -1 / 2 & 1 / 2 & 0 & 0 & -1 / 3 & -1 / 3 & 2 / 3
\end{array}\right] \\
& \left.\therefore \quad \mathrm{SQH}_{0}^{\left(3^{*}\right)}=5269,363181=\mathrm{RC} \alpha^{\circ} \mid \mu^{\circ}, \beta^{\circ}, \gamma^{\circ}\right)
\end{aligned}
$$

c) Quadro 5. B5

$$
\begin{aligned}
& H_{0}^{(4 *)}:\left\{\begin{array}{lll}
\mu_{19} & +\mu_{43}=\mu_{12} & +\mu_{42} \\
\mu_{19}+\mu_{29} & +\mu_{43}=\mu_{11}+\mu_{21} & +\mu_{41}
\end{array}\right. \\
& \Rightarrow B_{4 *}^{\prime}=\left[\begin{array}{rrrrrrrrrr}
0 & -1 & 1 & 0 & 0 & 0 & 0 & 0 & -1 & 1 \\
-1 & 0 & 1 & -1 & 1 & 0 & 0 & -1 & 0 & 1
\end{array}\right] \\
& \therefore \mathrm{SOH}^{(4 *)}=5034,412844
\end{aligned}
$$


INTERACÃO

Tem-se, nesse caso, 4 g. 1 . para interacão.

$$
\begin{gathered}
B_{5 *}^{\prime}=\left[\begin{array}{rrrrrrrrrr}
1 & 0 & -1 & -1 & 1 & 0 & 0 & 0 & 0 & 0 \\
1 & 0 & -1 & 0 & 0 & 0 & 0 & -1 & 0 & 1 \\
1 & -1 & 0 & 0 & 0 & -1 & 1 & 0 & 0 & 0 \\
1 & -1 & 0 & 0 & 0 & 0 & 0 & -1 & 1 & 0
\end{array}\right] \\
\left.\therefore \quad S_{0 H}^{(5 *)}=23,559927=R C \gamma \mid \mu, \alpha, \beta\right)
\end{gathered}
$$

Apresentam-se, abaixo, as saídas do SAS.

\begin{tabular}{|c|c|c|c|c|c|}
\hline Source & DF & $\begin{array}{l}\text { Sum of } \\
\text { Squares }\end{array}$ & $\begin{array}{r}\text { Mean } \\
\text { Square }\end{array}$ & $\mathrm{F}$ & Value \\
\hline Model & 9 & 7186.000000 & 798.444444 & & 61.74 \\
\hline Error & 15 & 194.000000 & 12.933333 & & \\
\hline Total & 24 & 7380.000000 & & & \\
\hline
\end{tabular}

Quadro 1.B5 - Quadro da análise de variância preliminar

Quadro 2.B5 - Quadro da análise de variancia para a hipótese do tipo I

\begin{tabular}{lrrrr} 
Source & DF & Type I SS & Mean Square & F Value \\
\hline L & 3 & 1853.125000 & 617.708333 & 47.76 \\
$C$ & 2 & 5309.315073 & 2654.657536 & 205.26 \\
$L * C$ & 4 & 23.559927 & 5.889982 & 0.46 \\
\hline
\end{tabular}

Quadro 3.B5 - Quadro da análise de variâncla para a hipótese do tipo II

\begin{tabular}{lrrrr} 
Source & DF & Type II SS & Mean Square & F Value \\
\hline L & 3 & 705.154358 & 235.051453 & 18.17 \\
C & 2 & 5309.315073 & 2654.657536 & 205.26 \\
L*C & 4 & 23.559927 & 5.889982 & 0.46 \\
\hline
\end{tabular}


Quadro 4.B5 - Quadro da análise de variâncla para a hipostese do tipo III

\begin{tabular}{lrrrr} 
Source & DF & Type III SS & Mean Square & F Value \\
\hline L & 3 & 715.710684 & 238.570228 & 18.45 \\
C & 2 & 5269.363181 & 2634.681590 & 203.71 \\
L*C & 4 & 23.559927 & 5.889982 & 0.46 \\
\hline
\end{tabular}

Quadro 5. B5 - Quadro da análise de variâncla para a hipótese do tipo IV

\begin{tabular}{lrrrr} 
Source & DF & Type IV SS & Mean Square & F Value \\
\hline L & $3 *$ & 643.905093 & 214.635031 & 16.60 \\
C. & $2 *$ & 5034.412844 & 2517.206422 & 194.63 \\
L*C. & 4 & 23.559927 & 5.889982 & 0.46 \\
\hline
\end{tabular}

4.2.6. Caso $B 6$ - Sem interaçá com duas caselas vazlas

- caso em questão é similar ao antertor. desprezando-se a interacão.

Concordando com os casos $\mathrm{B} 2$ e $\mathrm{B} 4$, as matrizes para esse caso são apresentadas.

Para a construçá de $w$ e $y$, é suficlente retirar as as 1 inhas que contêm as observacões dentro das caselas vazias, 1 sto é, as linhas $13,19,20$ e 21 , totalizando 4 observacóes. Assim, W flca com ordem (25x7) e $y(25 \times 1)$.

Novamente, usando-se (8), tem-se: 


$$
\vec{\mu}_{1}=\left[\begin{array}{r}
198,6997 \\
202,8715 \\
192,0000 \\
188,9106 \\
-126,0121 \\
-131,9758 \\
-93,1606
\end{array}\right]
$$

Com a obtencão de $\hat{\mu}$, agora é possivel determinar as somas de quadrados apropriadas para cada situacão.

\section{PARA LINHAS}

a) Tipo I

$$
\begin{aligned}
& H_{0}^{(1 *)}:\left\{\begin{array}{l}
\mu_{2}+\frac{3 \beta_{1}+2 \beta_{3}}{5}=\mu_{9}+\frac{2 \beta_{1}+\beta_{2}}{3} \\
\mu_{2}+\frac{3 \beta_{1}+2 \beta_{3}}{5}=\mu_{4}+\frac{3 \beta_{1}+3 \beta_{2}+2 \beta_{9}}{8} \\
\mu_{2}+\frac{3 \beta_{1}+2 \beta_{3}}{5}=\mu_{1}+\frac{4 \beta_{1}+3 \beta_{2}+2 \beta_{9}}{9}
\end{array}\right. \\
& \mu_{1} \mu_{2} \mu_{3} \mu_{4} \beta_{1} \quad \beta_{2} \quad \beta_{3} \\
& \Rightarrow B_{1 *}^{*}=\left[\begin{array}{rrrrccc}
\downarrow & \downarrow & \downarrow & \downarrow & \downarrow & \downarrow & \downarrow \\
0 & 1 & -1 & 0 & -1 / 15 & -1 / 3 & 2 / 5 \\
0 & 1 & 0 & -1 & 9 / 40 & -3 / 8 & 3 / 20 \\
-1 & 1 & 0 & 0 & 7 / 45 & -1 / 3 & 8 / 45
\end{array}\right] \\
& H_{0}^{(1 *)}:\left\{\begin{array}{l}
a_{2}-\alpha_{9}-\frac{1}{15} \beta_{1}-\frac{1}{3} \beta_{2}+\frac{2}{5} \beta_{3}=0 \\
\alpha_{2}-\alpha_{4}+\frac{9}{40} \beta_{1}-\frac{3}{8} \beta_{2}+\frac{3}{20} \beta_{9}=0 \\
\alpha_{2}-\alpha_{1}+\frac{7}{45} \beta_{1}-\frac{1}{3} \beta_{2}+\frac{8}{45} \beta_{3}=0
\end{array}\right. \\
& \therefore \mathrm{SQHO}^{(1 *)}=1853,1250=\mathrm{R}(\alpha \mid \mu)
\end{aligned}
$$


b) Tipo II

Com já se discutiu, as hipóteses, a partir de agora, são equivalentes e sempre com a seguinte caracterizacão:

$$
\text { Ho: } \mu_{1}=\mu_{2}=\mu_{9}=\mu_{4} \Rightarrow \text { Ho: } \alpha_{1}=\alpha_{2}=\alpha_{9}=\alpha_{4}
$$

Portanto, as matrizes hipóteses são iguais àquela construída para o caso B4. Assim,

$$
\begin{aligned}
& B_{*}^{\prime}=\left[\begin{array}{rrrrrrr}
0 & 0 & -1 & 1 & 0 & 0 & 0 \\
0 & -1 & 0 & 1 & 0 & 0 & 0 \\
-1 & 0 & 0 & 1 & 0 & 0 & 0
\end{array}\right] \\
& \therefore \quad \text { SQHo }=705,154358=\mathrm{RC} \alpha \mid \mu, \beta)
\end{aligned}
$$

PARA COLUNAS

De modo análogo, ao caso B4 a matriz hipótese para as análises é:

$$
\begin{aligned}
& B_{*}^{*}=\left[\begin{array}{lllllrr}
0 & 0 & 0 & 0 & 1 & -1 & 0 \\
0 & 0 & 0 & 0 & 1 & 0 & -1
\end{array}\right] \\
& \therefore \quad S Q H o=5309,315073=R C \beta \mid \mu, \alpha \\
& \text { As saídas do GLM comprovam as igual dades. }
\end{aligned}
$$

Quadro 1.BO - Quadro da análise de variância preliminar

\begin{tabular}{lrrrr} 
& & Sum of & Mean & \\
Source & DF & Squares & Square & F Value \\
\hline Model & 5 & 7162.440073 & 1432.488015 & 125.10 \\
Error & 19 & 217.559927 & 11.450522 & \\
\hline Total & 24 & 7380.000000 & &
\end{tabular}


Quadro 2.B6 - Quadro da análise de variância para a hi pótese do tipo I

\begin{tabular}{lrrrr} 
Source & DF & Type I SS & Mean Square & F Value \\
\hline L & 3 & 1853.125000 & 617.708333 & 53.95 \\
C & 2 & 5309.315073 & 2654.657536 & 231.84 \\
\hline
\end{tabular}

Quadro 3.BE - Quadro da análise de variância para a hipótese do tipo II

\begin{tabular}{lrrrrr} 
Source & DF & Type II SS & Mean Square & F Value \\
\hline L & 3 & 705.154358 & 235.051453 & 20.53 \\
C & 2 & 5309.315073 & 2654.657536 & 231.84 \\
\hline
\end{tabular}

Quadro 4.B6 - Quadro da análise de variancia para a hipótese do tipo III

\begin{tabular}{lrrrr} 
Source & DF & Type III SS & Mean Square & F Value \\
\hline L & 3 & 705.154358 & 235.051453 & 20.53 \\
$C$ & 2 & 5309.315073 & 2654.657536 & 231.84 \\
\hline
\end{tabular}

Quadro 5.86 - Quadro da análise de variâncla para a hipótese do tipo IV

\begin{tabular}{lrrrr} 
Source & DF & Type IV SS & Mean Square & F Value \\
\hline L & 3 & 705.154358 & 235.051453 & 20.53 \\
C & 2 & 5309.315073 & 2654.657536 & 231.84 \\
\hline
\end{tabular}


4.2.7. Caso B7 - Sem interacão e com três caselas vazias

Quadro 18 - Esquema do modelo de médias para o caso B7, conforme o Quadro 3.

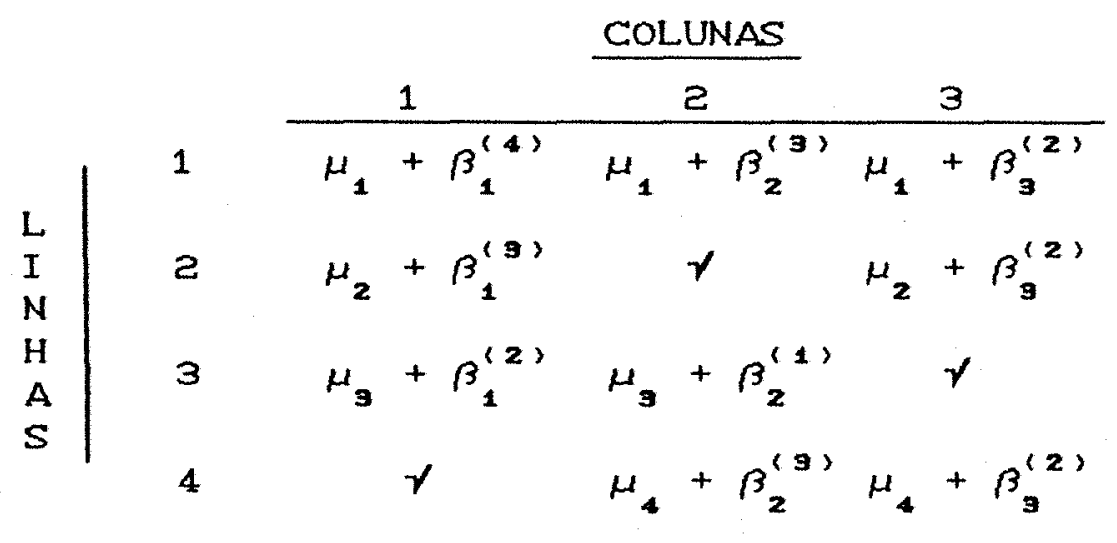

onde $\gamma$ indica a casela vazia.

Da mesma forma que o caso BO as Iinhas eliminadas aqui devem ser: 13, 19, 20, 21, 22, 23 e 24, para a obtenção de $w$ e $y$. Assim, a solucão de mínimos quadrados para $\mu$ fica:

$$
\hat{\mu}_{1}=\left[\begin{array}{r}
198,5339 \\
202,8640 \\
192,0000 \\
187,7185 \\
-126,3031 \\
-131,3939 \\
-92,7055
\end{array}\right]
$$

E as somas de quadrados são assim obtidas:

PARA LINHAS 
a) Tipo I

$$
\begin{aligned}
& H_{0}^{1 *}:\left\{\begin{array}{l}
\mu_{2}+\frac{3 \beta_{1}+2 \beta_{3}}{5}=\mu_{9}+\frac{2 \beta_{1}+\beta_{2}}{3} \\
\mu_{2}+\frac{3 \beta_{1}+2 \beta_{9}}{5}=\mu_{4}+\frac{3 \beta_{2}+2 \beta_{3}}{5} \\
\mu_{2}+\frac{3 \beta_{1}+2 \beta_{9}}{5}=\mu_{1}+\frac{4 \beta_{1}+3 \beta_{2}+2 \beta_{3}}{9}
\end{array}\right. \\
& \mu_{1} \mu_{2} \mu_{3} \mu_{4} \beta_{1} \beta_{2} \beta_{3} \\
& \Rightarrow B_{1 *}^{\prime}=\left[\begin{array}{rrrcccc}
\downarrow & \downarrow & \downarrow & \downarrow & \downarrow & \downarrow & \downarrow \\
0 & 1 & -1 & 0 & -1 / 15 & -1 / 3 & 2 / 5 \\
0 & 1 & 0 & -1 & 3 / 5 & -3 / 5 & 0 \\
-1 & 1 & 0 & 0 & 7 / 45 & -1 / 3 & 8 / 45
\end{array}\right] \\
& H_{0}^{\prime *)}:\left\{\begin{array}{l}
\alpha_{2}-\alpha_{3}-\frac{1}{15} \beta_{1}-\frac{1}{3} \beta_{2}-\frac{2}{5} \beta_{3}=0 \\
\alpha_{2}-\alpha_{4}+\frac{3}{5} \beta_{1}-\frac{3}{5} \beta_{2}=0 \\
\alpha_{2}-\alpha_{1}+\frac{7}{45} \beta_{1}-\frac{1}{3} \beta_{2}+\frac{8}{45} \beta_{3}=0
\end{array}\right. \\
& \therefore \mathrm{SOHo}^{(1 *)}=1492,518182=\mathrm{R}(\alpha \mid \mu)
\end{aligned}
$$

b) Tipo II

$$
\text { Mats uma vez, tem-se } \mathrm{SQH}_{0}^{\left(2^{*}\right)}=\mathrm{SQH}_{0}^{\left(3^{*}\right)}=\mathrm{SQH}^{\left(4^{*}\right)} \text {. }
$$

E a matriz hipótese é descrita de forma identica as dos casos que trabalham com o modelo sem interacão. Portanto,

$$
\mathrm{SOH}^{(2 *)}=561,583606=\mathrm{R}(\alpha \mid \mu, \beta)
$$


Os resultados são resumidos através das saidas do SAS, que podem ser encontrados na sequência.

Quadro 1.B7 - Quadro da análise de variancia preliminar

\begin{tabular}{lrrrr} 
& SF & $\begin{array}{c}\text { Sum of } \\
\text { Squares }\end{array}$ & $\begin{array}{c}\text { Mean } \\
\text { Square }\end{array}$ & F Value \\
\hline Model & 5 & 6696.298613 & 1339.259723 & 103.51 \\
Error & 16 & 207.019568 & 12.938723 & \\
\hline Total & 21 & 6903.318182 & &
\end{tabular}

Quadro 2.B7 - Quadro da análise de variância para a hipótese do tipo I

\begin{tabular}{lrrrrr} 
Source & DF & Type I SS & Mean Square & F Value \\
\hline L & 3 & 1492.518182 & 497.506061 & 38.45 \\
C & 2 & 5203.780432 & 2601.890216 & 201.09 \\
\hline
\end{tabular}

Quadro 3.B7 - Quadro da análise de variância para a hipótese do tipo II

\begin{tabular}{lrrrrr} 
Source & DF & Type II SS & Mean Square & F Value \\
\hline L & 3 & 561.583606 & 187.194535 & 14.47 \\
C & 2 & 5203.780432 & 2601.890216 & 201.09 \\
\hline
\end{tabular}

Quadro 4.BT - Quadro da análise de variâncla para a hipótese do tipo III

\begin{tabular}{lrrrr} 
Source & DF & Type III SS & Mean Square & F Value \\
\hline L & 3 & 561.583600 & 187.194535 & 14.47 \\
C & 2 & 5203.780432 & 2601.890216 & 201.09 \\
\hline
\end{tabular}

Quadro 5.B7 - Quadro da análise de variancia para a hipótese do tipo IV

\begin{tabular}{lrrrrr} 
Source & DF & Type IV SS & Mean Square & F Value \\
\hline L & 3 & 561.583606 & 187.194535 & 14.47 \\
C & 2 & 5203.780432 & 2601.890216 & 201.09 \\
\hline
\end{tabular}




\section{CONCLUSÕES}

Face aos resultados obtidos, concluiu-se que - problema inerente à interpretacão das hipóteses estatisticas na análise de dados desbalanceados, com ou sem caselas vazias, não é trivial e pode acarretar graves falácias aos usuários de pacotes estatisticos.

Sentiu-se, com clareza, que um primeiro passo para a minimizacão do problema pode ser a escolha adequada do modelo a ser utilizado na análise dos dados: o modelo com ou sem interacão. Daí, algumas diferencas podem ser observadas:

\section{1) Modelo com interação:}

a) dados bal anceados

Evidentemente, todas as hipóteses fornecidas pelos dois pacotes CSAS e STATGRAPHICSD são equivalentes. Ou seja, a escolha de qualquer quadro de análise de variancia fornecido pelos dois pacotes, permite chegar a mesma tomada de decisão na análise estatística.

b) uma casela vazia e demais dados balanceados

A hipótese do tipo I difere das demais que são iguais entre si.

c) dados desbalanceados sem casela vazia:

$$
\text { Ho tipo III }=\text { Ho tipo IV }
$$


Há situações nas quais Ho tipo II $=$ Ho tipo III, mas, em geral, isto ocorre para casos muito particulares, como por exemplo em número de observacões proporcionais por casela.

d) dados desbalanceados com casela vazia:

d. 1 - Primeiro exemplo:

$$
\text { Ho tipo III }=\text { Ho tipo IV }
$$

- caso do fatorial $2 \times b$ pode indicar uma conclusão errônea a respeito da igualdade entre as hipóteses do tipo III e IV. Ou seja, elas sempre serão equivalentes para o primeiro fator (com dois níveis) da ordenacão. Isso ocorre pois a matriz hipótese possui somente uma linha Cum g.1.) para o primeiro fator. Assim, as hipóteses são equivalentes devido à estrutura dos dados. Não se pode perder de vista que se não há casela vazia as duas hipóteses sempre serão equi valentes.

d. 2 - Segundo exemplo:

Ho tipo I $\neq$ Ho tipo II $\neq$ Ho tipo III $\neq$ Ho tipo IV

\section{2) Modelo sem interação:}

a) dados bal anceados:

Como já é de amplo conhecimento, todas as hipóteses são equi valentes, assim como no item 1.a. 
b) dados desbal anceados sem casela vazia:

Nesse caso tem-se:

Ho tipo I $\neq$ Ho tipo II $=H_{0}$ tipo III $=H_{0}$ tipo IV

c) dados desbalanceados com casela vazia:

Ho tipo I 7 Ho $_{0}$ ipo II $=H_{0}$ tipo III $=H_{0}$ tipo IV

Vê-se, até mesmo, que a posicão e a quantidade das caselas vazias não interferem na forma citada.

Nesse contexto, considerando-se que os modelos estudados não contêm restricões paramétricas, ficou evidente que 0 modelo com interacão, fundamentalmente, testa interacões. Qualquer hipótese sobre efeitos principais sempre terá, em sua expressão, outros efeitos: ou o efeito do outro fator mais a interacão CSQ tipo I , ou os efeitos cruzados (as interacões) para as demais hi póteses.

No modelo sem interacão, a única diferenca existente está na hipótese do tipo I, em relacão às demais hipóteses. Sendo que a hipótese tipo I "carrega", em seus contrastes, mais de um efeito do modelo aditivo, e as demals não. Assim, as somas de quadrados dos tipos II, III - IV podem testar hipóteses sobre os efeitos principais 
individualmente, ou seja, sem a presenca dos demais fatores, que não sejam, naquele instante, interessantes ao pesquisador.

A construcão das hipóteses do tipo III não é tão fácil. É necessário que as funcôes estimáveis fornecidas pelo PROC GLM auxiliem na obtenção da mesma. Por isso, acredita-se que o método criado neste trabalho pode ser visto como uma boa alternativa para a construcão dessas hipóteses.

Ademais, parece ser evidente que, por mais experiente que seja um pesquisador das ciências aplicadas, é necessário que seu trabalho de pesquisa tenha a orientacão de um conhecedor de pacotes estatisticos, possibilitando, assim, uma discussão que oriente na escolha da análise de dados mais apropriada para a situacão experimental.

Por fim, entende-se que é indispensável que os manuais dos pacotes estatisticos sejam mais esclarecedores, minimizando os erros de interpretacóes de hipóteses em análises de dados. 


\section{REFERENCIAS BIBLIOGRÁATCAS}

BANZATTO, D. A. \& KRONKA, S.N. Experimentacão Agríco1a. Jaboticabal, 1989 . 247p.

BRYCE, G.R.; SCOTT, D.T.; CARTER, M. W. Estimation and hypoteses testing in a reparameterization approach to the cell means model. Commun. Statist $=$ Theor. Meth., $A 9(2), 131-150.1980$.

BURDICK, D.S. Rows adjusted for columns versus simple row means in two-way ANOVA: when are the two hypoteses equivalent?" Iournal of the American Statistical Association, 74: 457-8, 1979.

BURDICK, D.S. \& HERR, D.G. Counterexamples in unbalanced two-way analysis of variance Commun. Statist. = Theor. Meth., $\Delta 9(2): 231-41,1980$.

CAMARINHA FILHO, J.A. \& IEMMA, A.F. Identificação de Hi póteses no Caso de Caselas Vazias. V-Congresso de Iniciacão Científica, ESALQ-USP, 1991.

CARLSON, J.E. \& TIMM, N.H. Analysis of nonorthogonal fixed-effects designs. Psychologial Bulletin, 81: $563-70,1974$.

DITCHBURNE, N. A method of analysis for a double classification arranged in a triangular table. Biometrics, 453-64, 1955. 
ELSTON, R.C. \&: BUSH, $N$ The hypotheses that can be tested when there are interactions in an analysis of variance model. Biometrics, $681-98,1964$.

FRANCIS, I. A comparison of several analysis of variance programs. Journal of the American Statistical Association, 68: 860-5, 1973.

FRANE, J.W. Some computing methods for unbalanced analysis of variance and covariance. Commun. Statist. - Theor. Meth., $A 9(2): 151-66,1980$.

FREUND, R.I. The case of missing cell. The Amertcan Statistician, 34(2): $94-8,1980$.

FREUND, R.J.; LITTEELL, R.C.; SPECTOR, P.C. SAS system for inear models. Cary, SAs Institute inc, 1986.

GOODNIGHT, J.R. Tests of hypotheses in fixed effects linear models. Cary, SAS Institute, 1978. CSAS Tecnical Report R-101D

GOODNIGHT, J.R. Arbitrary hipotheses in linear models with unbalanced data. Commun. Statist. - Theor. Meth. A9(2): $181-200,1980$.

GRAYBILL, F.A. An introduction to linear statistical models. New York, McGraw-Hi11, 1961, 461p. 
HEMMERLE, J.W. Recognizing balance with unbalanced data. Commun. Statist. - Theor. Meth., $\Delta 9(2)$ : $201-11,1980$

HERR, D. On the history of ANOVA in unbalanced, factorial designs: the first 30 years. The American Statistician, 40: 265-70, 1986.

HOCKING, R.R. \& SPEED, F.M. A full rank analysis of some linear model problems Journal of the American Statistical Association, 70: 706-12, 1975.

HOCKING, R.R.; SPEED, F.M.; COLEMAN, A. T. Hypotheses to be tested with unbalanced data. Commun. Statist. - Theor. Meth., Ag(2): 117-29, 1980.

IEMMA, A.F. Modelos lineares: uma introducão para profissionais da pesquisa agropecuária. Impresa oficial Est. Paraná, Londrina, 1987. 263p.

IEMMA, A.F. Álgebra de matrizes com aplicacões em estatistica, ESALQ-USP, 1990, $411 \mathrm{p}$.

IEMMA, A.F. Testes de hipóteses em modelos com amostras desequilibradas. Gembloux, F.S.A, 1991. $101 \mathrm{p}$

IEMMA, A. F. \& PALM, R. Les matrices inverses gènéralisées et leur utilsation dans le modèle Iinealre, Gembloux, $1991 / 92$, 25p. 
IEMMA, A.F. Análisis de varianza de experimentos con celdas Vácias. Córdoba, $\varphi$ a p publicacões, 1993. $10 \mathrm{ep}$.

IEMMA, A.F.; PALM, R.; CLAUSTRT AUX, J.J. Sobre a construcão de projetores ortogonais. Rev. Mat. Estat., São Paulo, 11: 133-42, 1993.

JENNINGS, E. \& WARD, J.H. Hypothesis identification in the case of the missing cell. The American Statistician, 36: $25-7,1982$.

KRAMER, C.Y. On the analysis of variance of a two-way classification with unequal sub-class numbers. Biometrics, 441-52, 1955.

KUTNER, M.H. Hypothesis testing in linear models CEisenhart model IJ. The American Statistician. 28: $98-100,1974$.

MONDARDO, M. Estimabilidade de funçóes paramétricas com dados desbalanceados através do PROC GLM do SAS: Aplicações à Pesquisa Agropecuária, Dissertacão de Mestrado - ESALQ USP, 1994.

MONLEZUN, C.J. \& SPEED, F.M. The geometry of estimation and hypothesis testing in the constrained linear model - the full rank case. Commun. Statist. - Theor. Meth., A9(2): 213-30, 1980 . 
MURRAY, L.W. Estimation of missing celis in randomized block and latin square designs. The American Statistician, 40: 289-93, 1986.

OVERALL, J.E. \& SPIEGEL, D.K. Concerning least squares analysis of experimental data. Psychological Bulletin, 72: 311 -2e, 1969.

RAO, C.R. . Linear statistical inference and its applications. New York, John Wiley \& Sons, 1965. $522 p$.

SANTOS, E.S. Utilizacão de "Softwares" estatisticos na interpretacão de hipóteses com dados desbal anceados. Tese, ESALQ-USP, 1994.

SCHEFFÉ, H., The analysis of variance. New York, John Wiley \& Sons, 1959 . 477p.

SEARLE, S.R. Linear models. New York, John Wiley \& Sons, 1971. 532p.

SEARLE, S.R. Variance components. New York, John Wiley \& Sons, $1992.501 \mathrm{p}$.

SEARLE, S.R. Arbitrary in linear models with unbal anced data. Commun. Statist. = Theor. Meth. A9(2): $181-200,1980$. 
SEARLE, S.R.; SPEED, F.M.; HENDERSON, H.V. SOME computational and model equivalences in analyses of variance of unequal-subclass-numbers data. The American Statistician, 35: 16-33, 1981.

SEARLE, S.R. Analysis of variance computing package output for unbalanced data from fixed-effects models with nested factor. The American Statistician, 48: 148-53. 1994.

SIMões, J.W. Métodos de Producão de Mudas de Eucalipto IPEF, 1: 101-16, 1970 .

SMI TH, D.W. 8 MURRAY, L.W. A simplified treatment of the estimation of parameters and tests of hypottheses in constrained design models with unbalanced data. The American Statistician, 37 : $156-58,1983$.

SNEDECOR, G.W. \& COCHRAN, W. G. Statistical methods. Ames, 1967 . $593 \mathrm{p}$.

SPEED, F.M. \& HOCKING, R.R. The use of the RCD notation with unbalanced. The Americam Statistician. 30: $30-33,1976$.

SPEED, F.M.; HOCKING, R.R.; HACKNEY, O.P. Methods of analysis of linear models with unbalanced data. Journal of the American Statistical Association, 72: $105-112,1978$. 
SPEED, F.M. \& MONLEZUN, C.J. Exatc F Tests for the method of unwelghted means in a $2^{k}$ experiment. The American Statistician, 33: 15-8, 1979.

SPJøTVOLL, E. \& STOLINE, M.R. An extension of the T-method of multiple comparison to include the cases with unequal sample sizes. Journal of the American Statistical Association, 68: 975-78, 1973.

URQUHART, N.S.; WEEKS, D.L.; HENDERSON,C.R. Estimation associated with 1 inear models: a revisitation.

Communications in Statistics, 1: $303-330,1973$.

URQUHART, N.S \& WEEKS, D.L. Linear model in messy data: some problems and alternatives. Biometrics, 34: $696-705,1978$.

YATES, F. The analysis of replicated experiments when the field results are incomplete. Empire Journal of Experimental Agriculture, 1: 129-142, 1933.

YATES, F. The analysis of multiple classifications with unequal numbers in the different classes. Journal of the American Statistical Association, 29: $51-66,1934$. 